Aus der Abteilung Virologie und Immunologie

(ehem. Leiter: Prof. Dr. med. G. Hunsmann)

des Deutschen Primaten Zentrums

in Göttingen

\title{
Bedeutung der mikrobiellen Transmission im SIV-Rhesusaffen-Tiermodell für die HIV/AIDS- Pathogenese
}

\author{
INAUGURAL - DISSERTATION \\ zur Erlangung des Doktorgrades \\ der Medizinischen Fakultät der \\ Georg-August-Universität zu Göttingen
}

vorgelegt von

Christoph Alexander Leinert

aus

Hamburg

Göttingen 2010 
Dekan: Prof. Dr. med. C. Frömmel

I. Berichterstatter: $\quad$ PD Dr. rer. nat. S. Sopper

II. Berichterstatter/in: Prof. Dr. rer. nat. Reichardt

III. Berichterstatter/in: Prof. Dr. med. Legler

IV. Berichterstatter/in: Prof. Dr. rer. nat. Virsik-Köpp

Tag der mündlichen Prüfung: $\quad$ 21. Februar 2011 
$\underline{\text { Inhaltsverzeichnis }}$

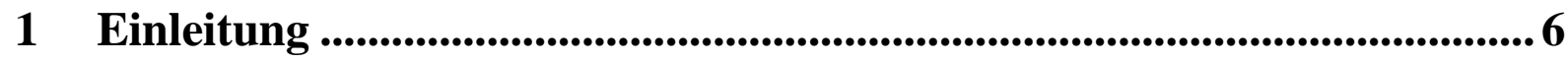

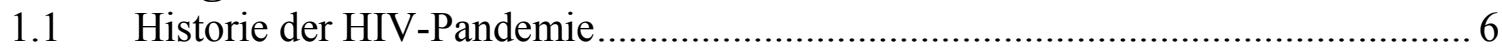

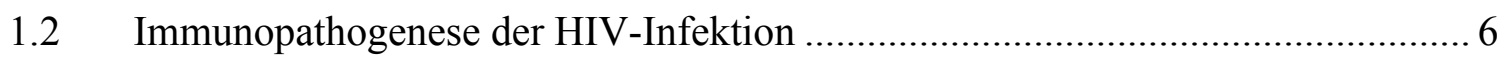

1.3 Akute und Chronische HIV-Infektion ........................................................... 7

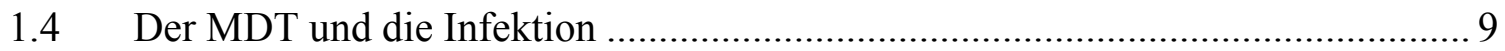

1.5 Die Antwort des menschlichen Körpers auf eine LPS-Exposition ....................... 10

1.6 Die SIV-Infektion von Rhesusmakaken als Modell der HIV-Infektion des

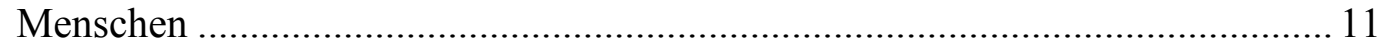

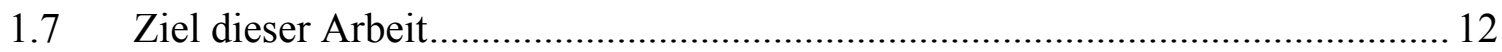

2 Material und Methoden .............................................................................. 14

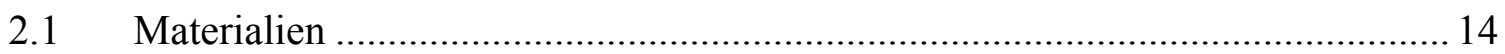

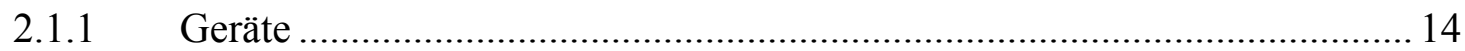

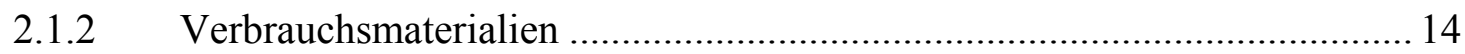



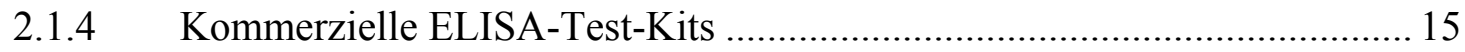

2.1.5 Kommerzielle Limulus-Amebocyte-Lysate (LAL)-Test-Kits ...................... 15

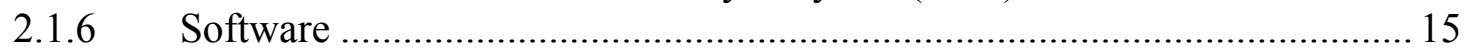

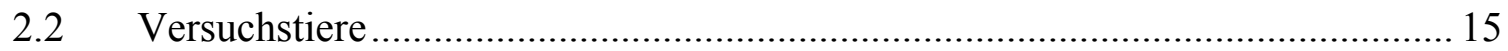

2.2.1 Infektionsverlauf und Gewinnung des Probenmaterials .............................. 15

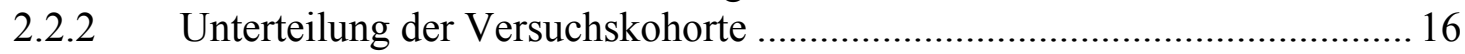

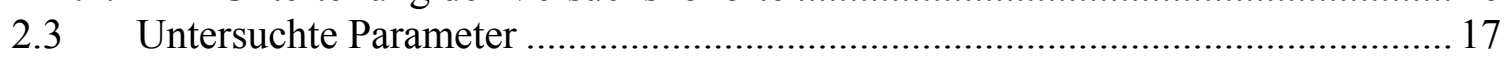

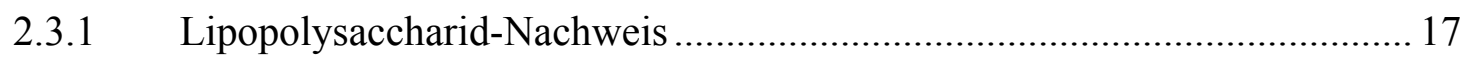

2.3.2 Enzym-linked immunosorbent assay (ELISA) ....................................... 18

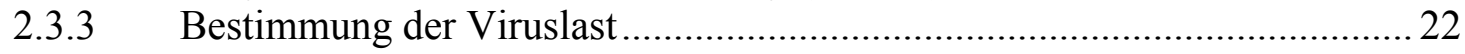

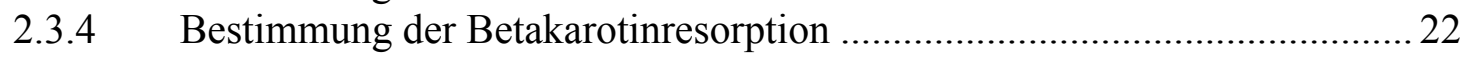

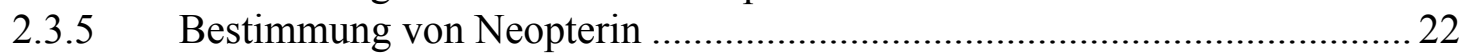

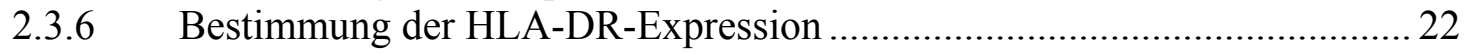

2.3.7 Statistische Auswertung und graphische Darstellung ................................. 23

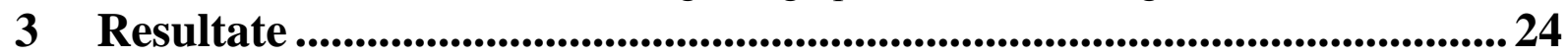

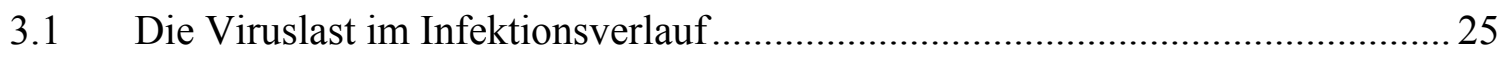

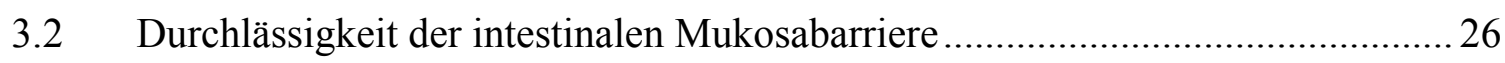

3.3 Zeitverlauf der Lipopolysaccharide (LPS) im Plasma ........................................2

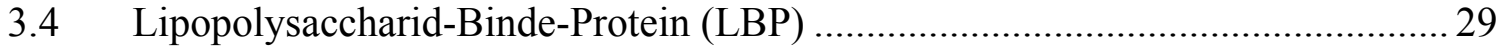

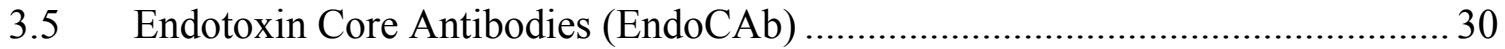

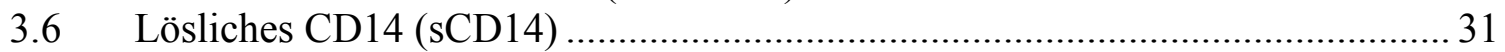

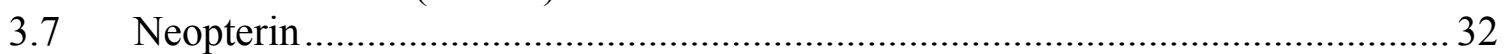

3.8 Expression von HLA-DR auf CD4 ${ }^{+}$- und $\mathrm{CD}^{+}$-T-Lymphozyten ........................ 33

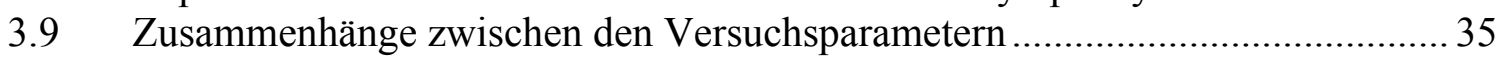

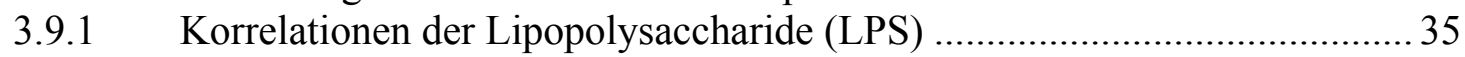

3.9.2 Beziehung zwischen IA und Krankheitsverlauf....................................... 37

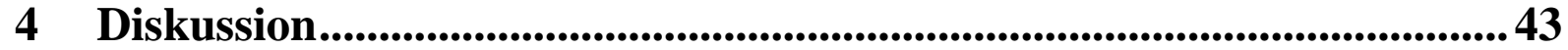

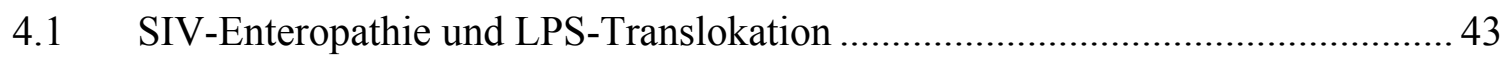

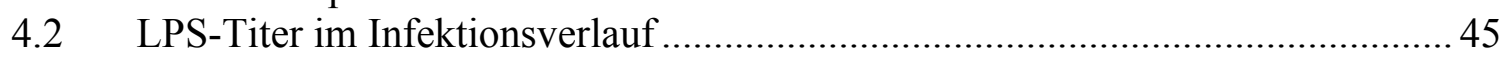

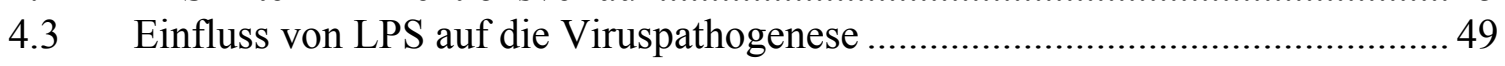

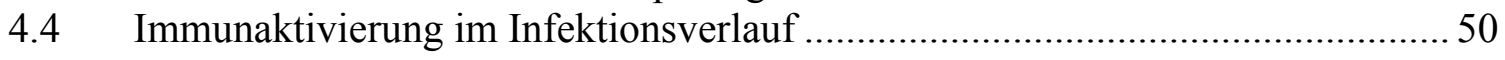

5 Zusammenfassung und Ausblick ............................................................. 53

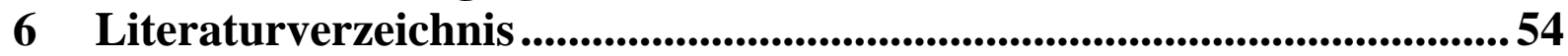




\section{Abkürzungsverzeichnis:}

AGM

bzgl.

ca.

CDC

CED

ELISA

EndoCAb

etc.

EU

GALT

HIV

HLA

IA

i.v.

LBP

LPS

LTA

MALT

MDT

$\min$

$\mathrm{ml}$

MMU

$\mu \mathrm{g}$

ng

nm

pg

$\mathrm{RM}$

RP

s. Abb.

SCD14

SIRS

SIV

SM

s.o.

$\mathrm{SP}$

TMB

VL

wpi

z.B. englisch, african green monkey

bezüglich

circa, ungefähr

englisch, center for disease control

Chronisch entzündliche Darmerkrankungen

englisch, enzyme-linked immunosorbent assay

englisch, endotoxin core antibodies

lateinisch, et cetera

englisch, endotoxin units

englisch, gut-associated lymphatic tissue

humanes Immundefizienzvirus

englisch, human leukocyte antigen

Immunaktivierung

intravenös(en)

Lipopolysaccharid-Binde-Protein

Lipopolysaccharide

englisch, lipoteichoic acid

englisch, mucosa-associated lymphatic tissue

Magen-Darm-Trakt

Minuten

Milliliter

englisch, IgM median units

Mikrogramm

Nanogramm

Nanometer

Pikogramm

Rhesusmakaken

englisch, rapid progressors

siehe Abbildung

lösliches CD14

englisch, systemic inflammatory response

syndrome

simianes Immundefizienzvirus

englisch, sooty mangabey

siehe oben im Text

englisch, slow progressors

Tetramethylbenzidin

Viruslast

englisch, weeks post infection

zum Beispiel 


\section{Abbildungsverzeichnis:}

Abb. 1: Krankheitsverlauf der HIV-Infektion...................................................................... 7

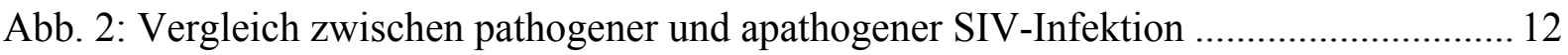

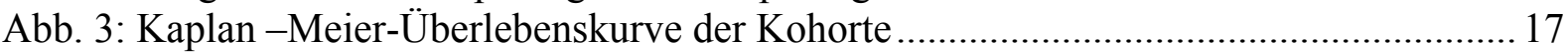

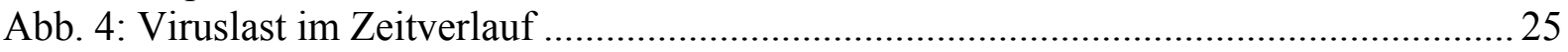

Abb. 5: Beta-Karotinresorption im Vergleich vor der Infektion und 12wpi..........................26

Abb. 6: LPS-Konzentration im Vergleich vor der Infektion und 14wpi................................ 27

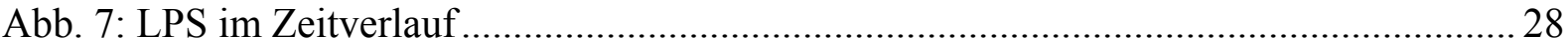

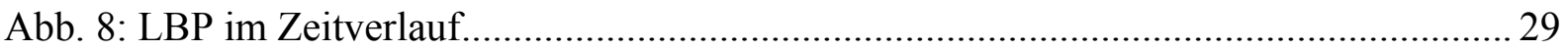

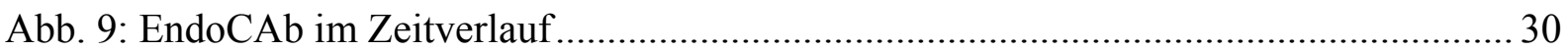

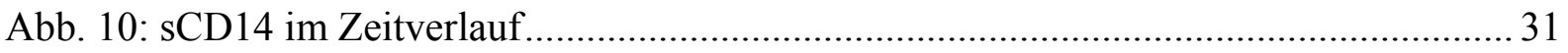

Abb. 11: Neopterin im Zeitverlauf......................................................................................... 32

Abb. 12: HLA-DR exprimierende CD4 ${ }^{+}$-T-Zellen im Zeitverlauf ........................................ 33

Abb. 13: HLA-DR exprimierende CD8 ${ }^{+}$-T-Zellen im Zeitverlauf .......................................... 34

Abb. 14: Korrelationen zwischen LPS zu verschiedenen Zeitpunkten und VL, Neopterin bzw.

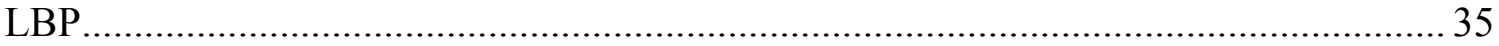

Abb. 15: Korrelationen zwischen der Viruslast zu verschiedenen Zeitpunkten und der

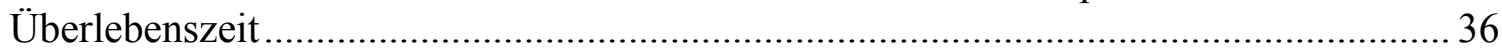

Abb. 16: Korrelationen zwischen Neopterin zu verschiedenen Zeitpunkten und der Viruslast

Abb. 17: Korrelationen zwischen Neopterin zu verschiedenen Zeitpunkten und der Überlebenszeit.

Abb. 18: Korrelationen zwischen sCD14 zu verschiedenen Zeitpunkten und der Neopterinausscheidung bei den SP

Abb. 19: Korrelationen zwischen HLA-DR ${ }^{+} \mathrm{CD}^{+}$Zellen zu verschiedenen Zeitpunkten und

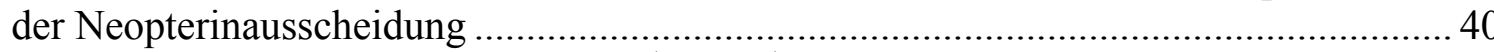

Abb. 20: Korrelationen zwischen HLA-DR ${ }^{+}-\mathrm{CD}^{+}$Zellen zu verschiedenen Zeitpunkten und

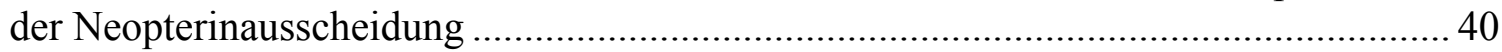

Abb. 21: Korrelationen zwischen HLA-DR ${ }^{+} \mathrm{CD}^{+}$Zellen zu verschiedenen Zeitpunkten und

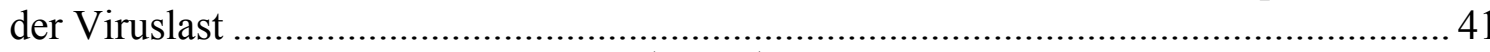

Abb. 22: Korrelationen zwischen HLA-DR ${ }^{+} \mathrm{CD}^{+}$Zellen zu verschiedenen Zeitpunkten und

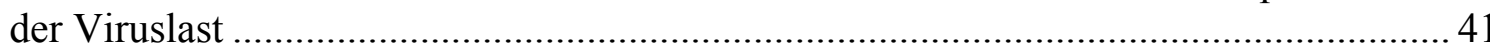

Abb. 23: Korrelationen zwischen $\mathrm{HLA}_{-} \mathrm{DR}^{+} \mathrm{CD}^{+}$Zellen zu verschiedenen Zeitpunkten und

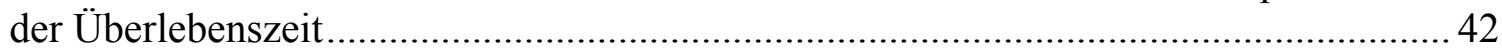

Abb. 24: Korrelationen zwischen HLA-DR ${ }^{+} \mathrm{CD} 8^{+}$Zellen zu verschiedenen Zeitpunkten und

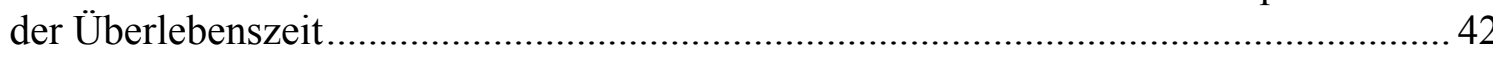




\section{Einleitung}

\subsection{Historie der HIV-Pandemie}

Im Jahre 1981 kam es zu ersten Beschreibungen schwerer Immunschwächen, die mit Infektionen des opportunistischen Erregerspektrums einhergingen und vorwiegend bei homosexuellen Männern auftraten (Gottlieb et al. 1981; Masur et al. 1981; Siegal et al. 1981). Die Erkrankung wurde wenig später als erworbenes Immundefizienzsyndrom (engl., acquired immunodeficiency syndrome, AIDS) bezeichnet. Den Arbeitsgruppen von Gallo und Montagnier gelang es 1983 erstmals, ein bis dahin unbekanntes Retrovirus, das sich vorwiegend in T-Lymphozyten repliziert, als Erreger dieser neuen Krankheit zu isolieren (Barre-Sinoussi et al. 1983; Gallo et al. 1983). Ab 1986 wurden dieses Retrovirus und zwei weitere Virusvarianten unter dem Namen Humanes Immundefizienzvirus 1 (engl., human immunodeficiency virus, HIV-1) zusammengefasst sowie ein weiteres entdecktes Immundefizienzvirus mit dem Namen HIV-2 bezeichnet und somit mit der heute gebräuchlichen Nomenklatur versehen (Clavel et al. 1986; Coffin et al. 1986).

Die weltweite Durchseuchung mit HIV wurde durch den AIDS-Bericht der Vereinten Nationen im Jahre 2008 auf 33 Millionen Infizierte beziffert (Report on the Global AIDS Epidemic-UNAIDS, 2008).

Durch langjährige Forschungsarbeit ist es heute möglich, HIV und AIDS durch antiretrovirale Medikamente zu behandeln. Eine Heilung der Infizierten und alle Versuche der Entwicklung eines Impfstoffes, der den Verlauf der Krankheit abschwächen oder die Infektion verhindern könnte, sind jedoch bisher gescheitert.

\subsection{Immunopathogenese der HIV-Infektion}

Ein wichtiger Schlüssel zur Entwicklung neuer Behandlungs- und Impfstrategien stellt das Verständnis der Pathogenese des Virus dar. Das primäre Ziel des HI-Virus und die Ursache für die Entwicklung der Immundefizienz wurden schnell identifiziert: Der Replikationsort von HIV ist die CD4 ${ }^{+}-\mathrm{T}$-Zelle, über deren CD4-Rezeptor das Virus in die Wirtszelle eindringt (Dalgleish et al. 1984; Klatzmann et al. 1984). Die Infektion führt zu einem Verlust dieser $\mathrm{CD}^{+}$Zellen, deren Mangel letztendlich für die Immunschwäche verantwortlich ist. Der genaue Mechanismus dieser Zelldepletion ist allerdings auch 25 Jahre nach der Erstbeschreibung nicht abschließend geklärt. 
Schnell war klar, dass die Replikation des Virus und die Zerstörung der CD4 ${ }^{+}$Wirtszelle zur Freisetzung neuer Viruspartikel nicht der alleinige Grund für die mit langer Verzögerung zur Primärinfektion einsetzende Immundefizienz sein konnte (Ascher und Sheppard 1990). Eine frühe Theorie postulierte, dass infizierte Zellen nach einer spezifischen Aktivierung durch ein Pathogen bei gleichzeitiger intrazellulärer viraler Replikation den programmierten Zelltod eingehen (Meyaard et al. 1992). Diese Theorie wurde aber wenige Jahre später verworfen, da die Apoptoserate in der akuten, asymptomatischen Phase sehr viel höher war, als zu späteren Zeitpunkten im Infektionsverlauf, wenn vermehrt Pathogene zu Infektionen führen (Meyaard et al. 1994). Eine weitere Theorie besagt, dass hauptsächlich uninfizierte, sogenannte „bystander-“ $\mathrm{CD} 4{ }^{+}$Zellen, auf indirektem Wege durch die infizierten Zellen angestoßen, den programmierten Zelltod eingehen (Finkel et al. 1995).

Mitte der 90er Jahre konnten zwei Korezeptoren identifiziert werden, die neben der CD4Oberflächenstruktur zur Infektion der Immunzellen notwendig sind. CCR5 wurde als notwendiger Korezeptor für monozytotrope HIV-Isolate identifiziert und CXCR4 wurde als Korezeptor der T-Zelltropen HIV-Isolate festgestellt (Deng et al. 1996; Doranz et al. 1996; Dragic et al. 1996; Feng et al. 1996). In den letzten Jahren wurde zunehmend klar, dass sich die Krankheitsmechanismen in der akuten und chronischen Phase unterscheiden (Derdeyn und Silvestri 2005).

\subsection{Akute und Chronische HIV-Infektion}

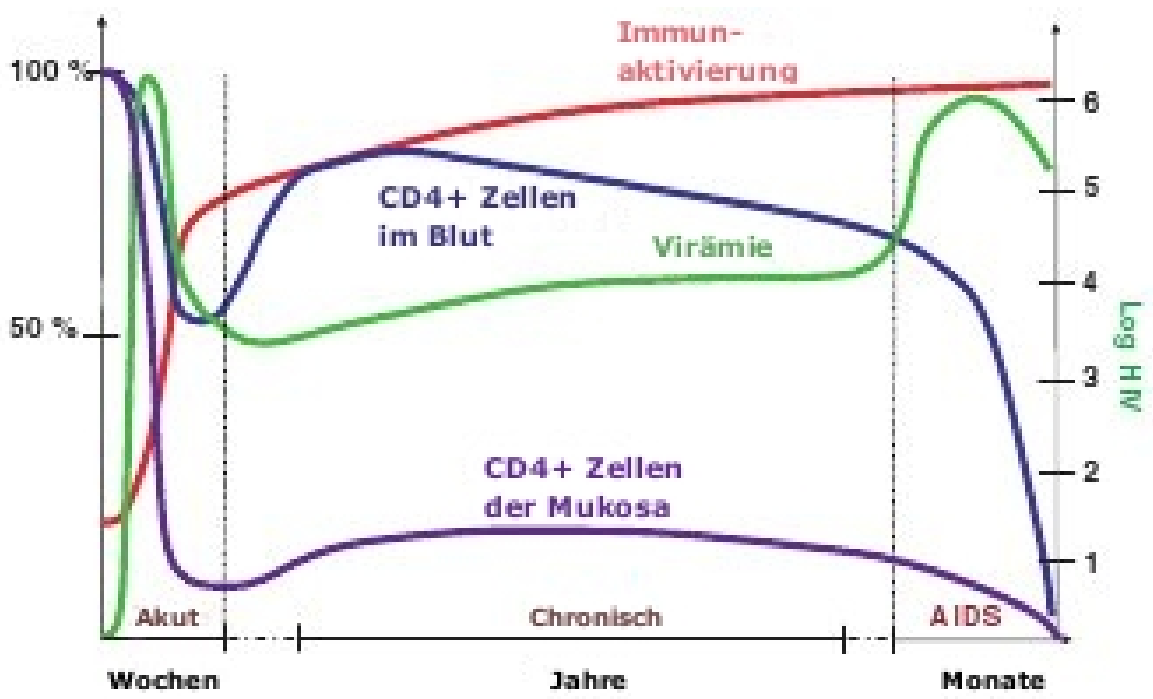

Abbildung 1: Krankheitsverlauf der HIV-Infektion. Dargestellt ist die Kinetik der $\mathrm{VL}$, der $\mathrm{CD} 4^{+}-\mathrm{T}-$ Zellen im peripheren Blut bzw. der Mukosa sowie die Immunaktivierung in den unterschiedlichen Krankheitsphasen der HIV-Infektion. (modifiziert nach Grossman et al. 2006, 293.) 
In der Akutphase der Infektion kommt es zu einer immensen CD4 ${ }^{+}-\mathrm{T}-$ Zell-Depletion, die im wesentlichen im mukosaassoziierten lymphatischen Gewebe (engl., mucosa associated lymphatic tissue, MALT) stattfindet (s. Abb. 1) (Brenchley et al. 2004; Li et al. 2005; Mattapallil et al. 2005; Mehandru et al. 2007). Im MALT, wo sich ein großer Teil der körpereigenen $\mathrm{CD}^{+}$-Zellen befindet, wird eine besondere Subpopulation der T-Zellen, die sogenannten T-Gedächtniszellen, vermehrt befallen. Da diese überdurchschnittlich viel CCR5 auf ihrer Oberfläche exprimieren, nehmen die monozytotropen Virusisolate eine besondere Stellung in der Frühphase der Erkrankung ein. Der Verlauf der weiteren Erkrankung hängt hierbei auch von der Fähigkeit des Organismus ab, diesen Verlust an T-Gedächtniszellen durch Proliferation und Differenzierung naiver T-Zellen wieder auszugleichen (Picker et al. 2004).

Nach der starken Depletion der $\mathrm{CD}^{+}$-Zellen in der Akutphase kommt es zunächst zu einer leichten Regeneration der CD4 ${ }^{+}$-T-Zellen im peripheren Blut, dann jedoch in der chronischen Phase $\mathrm{zu}$ einem kontinuierlichen Abfall dieser Zellen (Grossman et al. 2006). Die asymptomatische chronische Phase der Infektion geht schließlich, nach manchmal vielen Jahren, in das Endstadium der Erkrankung, AIDS, über. Der Eintritt von AIDS ist hierbei nach dem amerikanischen Center for Disease Control (CDC) durch das Auftreten von verschiedenen opportunistischen Infektionen bzw. das Absinken der CD4 ${ }^{+}$-T-Zellen im peripheren Blut unter 200/ $\mu 1$ definiert (CDC et al. 1992). Der stetige Abfall der CD4 ${ }^{+}$Zellen wird heute im Wesentlichen durch eine anhaltende chronische Aktivierung des Immunsystems erklärt (Fahey et al. 1998; Giorgi et al. 1999; Hazenberg et al. 2003). Es konnte außerdem nachgewiesen werden, dass verschiedene Marker für eine Immunaktivierung (IA) mit dem Krankheitsverlauf korrelieren und die IA in Kombination mit der Anzahl an $\mathrm{CD}^{+}-\mathrm{T}-Z$-Zellen sogar eine bessere Korrelation mit dem Krankheitsverlauf besitzt als die VL zusammen mit der Zahl an $\mathrm{CD}^{+}$Zellen (Fahey et al. 1998; Fuchs et al. 1990). Hierbei wird angenommen, dass unter der jahrelangen chronischen Aktivierung des Immunsystems es zuletzt zu einer Erschöpfung der Immunreserven kommt. Dieser Kollaps des Immunsystems führt dann zum Stadium AIDS.

Die genaue Ursache der chronischen IA ist bisher noch ungeklärt. Neben dem Virus selbst wurde zuletzt eine Schädigung des Magen-Darmtraktes (MDT) als Ursache diskutiert (Brenchley et al. 2006a; Brenchley et al. 2004; Lackner et al. 2009). Von Brenchley et al. wurde in diesem Zusammenhang die Hypothese aufgestellt, dass es in der akuten Phase der Infektion zu einer Schädigung der Darmmukosa kommt und so deren Barrierefunktion 
nachhaltig gestört wird (Brenchley und Douek 2008; Brenchley et al. 2006b). Dadurch kommt es in der chronischen Phase der Infektion zu einer vermehrten Translokation von Bakterien und Bakterienbestandteilen über diese Barriere. Durch deren Anwesenheit im Körper wird das Immunsystem chronisch aktiviert. Somit könnte, wie auch schon in der akuten Phase der Infektion, der Mukosabarriere und dem MALT eine Schlüsselfunktion im Verständnis der chronischen Immunaktivierung zukommen.

\subsection{Der MDT und die Infektion}

Der Magen-Darmtrakt (MDT) beherbergt mit dem GALT (engl., gut associated lymphatic tissue) den größten Anteil des MALT und erfährt in der akuten HIV-Infektion eine erhebliche Schädigung. Noch vor diesen Erkenntnissen beschrieben Kotler et al. spezifische pathologische Prozesse in histologischen Schnitten aus Dünn- und Dickdarm als Ursache einer Enteropathie, die viele Infizierte schon in den ersten Jahren der Pandemie als ein Symptom von AIDS betraf (Kotler et al. 1984).

Der Begriff HIV-Enteropathie umfasst verschiedenste klinische Symptome wie Diarrhoen, ohne pathogenen Keimnachweis, und Malabsorption mit Mangelernährung. Aber auch auf histologischer Ebene konnten weitere Veränderungen im MDT nachgewiesen werden, so konnte eine Atrophie intestinaler Krypten und lokale Zeichen der Inflammation nachgewiesen werden (Kewenig et al. 1999; Kotler et al. 1993). Auch eine Erhöhung der intestinalen Permeabilität, die durch den erhöhten Übertritt von markierten Zuckermolekülen nachgewiesen werden konnte, ist mit der Enteropathie vergesellschaftet (Kapembwa et al. 1991; Sharpstone et al. 1999). Zuletzt wurde als mögliche Ursache dieser Enteropathie die Interaktion in der Frühphase der Infektion zwischen dem HIV-Oberflächenprotein gp120 und dem HIV-Korezeptor Bob/GPR15, der vornehmlich auf intestinalen Mukosazellen exprimiert wird, beschrieben (Clayton et al. 2001; Li et al. 2008).

Mitte der neunziger Jahre wurde das erste Mal der Nachweis angestellt, dass der in der HIVInfektion geschädigte Darm nicht nur zu einer verminderten Resorption, sondern auch zu einer erhöhten Durchlässigkeit für Pathogene führt (Stein et al. 1997). Dieser Gedanke wurde ca. 10 Jahre später von Brenchley et al. aufgegriffen und weiterverfolgt (Brenchley et al. 2006b). Beide Arbeitsgruppen bestimmten bakterielle Produkte in Körperflüssigkeiten des Menschen, deren Menge sie als repräsentativ für den Übertritt von kommensalen Keimen über die Darmmukosabarriere ansahen. Während Stein et al. Buttersäure im Urin bestimmten, vermaßen Brenchley et al. Lipopolysaccharide (LPS) im Serum von HIV-Patienten. LPS bilden einen Teil der Zellwand gramnegativer Bakterien, die die Mehrheit der kommensalen 
Keime im Darm des Menschen ausmachen. Durch die eingeschränkte Barrierefunktion der Darmmukosa bei HIV-Infizierten kommt es, nach ihrer Hypothese, zum Übertritt von Bakterien und mikrobiellen Produkten (mikrobielle Translokation) über diese Barriere. Hierfür stellen LPS, die auch bei anderen darmkompromittierenden Erkrankungen, wie z.B. Chronisch Entzündlichen Darmerkrankungen (CED), im Plasma nachweisbar sind, einen geeigneten Indikator dar (Gardiner et al. 1995).

Brenchley et al. stellten die Hypothese auf, dass die erhöhten Mengen an mikrobiellen Produkten im Körper zur chronischen Immunaktivierung beitragen, die als Hauptursache für die Entstehung von AIDS anzusehen ist.

\subsection{Die Antwort des menschlichen Körpers auf eine LPS-Exposition}

Der Kontakt des Körpers mit Bakterien stellt eine Reizsituation dar, bei der es zu einer Abwehrreaktion des Organismus kommt. Abgesehen von den Bakterien selbst können auch Bakterienbestandteile, wie LPS, einen solchen Reiz darstellen. LPS bilden einen wichtigen Virulenzfaktor gramnegativer Bakterien, den diese als Endotoxin in ihrer Zellwand tragen (Heumann und Roger 2002). Auf Grund der weiten Verbreitung dieses Virulenzfaktors unter Bakterien hat der menschliche Körper vielfältige Abwehrmechanismen entwickelt, die LPS aus der Körperzirkulation entfernen können. Diese stellen einen wichtigen Teil der Körperabwehr dar und stimulieren z.B. die angeborene zelluläre Immunität in Form der Makrophagen. Im Rahmen der Akutphasereaktion kommt es in der Leber und den Epithelgeweben $\mathrm{zu}$ einer vermehrten Produktion von LPS-Binde-Protein (LBP). Nach Bindung an LPS kann es diese aus dem Kreislauf entfernen oder die Makrophagen-LPSInteraktion erleichtern und so $\mathrm{zu}$ einer Erniedrigung der LPS-Titer beitragen (Fenton und Golenbock 1998). Diese LBP-Makrophagen-Interaktion kann zusätzlich durch lösliches CD14 (engl., soluble CD14, sCD14) erleichtert werden. sCD14 ist ein Glykoprotein, das von Makrophagen bei Kontakt mit LPS abgegeben wird (Bazil und Strominger 1991; Frey et al. 1992). Aber auch die spezifische Immunität setzt sich mit LPS auseinander. Durch die Produktion und Abgabe von Endotoxin Kern Antikörpern (engl., endotoxin core antibodies, EndoCAb) tragen auch B-Zellen dazu bei, die zirkulierenden LPS-Titer zu erniedrigen (Barclay 1995). 


\subsection{Die SIV-Infektion von Rhesusmakaken als Modell der HIV-Infektion des Menschen}

1986 wurde ein weiteres Retrovirus beschrieben, das vergleichbare Charakteristika und Symptome der Immundefizienz bei Makaken in einer amerikanischen Zuchtkolonie auslösen konnte (Daniel et al. 1985). Dieses simiane Immundefizienzvirus (engl., simian immunodeficiency virus, SIV) entstammte ursprünglich einer anderen Primatenspezies, die jedoch keinen mit HIV vergleichbaren Krankheitsverlauf zeigte, sondern das Virus viel mehr als unbedeutenden Kommensalen beherbergte (Coffin et al. 1986). Bei Primatenspezies aus dem asiatischen Raum, zu denen auch die Makaken zählen, kommt eine natürliche Infektion mit Immundefizienzviren nicht vor. Sowohl HIV als auch SIV gehören der Familie der Lentiviridae an (Modrow et al. 2009).

Die SIV Infektion von Rhesusmakaken (Macaca mulatta) eignet sich sehr gut als Tiermodell der HIV-Infektion beim Menschen, da sowohl Virus als auch Wirt eine große genetische Übereinstimmug aufweisen (Johnson und Hirsch 1992). Der größte Unterschied zwischen den beiden Infektionen ist, dass die Infektion der Makaken mit SIV schneller verläuft als die HIVInfektion des Menschen (Letvin und King 1990). SIV ist insbesondere auch als Tiermodell für Pathogenesestudien geeignet. So befällt SIV genauso wie HIV vorwiegend CD4-positive Zellen, wie T-Lymphozyten und Makrophagen, und es kommt ebenso zu einer starken Depletion dieser Zellpopulation im MDT (Desrosiers 1990; Veazey et al. 1998).

Zusätzlich bietet das SIV-Tiermodell die Möglichkeit, den unterschiedlichen Infektionsverlauf verschiedener SIV-infizierter Tiere und Spezies miteinander zu vergleichen. Zum einen kann der pathologische Infektionsverlauf der Rhesusmakaken mit den apathogenen Verläufen der natürlichen Wirte des SI-Virus, wie z.B. der grünen Meerkatze (engl. african green monkey, AGM), verglichen werden (Hahn et al. 2000; Santiago et al. 2002). In diesen apathogenen Modellen treten trotz hoher nachweisbarer Viruslast und mukosaler $\mathrm{CD}^{+}$-Zelldepletion keine Symptome der Immundefizienz auf. In diesen Tieren induziert die Infektion auch keine chronische Aktivierung des Immunsystems und es können keine erhöhten Plasmatiter an LPS gefunden werden (Silvestri 2009, s. Abb. 2). Zum anderen ist der Vergleich von verschiedenen Progressionstypen bei den infizierten Rhesusaffen selbst möglich. In manchen Rhesusaffen führt die SIV-Infektion besonders schnell zum Auftreten von AIDS-Symptomen, in anderen dauert es überdurchschnittlich lange, oder es kommt gar nicht zu deren Entstehen. Bei diesem Vergleich besteht der zusätzliche Vorteil, dass die gleiche Spezies mit dem gleichen Erreger infiziert wird und dadurch intermodell-bedingte Abweichungen minimiert werden können. Viele Experten vermuten im Verständnis der 
Unterschiede zwischen den verschiedenen Pathogenesetypen der SIV-infizierten Rhesusmakaken bzw. der pathogenen und apathogenen SIV-Infektion den Schlüssel zur Heilung der HIV-Infektion des Menschen.

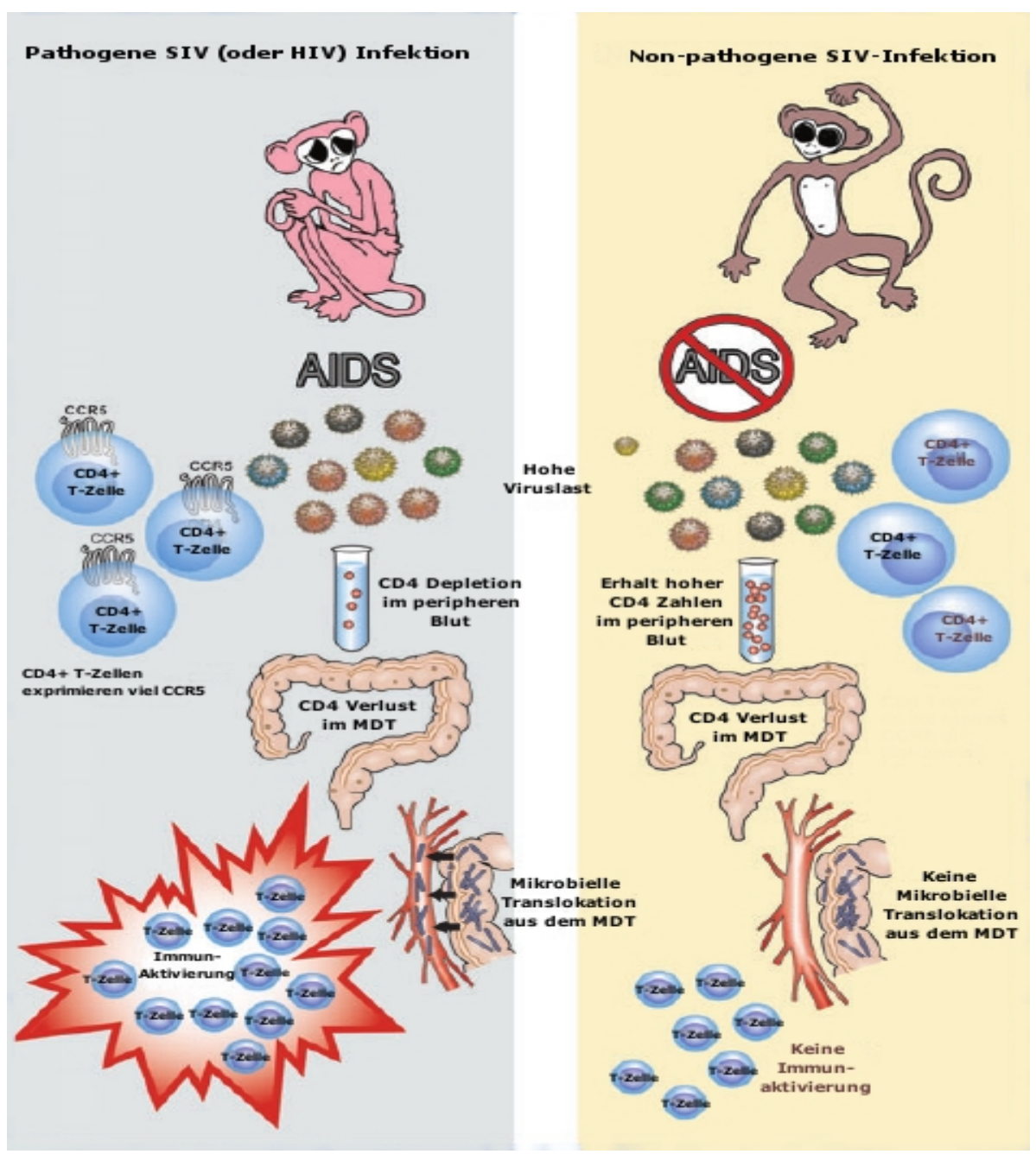

Abbildung 2: Vergleich zwischen pathogener und apathogener SIV-Infektion. (modifiziert nach Silvestri et al. 2008, 106)

\subsection{Ziel dieser Arbeit}

Ausgehend von der Hypothese, dass in der bakteriellen Translokation eine Ursache der chronischen Immunaktivierung in der HIV-Infektion liegt (Brenchley et al. 2006b), wurde in der vorliegenden Arbeit die Bedeutung der mikrobiellen Translokation für die Pathogenese von AIDS im SIV-Rhesusaffen-Tiermodell untersucht. Das Ziel dieser Arbeit war es, die Translokation bakterieller Bestandteile aus dem MDT im Zeitverlauf der SIV-Infektion nachzuvollziehen und im Zusammenhang mit der Immunaktivierung und dem Krankheitsverlauf zu betrachten. Dazu untersuchten wir eine Kohorte von 37 SIV-infizierten 
Rhesusaffen mit heterogenen Krankheitsverläufen und Überlebenszeiten. In einer retrospektiven longitudinalen Studie erhoben wir vor der Infektion und engmaschig während des gesamten Infektionsverlaufs bis zum Tode der Versuchstiere Proben zur Bestimmung der Untersuchungsparameter.

Als Maßeinheit der mikrobiellen Translokation wurden Lipopolysaccharide (LPS) verwendet, die im Plasma der Tiere bestimmt wurden. Zusätzlich wurden verschiedene Moleküle, die in die systemische Antwort des Körpers auf LPS-Kontakt involviert sind, gemessen.

Als Marker für die Aktivierung des angeborenen Immunsystems wurde Neopterin im Urin der Tiere gemessen. Neopterin wird von aktivierten Makrophagen sezerniert und ist ein etablierter Immunaktivierungsmarker für HIV und andere infektiöse Erkrankungen (Hoffmann et al. 2003; Mitaka 2005). Zur Darstellung der Aktivierung der erworbenen Immunität wurde die Expression von HLA-DR auf $\mathrm{CD} 4^{+}$- und $\mathrm{CD} 8^{+}$-T-Lymphozyten gemessen. 


\section{Material und Methoden}

\subsection{Materialien}

\subsubsection{Geräte}

$\underline{\text { Name }}$

Kühl-/Gefrierkombination

Laminarbank (HeraSafe Heraeus)

Pipetten (versch. Volumina)

Mehrkanalpipette

Pipettierhilfe (Pipetus-Akku)

Genios -Photometer

Tischzentrifuge 5415C

Vortex

Heizblock Thermomixer 5436

$37^{\circ} \mathrm{C}$ Raum

Stoppuhr

Zellkulturschrank HeraCell 240

\subsubsection{Verbrauchsmaterialien}

Name

BD Falcon 5ml Rundboden Röhrchen

BD Microlance $3(0,9 \mathrm{~mm} \times 40 \mathrm{~mm})$

BD Vacutainer EDTA oder Zitrat

Einmalspritze (Soft-Ject) $1 \mathrm{ml}$

Reaktionsgefäße 0,5 und 1,5ml

Zellkulturplatten 96-well

Pipettierwannen Costar, 50ml

\subsubsection{Chemikalien}

$\underline{\text { Name }}$

Ethanol $\geq 99,8 \%$

Dodecylsulfat Natriumsalz (SDS) $\underline{\text { Hersteller }}$

Liebherr, Biberach an der Riss

Thermo Electron LED, Langenselbold

Eppendorf AG, Wesseling

Eppendorf AG, Wesseling

Hirschmann, Eberstadt

Tecan, Crailsheim

Eppendorf AG, Wesseling

Schütt Biotec, Göttingen

Eppendorf AG, Wesseling

Carl Roth, Karlsruhe

Thermo Fisher Scientific, Waltham, USA

\section{Hersteller}

BD Biosciences, San Jose, USA

BD Biosciences, San Jose, USA

BD Biosciences, San Jose, USA

Henke-Sass, Wolf, Tuttlingen

Greiner bio-one, Kremsmünster, Österreich

Sarstedt, Nümbrecht

Vitaris, Baar $\underline{\text { Hersteller }}$

Carl Roth, Karlsruhe

Merck, Darmstadt 


\subsubsection{Kommerzielle ELISA-Test-Kits}

$\underline{\text { Name }}$

Quantikine ${ }^{\circledR}$ Human sCD14

LBP - For a wide variety of species

EndoCab ${ }^{\circledR}$
Hersteller

R\&D Systems, Minneapolis, USA

Hycult biotechnology b.v., Uden, Niederlande

Hycult biotechnology b.v., Uden, Niederlande

\subsubsection{Kommerzielle Limulus-Amebocyte-Lysate (LAL)-Test-Kits}

$\underline{\text { Name }}$

QCL-1000®

\subsubsection{Software}

$\underline{\text { Name }}$

Endnote, Version 8.0

Pad Prism, Version 5 $\underline{\text { Hersteller }}$

LONZA, Basel, Schweiz (ehemals Cambrex)

\subsection{Versuchstiere}

Die Versuche wurden an adulten Rhesusaffen (Macaca mulatta) indischer Abstammung durchgeführt. Die Tiere wurden alle am Deutschen Primatenzentrum (DPZ) gehalten und entstammten entweder dem eigenen Zuchtprogramm, oder wurden von Zuchtstationen aus England importiert. Sämtliche Tiere wurden von geschulten Veterinärmedizinern und Tierpflegern der Abteilung Virologie und Immunologie gemäß den Richtlinien des Deutschen Primatenzentrums und der aktuellsten Fassung des Deutschen Tierschutzgesetzes vom 25. Mai 1998 betreut.

Zur Infektion der Tiere wurden zwei unterschiedliche SIV Stämme eingesetzt: der virale Klon SIVmac239 (Kestler et al. 1990), der tonsillär appliziert wurde, und das Schwarmvirus SIVmac251 (Le Grand et al. 1992)., das intravenös injiziert wurde.

\subsubsection{Infektionsverlauf und Gewinnung des Probenmaterials}

Die SIV-Infektion zeichnet sich, genauso wie die HIV Infektion, durch einen typischen Verlauf der Viruslast aus. Dieser Verlauf der Viruslast hatte im wesentlichen Einfluss auf die Zeitpunkte der Probenentnahmen. 
Blut und Urin wurde mehrmals vor der Infektion und 2wpi (engl., weeks post infection, wpi), zum Zeitpunkt der akuten Virämie, 4wpi, 8wpi, 12wpi und 16wpi sowie zum Zeitpunkt der Sektion gewonnen. Hierzu wurde den Rhesusaffen unter Betäubung (intramuskuläre Injektion von 10mg Ketamin/kg Körpergewicht) Vollblut durch Punktion der Vena femoralis mittels BD Vacutainer-Blutentnahmeröhrchen entnommen bzw. der ausgeschiedene Urin mittels Matratzen aufgefangen. Die Proben wurden daraufhin aufbereitet, ihr Plasmabestandteil wurde extrahiert und bis zur weiteren Verwendung bei $-80^{\circ} \mathrm{C}$ tiefgefroren. Bei manchen langsam progredienten Tieren unserer Kohorte bestimmten wir zusätzlich Messwerte zu einem chronischen Zeitpunkt der Infektion, der im Durchschnitt bei 68wpi lag (Spannweite: 42 bis 76wpi). Bis auf 4wpi und 8wpi, wo auf Grund des geringen Probenvolumens nur LPS und VL sowie die HLA-DR-Expression gemessen werden konnte, wurden zu allen Zeitpunkten alle Parameter bestimmt.

\subsubsection{Unterteilung der Versuchskohorte}

Die Zeitspanne bis zur Sektion von 29 Tieren der Kohorte war unterschiedlich lange (Spannweite: 14 bis 155wpi). 5 der 29 Tiere lebten noch zum Zeitpunkt der Erhebung dieser Versuchsdaten. Als Sektionszeitpunkt wurde das Auftreten von AIDS-definierenden Symptomen festgelegt. $\mathrm{Zu}$ diesen gehören z.B. opportunistische Lungeninfektionen mit Pneumocystis jirovecii oder eine Enteropathie mit Diarrhoen ohne Nachweis eines Pathogens im Rahmen des sogenannten „wasting“-Syndroms (CDC et al. 1992). Die Zeitspanne bis zur Entwicklung dieser AIDS-spezifischen Symptome ist sowohl in der SIV- wie auch in der HIV-Infektion individuell verschieden. Es gibt Tiere, die besonders schnell derartige Symptome entwickeln, im folgenden rapid progressors (engl., RP) genannt, und es gibt Tiere, die lange einen asymptomatischen Infektionsverlauf aufweisen, im folgenden slow progressors (engl., SP) genannt.

Zur Unterteilung der Versuchskohorte in eine kürzer und eine länger überlebende Subpopulation setzten wir im Vorhinein als Grenze den Zeitpunkt 40wpi fest. Auf einer Kaplan-Meier-Überlebenskurve entspricht dies etwa dem Zeitpunkt bei dem 65\% der Tiere unserer Kohorte noch lebten (s.Abb. 3).

Damit ergab sich eine RP-Subkohorte von 13 Tieren (Durchschnittliches Überleben 22,5wpi, Spannweite 14-37wpi) und eine SP-Subkohorte von 16 Tieren (Durchschnittlicher Sektionszeitpunkt 74wpi, Spannweite 44-155wpi). 


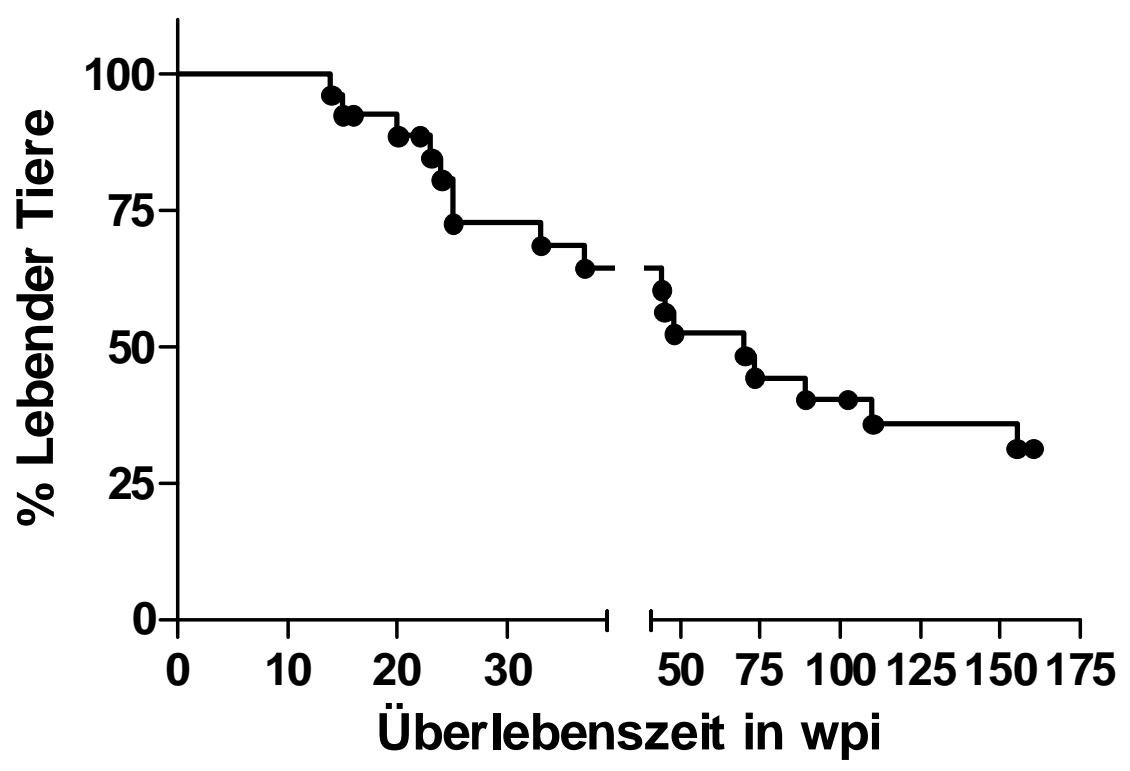

Abbildung 3: Kaplan-Meier-Überlebenskurve der Kohorte. Aufgetragen wurden alle Tiere der Kohorte. Zum Zeitpunkt 40wpi leben noch 65\% der Tiere.

\subsection{Untersuchte Parameter}

Sämtliche Tests wurden unter sterilen Bedingungen unter einer Laminarbank in einem Labor der Sicherheitsstufe S2 durchgeführt, um Verunreinigungen und Infektionsrisiken so gering wie möglich zu halten. Wo immer möglich, wurde eine reverse Pipettiertechnik verwendet, um Pipettierfehler so gering wie möglich zu halten.

\subsubsection{Lipopolysaccharid-Nachweis}

Der QCL-1000® ist ein handelsüblicher Limulus Amebocyte Lysate Test zur Detektion von bakteriellen Pyrogenen und Endotoxinen in Arzneimitteln, biotechnologischen Erzeugnissen oder an medizinischen Geräten. Auch zum Nachweis von Pyrogenen in humanen Plasmaproben ist dieser Test geeignet (Fukui et al. 1989).

Zur Analyse von Plasmaproben wurden diese zunächst durch Erhitzen auf $70^{\circ} \mathrm{C}$ für $10 \mathrm{~min}$ im Heizblock inaktiviert. Die Proben wurden daraufhin im Verhältnis 1:10 mit endotoxinfreiem Reagenzwasser verdünnt. Aus der im Testkit enthaltenen Eschericha-coliEndotoxinpräparation wurde nach Zugabe von Reagenzwasser und 15min Vortexen die Standardverdünnungsreihe hergestellt. Es wurden Verdünnungsstufen mit 1, 0.5, 0.25 und 0.1EU/ml nach Herstellerangaben hergestellt. Zusätzlich wurde zur besseren Darstellung des 
Endotoxingehalts bei niedrigen Messwerten die Stufe $0.05 E U / \mathrm{ml}$ eingeführt. Den Herstellerangaben folgend wurden alle weiteren Schritte unter $37^{\circ} \mathrm{C}$ Raumtemperatur durchgeführt. Jeweils $50 \mu 1$ der verdünnten Plasmaprobe bzw. der Standardlösung wurden in doppelten Ansätzen auf eine sterile 96-Well-Zellkulturplatte aufgebracht. Außerdem wurde eine Blindprobe aus Reagenzwasser ebenfalls in Doppelbestimmung angesetzt. Als nächstes wurden 50 $\mu 1$ LAL-Enzym aufgebracht, mit der Probe durch Auf- und Abpipettieren vermischt und für 10min inkubiert. Um die genaue Einhaltung der Inkubationszeit zu gewährleisten, wurde ab der Zugabe des Enzyms in den ersten Reaktionsansatz die Zeit per Stoppuhr vermessen. Nach Ablauf der 10min wurde $100 \mu$ l chromogenes Substrat, das zuvor auf $37^{\circ} \mathrm{C}$ erwärmt worden war, zugegeben und mit dem Inhalt der Wells vermischt. Wiederum wurde die daraufhin folgende Inkubationszeit von 6min genau per Stoppuhr terminiert. Nach Ablauf der 6min wurde der nun entstehende Farbumschlag photometrisch im Reaktionsverlauf gemessen, um die optimale Bandbreite der Absorptionswerte zu gewährleisten. Daraufhin

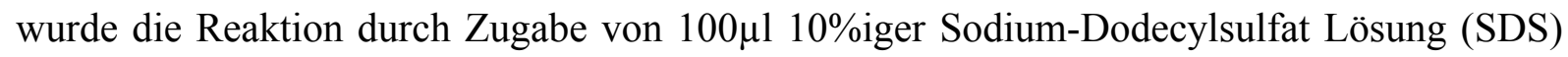
gestoppt und durch Auf- und Abpipettieren vermischt. Die nachfolgende finale photometrische Messung bei einer Absorption von 405nm mit einem Tecan-Photometer wurde als Grundlage für die weitere Auswertung verwendet.

\subsubsection{Enzym-linked immunosorbent assay (ELISA)}

Die drei Parameter EndoCab, LBP und sCD14 wurden mittels kommerziell erwerblichen ELISA Test-Kits im Affenplasma gemessen. Alle diese Tests wurden nach dem Prinzip des Sandwich-ELISAs durchgeführt.

Die Versuche wurden leicht modifiziert nach Herstellerangaben durchgeführt. Sämtliche Tests wurden in Doppelbestimmung durchgeführt. Da die Test-Kits, mit Ausnahme des LBPKits, für humanes Plasma konzipiert worden waren, musste zunächst die Kreuzreaktivität mit Rhesusaffenantigenen getestet und die normalen Konzentrationen der Moleküle im Affenplasma bestimmt werden. Die Probenverdünnung wurde daraufhin an die teilweise herabgesetzte Reaktivität bzw. die veränderten Normalwerte gegebenenfalls entsprechend angepasst.

\subsubsection{EndoCab-ELISA-Testkit}

Der EndoCab-ELISA-Test ermöglicht die gesonderte Detektion von IgA, IgG und IgM Antikörpern. Allerdings erwies sich lediglich der Antikörper der Klasse M als ausreichend kreuzreaktiv, so dass nur dieser Antikörper in der Datenerhebung zum Einsatz kam. 
Die Entscheidung bezüglich der Kompatibilität der Antikörperklassen wurde anhand der Steilheit der Steigung einer Titrationsgeraden des entsprechenden Antikörpers im Vergleich zu der Geraden der Standardverdünnungsreihe getroffen, wobei die Steigung annährend gleich ausfallen sollte und die Geraden möglichst parallel zueinander liegen sollten.

Die Plasmaproben wurden um den Faktor 1:40 mit dem kiteigenen Verdünnungspuffer auf einer separaten Zellkulturplatte verdünnt. Eine Standardverdünnungsreihe wurde hergestellt. Hierzu verdünnte man $450 \mu 1$ einer 3,5MMU/ml Standardlösung durch Überpipettieren jeweils der Hälfe des Ansatzes auf die nächst-niedrigere Verdünnungsstufe und füllte den Ansatz zur anderen Hälfte mit $225 \mu 1$ Verdünnungspuffer auf. Nach sorgfältigem Durchmischen durch Auf- und Abpipettieren wiederholte man diese 1:2 Verdünnung fünf mal, bis man in dem siebten Ansatz eine Verdünnungsstufe von 1:64 erreicht hatte. Als achter Ansatz wurde als Blindprobe reiner Verdünnungspuffer verwendet. Zusätzlich zu dieser kiteigenen Standardkurve wurde zur Etablierung und Kompatibilitätsprüfung ein aus drei gesunden Rhesusaffen zusammengestelltes Referenzplasma in den Verdünnungsstufen 1:10, 1:20, 1:40 und 1:80 eingesetzt. 100 $\mu 1$ der Plasmaansätze und Standardlösungen wurden sodann jeweils zweifach auf die mit Antikörpern beschichtete 96-Well-ELISA-Platte aufgetragen. Die Plasmaproben wurden per 12-Kanalpipette von der Zellkulturplatte auf die Platte aufgebracht, die Kit-Standardreihe und der Rhesusmix-Standard einzeln aus den jeweiligen Röhrchen. Für eine einstündige Inkubationszeit wurde die Platte abgedeckt und bei $37^{\circ} \mathrm{C}$ im Zellkulturschrank gelagert. Nach Ablauf der Inkubationszeit wurde der Inhalt der Wells mit der Mehrfachpipette einzeln abgezogen und verworfen. Dann wurde 200 $\mu$ l kiteigener Waschpuffer aufgetragen und für 20 Sekunden inkubiert. Der Waschpuffer wurde durch Abkippen und anschließendes drei- bis viermaliges Ausschlagen der Platte auf einer Lage Tücher möglichst vollständig entfernt und der Waschvorgang dreimal wiederholt, so dass die Wells insgesamt viermal ausgewaschen wurden. Als nächstes wurden per Mehrkanalpipette $100 \mu 1$ Tracer-Antikörper, der zuvor im Verhältnis 1:100 mit Verdünnungspuffer verdünnt worden war, in die Wells gegeben. Einer erneuten Inkubationszeit von einer Stunde im Zellkulturschrank folgte ein abermaliger Waschschritt (s.o.). Hiernach wurde als Substrat des Peroxidaseenzyms, das an den Tracer-Antikörper gekoppelt zugegeben worden war, $100 \mu 1$ Tetramethylbenzidin (TMB) zugegeben. Binnen ca. 20min Inkubationszeit unter Lichtausschluss bei Raumtemperatur kam es zu einem blauen Farbumschlag. 100 $\mu$ l StoppPuffer wurden nach ca. 25min hinzugegeben und damit die Enzymaktivität nachhaltig gestört. Es kam zu einem Farbumschlag von blau zu gelb. Anschließend wurde durch Auf- und 
Abpipettieren der Probenansatz vermischt und die Absorption bei einer Wellenlänge von 450nm im Tecan-Photometer bestimmt.

\subsubsection{LBP-ELISA-Testkit}

Der LBP-ELISA-Kit war nach Herstellerangaben für die Untersuchung von Affenplasma geeignet, was sich in den durchgeführten Vortests bestätigte. Allerdings musste auf Grund der großen Bandbreite der LBP-Spiegel nicht nur in einer 1:100 Verdünnung, wie es auch der Hersteller vorsieht, sondern auch in einer 1:1000 Verdünnung gemessen werden. Teilweise war es sogar notwendig, zusätzliche Messungen in einer 1:10.000 Verdünnung anzustellen, da die Werte ansonsten nicht im linearen Bereich der Messkurve lagen. Nach Berücksichtigung des Verdünnungsfaktors lieferten diese stärker verdünnten Proben jedoch vergleichbare Werte, weswegen keine Notwendigkeit für eine zweite Wertbestimmung in einer Verdünnung bestand.

Das Probenmaterial wurde 1:100 mit dem kiteigenen Verdünnungspuffer auf einer separaten Zellkulturplatte verdünnt und ein Teil davon per 12-Kanal-Pipette zur Erstellung einer 1:1000 Verdünnung auf eine zweite Zellkulturplatte überführt. Eine Standardverdünnungsreihe wurde hergestellt, indem eine 100ng/ml Standardlösung durch Überpipettieren 1:2 mit Puffer verdünnt wurde. Diese 1:2 Verdünnung wurde bis zu einer Verdünnung von 1:64 fortgeführt, so dass insgesamt sieben Standardansätze verwendet wurden. Als achter Ansatz wurde als Blindprobe reiner Verdünnungspuffer verwandt. Zusätzlich wurde bei der Etablierung des Testkits ein aus drei gesunden Rhesusaffen zusammengestelltes Referenzplasma in den Verdünnungsstufen 1:50, 1:100, 1:200 und 1:400 verwendet. 100 $\mu 1$ der Plasma- und Standardverdünnungen wurden jeweils doppelt auf die mit Antikörpern beschichtete ELISAPlatte aufgetragen. Die Proben wurden per 12-Kanalpipette von der Zellkulturplatte auf die Platte übertragen, die Kit-Standardreihe und der Rhesusmix-Standard einzeln aus den jeweiligen Einzelröhrchen. Es folgte ein Abdecken der Platte und eine Inkubation bei Raumtemperatur für eine Stunde. Anschließend wurde der Inhalt der Wells mit der Mehrfachpipette einzeln abgezogen und verworfen, sodann $200 \mu$ l Waschpuffer aufgetragen und für 20 Sekunden inkubiert. Der Waschpuffer wurde durch Abkippen und anschließendes drei- bis viermaliges Ausschlagen der Platte auf einer Lage Tücher möglichst vollständig entfernt und der Waschvorgang dreimal wiederholt, so dass insgesamt viermal gewaschen wurde. Als nächstes wurde per 12-Kanal-Pipette jeweils 100 $\mu 1$ Tracer-LPS, das zuvor 1:6 mit Verdünnungspuffer verdünnt worden war, in die Wells gegeben und durch Auf- und Abpipettieren vermischt. Nach erneutem Abdecken und einstündiger Inkubation bei 
Raumtemperatur wurde der Waschvorgang wiederholt (s.o.). Dann wurde je Well $100 \mu 1$ Streptavidin-Peroxidase-Konjugat, das zuvor 1:24 mit Puffer verdünnt worden war, hinzugegeben und durch Auf- und Abpipettieren vermischt. Nach abermaliger einstündiger Inkubation und Waschen der Wells wurde 100 $\mu$ 1 Tetramethylbenzidin (TMB) als Substrat zugegeben. Binnen ca. 20min Inkubation bei Dunkelheit und Raumtemperatur kam es zu einem blauen Farbumschlag. Dieser Veränderte sich unter Zugabe von je 100 $\mu$ l Stopp-Puffer pro Well hin zu einer Gelbfärbung. Nach Durchmischung der Ansätze wurde die Absorption bei 450nm Wellenlänge mit dem Tecan-Photometer vermessen.

\subsubsection{Quantikine Human-sCD14-ELISA-Testkit}

Die Plasmaproben wurden 1:100 mit Kalibrierungspuffer auf einer separaten Zellkulturplatte verdünnt. Eine Standardverdünnungsreihe wurde hergestellt. Ausgehend von der im Kit enthaltenen $16000 \mathrm{pg} / \mathrm{ml}$ Standardlösung wurden $500 \mu \mathrm{l} \mathrm{zu}$ gleichem Anteil mit Kalibrierungspuffer verdünnt, so dass ein $8000 \mathrm{pg} / \mathrm{ml}$ Lösung entstand. Diese 1:2 Verdünnung wurde bis zum Erhalt eines 250pg/ml Ansatzes sechs mal fortgesetzt. Jeweils $100 \mu 1$ des Plasmaansatzes wurden per 12-Kanal-Pipette von der Zellkulturplatte in die antikörperbeschichteten Wells der ELISA-Platte übertragen. Jeder Messansatz wurde in doppelter Ausführung bestimmt. Die Standardansätze wurden zu 100 $\mu 1$ einzeln aus separaten Eppendorf-Cups auf die ELISA-Platte übertragen und ebenfalls doppelt vermessen.

Daraufhin folgte das Abdecken der Platte und die Inkubation bei Raumtemperatur für drei Stunden. Danach wurde mit der Mehrfachpipette der Inhalt der Wells einzeln abgezogen und verworfen, sodann $200 \mu \mathrm{l}$ Waschpuffer aufgetragen und für 20 Sekunden inkubiert. Der Waschpuffer wurde durch Abkippen und anschließendes drei- bis viermaliges Ausschlagen der Platte auf einer Lage Tücher möglichst vollständig entfernt und der Waschvorgang dreimal wiederholt, so dass insgesamt viermal gewaschen wurde. Als nächster Schritt wurde jeweils $200 \mu \mathrm{l}$ sCD14-Konjugat in die Wells gegeben und per Auf- und Abpipettieren gut vermischt. Nach Abdecken der Platte und Inkubation bei Raumtemperatur für eine Stunde wurden die Waschschritte wie oben beschrieben wiederholt. Die Substratlösung war 15min vor dem Ende der letzten Inkubationszeit aus zwei Kit-Reagenzien im Verhältnis 1:1 hergestellt worden und wurde nun jeweils á $200 \mu 1$ per 12-Kanal-Pipette in die Wells gegeben. Daraufhin wurde die Platte weitere 30min bei Raumtemperatur und unter Lichtausschluss

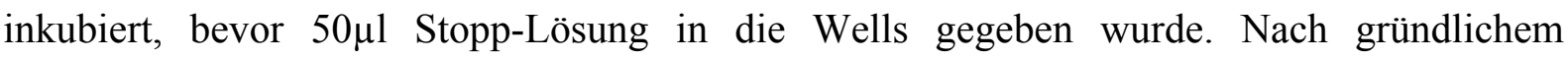
Vermischen durch Auf- und Abpipettieren wurde die Absorption bei 450nm mit dem TecanPhotometer gemessen. 


\subsubsection{Bestimmung der Viruslast}

Zur Bestimmung der Viruslast wurde zunächst Virus-RNA der SIV-infizierten Versuchstiere aus Blutplasma mit Hilfe des Mag Attract $\AA^{\circledR}$ Virus Mini M48-Isolations-Kit und des BioRobot M48 der Firma Qiagen isoliert. Mittels einer reversen TranskriptionsPolymeraseketternreaktion (RT-PCR), als Kit ebenfalls von der Firma Qiagen erhältlich (QuantiTect ${ }^{\circledR}$ Probe), wurde in einem nächsten Schritt die Viruslast der Tiere im 7500 RealTime PCR System von Applied Biosystems bestimmt (Tenner-Racz et al. 2004). Diese Messungen wurden von Frau Dr. Sauermann und ihren Mitarbeitern durchgeführt.

\subsubsection{Bestimmung der Betakarotinresorption}

Bei 8 Tieren der Kohorte wurde die Serumkonzentration an Betakarotin, nach Deproteinisierung mit Ethanol und Extraktion in Petroleumether, photometrisch bei einer Wellenlänge von 456nm bestimmt (Kewenig et al. 1999). Die Messungen wurde von der Arbeitsgruppe Thomas Schneider, Charité, Berlin, durchgeführt und freundlicherweise zur Verfügung gestellt.

\subsubsection{Bestimmung von Neopterin}

Der Nachweis von Neopterin im Urin der SIV-infizierten Versuchstiere wurde mit einer Hochdruck-Flüssigkeitschromatographie (engl., high-pressure liquid chromatography) ermöglicht. Hierbei wurden die gemessenen Neopterinwerte mit gemessenen KreatininKonzentrationen verrechnet, um physiologische Schwankungen des spezifischen Uringewichtes zu berücksichtigen (Fendrich et al. 1989). Die Methode wurde von Herrn Prof. Fuchs der Abteilung Biochemie des Biozenters der Universität Innsbruck, Österreich, etabliert und durchgeführt (Fuchs et al. 1988).

\subsubsection{Bestimmung der HLA-DR-Expression}

Die Expression von HLA-DR wurde sowohl auf $\mathrm{CD}^{+}-$als auch CD8 ${ }^{+}$-T-Lymphozyten als Marker der spezifischen IA bestimmt. Periphere mononukleäre Blutleukozyten wurden mit Hilfe eines Ficoll Dichtegradienten isoliert und 300000 Zellen mit bis zu zehn verschiedenen Antikörpern inkubiert (Schulte et al. 2009). Nach waschen und fixieren der Zellen wurden diese mit einem LSRII Durchflusszytometer gemessen und deren Zusammensetzung mit dem Programm FloJo analysiert. Diese Untersuchungen wurden von Herrn PD Dr. Sopper und seinen Mitarbeitern durchgeführt. 


\subsubsection{Statistische Auswertung und graphische Darstellung}

Statistische Analysen wurden mit dem Programm Graph Pad Prism 5.0 durchgeführt. Zur Bestimmung von Korrelationen zwischen den einzelnen Parametern wurde der nichtparametrische Spearman-Rank-Test angewendet. Vergleiche zwischen RP und SP wurde mit dem nicht-parametrischen Mann-Whitney-U-Test angestellt. Die Veränderungen eines Parameters im Zeitverlauf der Infektion wurden mit dem nicht-parametrischen, gepaarten Wilcoxon signed-rank-Test auf ihre Signifikanz überprüft. Alle drei Tests wurden zweiseitig und mit einem Konfidenzintervall von 95\% durchgeführt. Ein p-Wert kleiner als 0,05 wurde als statistisch signifikant angesehen.

Die abgebildeten Graphen wurden ebenfalls mit dem Programm Graph Pad Prism 5.0 erstellt. Bei den Graphen, die Zeitverläufe abbilden, sind Mediane und zusätzlich der Interquartilenabstand dargestellt. 


\section{Resultate}

In der vorliegenden Arbeit wurde die mikrobielle Translokation im SIV Tiermodell der HIVInfektion untersucht. Das Ziel war, die Bedeutung dieser Translokation für den Infektionsverlauf und deren mögliche Auswirkung auf die Aktivierung des Immunsystems und die Pathogenese der HIV-Infektion zu betrachten.

Die Versuche wurden retrospektiv in einer Kohorte von 37 nicht-immunisierten Rhesusaffen aus 8 verschiedenen Vakzinierungsexperimenten am Deutschen Primatenzentrum in Göttingen durchgeführt. Die Tiere wurden je etwa zur Hälfte mit dem lymphozytotropen Virusstamm SIVmac239 (19 Tiere) und dem monozytotropen Erregerstamm SIVmac251 MPBMC (18 Tiere) infiziert.

Den Tieren wurde zu bestimmten Zeitpunkten des Infektionsverlaufs Plasmaproben entnommen und auf Lipopolysaccharide (LPS), die als Ausdruck einer bakteriellen Translokation angenommen wurden, hin untersucht. Neben verschiedenen mit LPS assoziierten Molekülen wurde zusätzlich die Viruslast und zwei Parameter der Immunaktivierung im Plasma bzw. im Urin bestimmt sowie die Überlebenszeit der Tiere errechnet. Ausgehend von der Überlebenszeit konnte die Versuchskohorte in zwei Subpopulationen unterteilt werden. Diese unterschiedlichen Infektionsverläufe wurden ebenfalls in die Betrachtung der mikrobiellen Translokation einbezogen. 


\title{
3.1 Die Viruslast im Infektionsverlauf
}

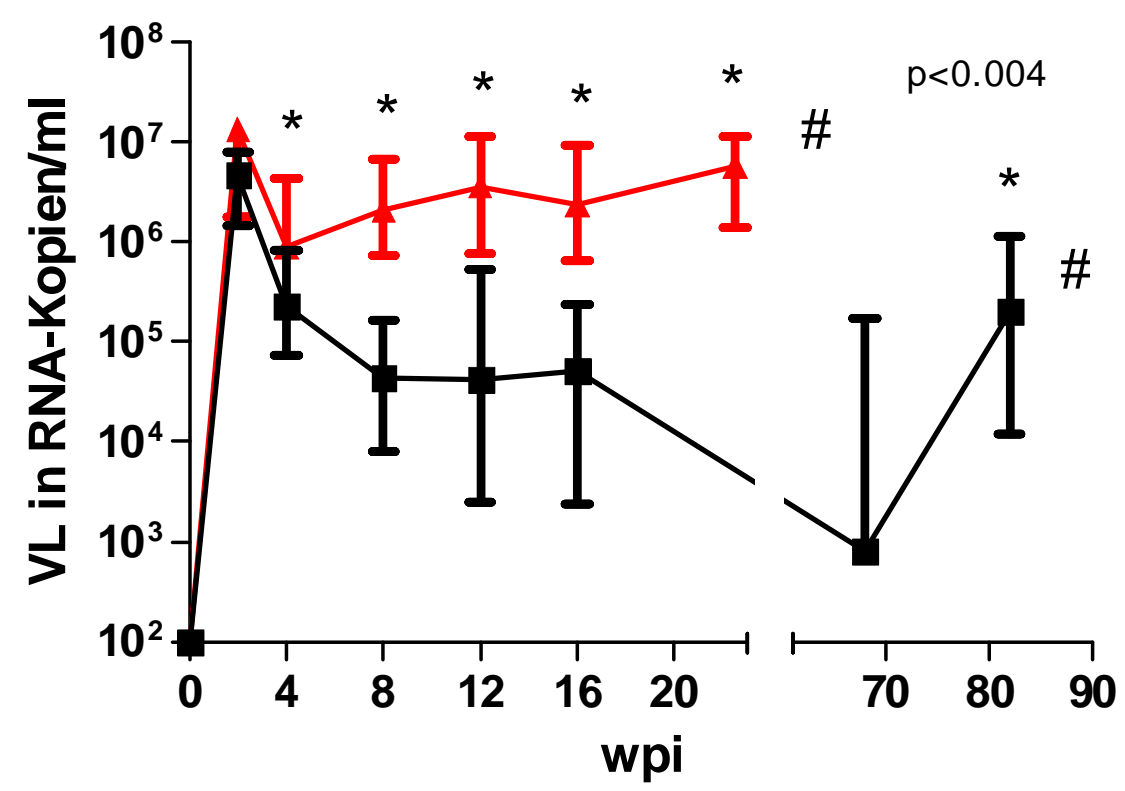

\begin{abstract}
Abbildung 4: Viruslast im Zeitverlauf. Auf der Y-Achse ist die Viruslast in RNAKopien/ml aufgetragen, auf der X-Achse ist die Zeit in wpi dargestellt. Dargestellt sind Mediane inkl. der interquartilen Abstände. Die roten Dreiecke sind RP, die schwarzen Quadrate SP, \# markiert die Werte zum durchschnittlichen Sektionszeitpunkt, * markiert signifikante Unterschiede zwischen RP und SP, der p-Wert stellt den am wenigsten signifikanten Unterschied dar und wurde mittels Mann-Whitney-Test ermittelt.
\end{abstract}

Bei der SIV-, wie auch der HIV-Infektion, lässt sich die Infektion anhand der Viruslast in einen typischen Verlauf gliedern. Diesen typischen Verlauf der peripheren VL-Kurve fanden wir auch in unserer Kohorte wieder (s. Abb. 4).

Der Infektion folgte eine akute Phase der Virämie. Diese Phase des steilen Anstiegs der VL hat regelhaft 2wpi ihr Maximum und erreichte in beiden Progressionsgruppen mittlere Werte von ca. $1 * 10^{\wedge} 7$ RNA-Kopien/ml. In der daraufhin folgenden postakuten Phase kam es zu einer Erniedrigung der peripheren VL-Titer. Sowohl RP als auch SP zeigten von 4wpi bis 16wpi eine Plateauphase der VL, die bei den RP allerdings ca. zwei Dekaden höher lag als bei den SP. Dieser Unterschied war zu jedem Zeitpunkt signifikant $(p \leq 0,004)$. Diese postakute Phase ging bei den SP in eine chronische Phase über, bei der die individuellen VL-Titer in etwa gleich blieben. Bei Erreichen von AIDS kam es in beiden Gruppen zu einem abermaligen Anstieg der VL, dessen Höhe sich wiederum signifikant zwischen RP und SP unterschied $(\mathrm{p}=0,0008)$.

Der Infektionsverlauf und die Viruslast zeigte keine Abhängigkeit von dem zur Infektion verwandten Virusstamm. 


\subsection{Durchlässigkeit der intestinalen Mukosabarriere}

Als Ursprung der erhöht gemessenen LPS-Titer wurde wiederholt der MDT angenommen. Um eine Fehlfunktion der intestinalen Mukosa im postakuten Stadium der SIV-Infektion nachzuweisen, wurden $\beta$-Karotin als Marker der Malabsorption gemessen und mit den LPSWerten, einem Mittelwert, errechnet aus Messwerten 12wpi und 16wpi, verglichen. Der Zeitpunkt der LPS-Messung (ca. 14wpi) entspricht somit dem Zeitpunkt 100 Tage nach der Infektion, an dem von Brenchley et al. die Messungen angestellt wurden, die zur Ausbildung ihrer Hypothese führten (Brenchley et al. 2006b). Der Zeitpunkt der Betakarotinmessung liegt bei 12wpi. (s. Abb. 5)

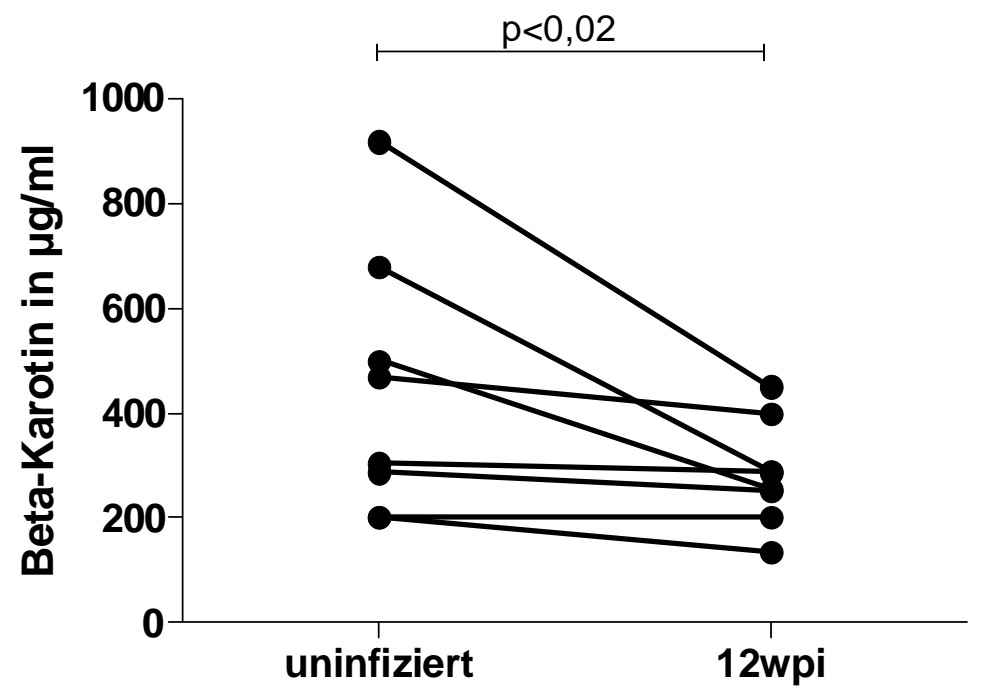

Abbildung 5: Beta-Karotinresorption im Vergleich vor der Infektion und 12wpi. Auf der Y-Achse ist die Beta-Karotinkonzentration im Serum in $\mu \mathrm{g} / \mathrm{ml}$ aufgetragen, auf der XAchse sind die beiden Zeitpunkte uninfiziert und 12wpi dargestellt. Der p-Wert stellt den signifikanten Abfall dar und wurde mittels Mann-Whitney-Test ermittelt.

In 8 repräsentativen Tieren unserer Kohorte zeigte sich ein signifikanter Abfall in der $\beta$ Karotin-Konzentration 12wpi im Vergleich mit individuellen Werten vor der Infektion $(\mathrm{p}<0,02$, s. Abb. 5). LPS zeigte im gleichen Zeitraum einen signifikanten Anstieg im Vergleich zu individuellen Werten vor der Infektion ( $p=0,0007$, s. Abb. 6) Hierbei war bei 20 Tieren ein Anstieg messbar, bei 6 Tieren blieb die Konzentration gleich und 3 Tiere fielen mit den LPS-Titern ab. Eine signifikante Korrelation zwischen individuellem $\beta$-Karotin und LPS konnte jedoch nicht festgestellt werden. 


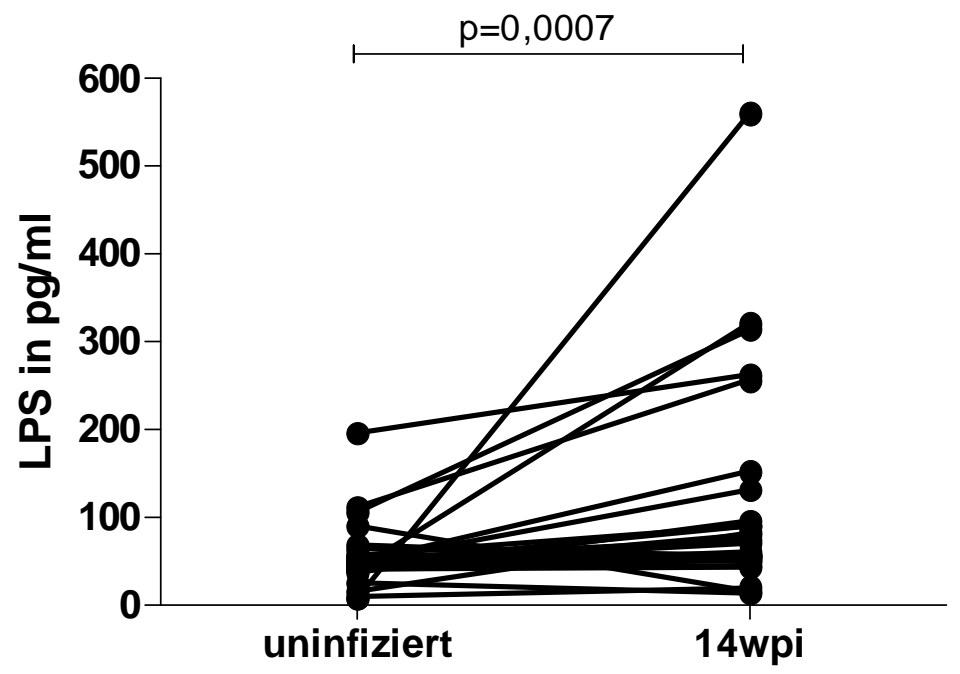

Abbildung 6: LPS-Konzentration im Vergleich vor der Infektion und 14wpi. Auf der YAchse ist die LPS-Konzentration im Plasma in pg/ml aufgetragen, auf der X-Achse sind die beiden Zeitpunkte uninfiziert und 14wpi dargestellt. Der p-Wert stellt den signifikanten Anstieg dar und wurde mittels Mann-Whitney-Test ermittelt. 


\subsection{Zeitverlauf der Lipopolysaccharide (LPS) im Plasma}

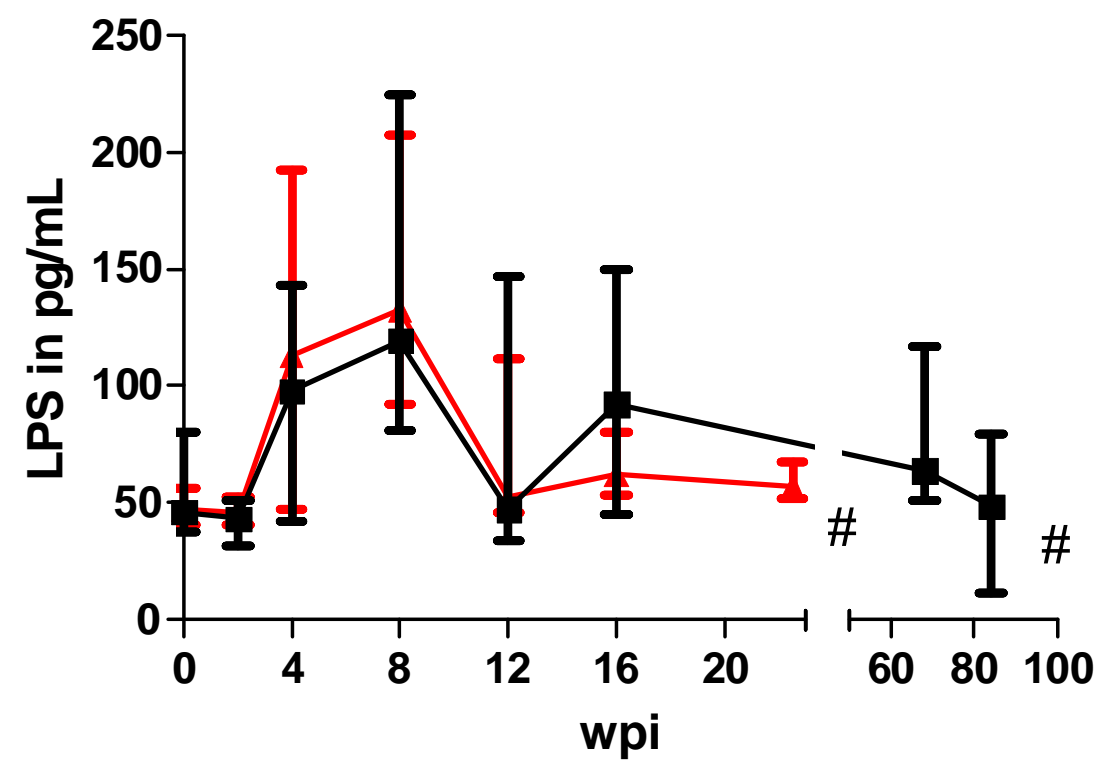

Abbildung 7: LPS im Zeitverlauf. Auf der Y-Achse ist die LPS-Konzentration im Plasma in $\mathrm{pg} / \mathrm{ml}$ aufgetragen, auf der X-Achse ist die Zeit in wpi dargestellt. Dargestellt sind Mediane inkl. der interquartilen Abstände. Die roten Dreiecke sind RP, die schwarzen Quadrate SP, \# markiert den Sektionszeitpunkt.

Da 100 Tage nach der Infektion ein LPS Anstieg messbar war, sollte nun die Kinetik der LPS-Konzentration im Infektionsverlauf engmaschig betrachtet werden. In der akuten Phase der Infektion 2wpi kam es weder bei den RP noch bei den SP zu einem Anstieg der LPSSpiegel im Plasma (s. Abb. 7). Zum Zeitpunkt 4wpi stiegen sowohl bei den RP als auch bei den SP die LPS-Titer im Vergleich zum Ausgangswert auf Werte um 100pg/ml an $(\mathrm{p}<0,05)$. Auch 8wpi setzte sich dieser Trend fort $(p<0,007)$. Im weiteren Verlauf kam es zu einem Rückgang der LPS-Titer, die bis zum Sektionszeitpunkt erneut im Bereich der Ausgangswerte lagen. Hierbei war 12wpi ein nicht signifikanter Abfall und 16wpi in beiden Gruppen erneut eine signifikante Erhöhung im Vergleich zur Vorinfektion messbar. Die LPS-Titer 16wpi der RP lagen im Mittel auf $65 \mathrm{pg} / \mathrm{ml}(\mathrm{p}<0,05)$ und die der SP auf im Mittel 183pg/ml $(\mathrm{p}<0,01, \mathrm{~s}$. auch Abb. 6). Zum chronischen Messzeitpunkt der SP wurden Mittelwerte von 82pg/ml gemessen. Zum Sektionszeitpunkt wurden weiter abgefallene LPS-Werte von ca. $57 \mathrm{pg} / \mathrm{ml}$ in beiden Gruppen gemessen.

Die unterschiedlichen Virusstämme hatten keinen Einfluss auf die Höhe der LPS-Werte. 


\title{
3.4 Lipopolysaccharid-Binde-Protein (LBP)
}

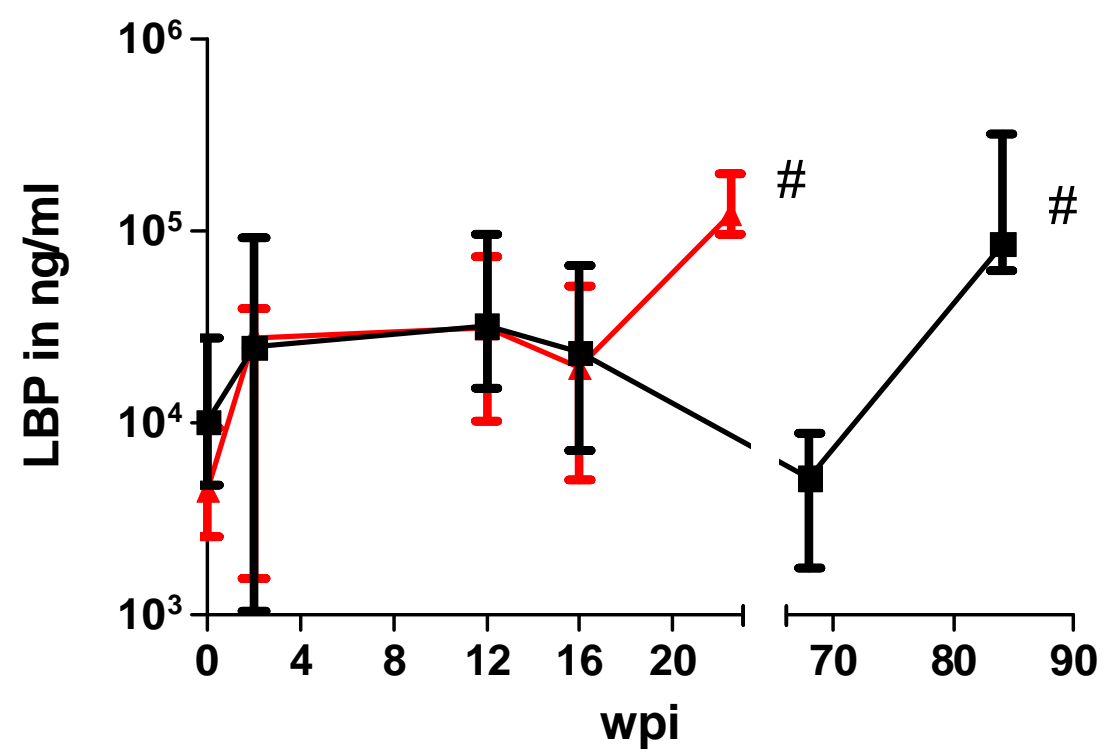

\begin{abstract}
Abbildung 8: LBP im Zeitverlauf. Auf der Y-Achse ist die LBP-Konzentration im Plasma in $\mathrm{ng} / \mathrm{ml}$ aufgetragen, auf der X-Achse ist die Zeit in wpi dargestellt. Dargestellt sind Mediane inkl. der interquartilen Abstände. Die roten Dreiecke sind RP, die schwarzen Quadrate SP, \# markiert den Sektionszeitpunkt.
\end{abstract}

Als Teil der LPS spezifischen Abwehrreaktion des Körpers maßen wir LBP im Plasma der Tiere. Die LBP-Titer stiegen in der virämischen Phase 2wpi signifikant im Vergleich zum Wert vor der Infektion (SP: ca. $10.000 \mathrm{ng} / \mathrm{ml}$ im Median, RP: ca. 4500ng/ml im Median) auf Werte um 25.000ng/ml an ( $<<0,05$, s. Abb. 8). Im weiteren Verlauf blieben sie erhöht, wobei sich die Menge in der chronischen Phase etwas erniedrigte. Zum Zeitpunkt 12wpi wurde ebenfalls ein zu Vorinfektionswerten signifikant erhöhter Wert in beiden Gruppen gemessen $(\mathrm{p}<0,002)$. Zum Zeitpunkt 16wpi kam es zu einem leichten Abfall der LBP-Werte der beiden Teile der Kohorte und zum chronischen Messzeitpunkt der SP wurde ein weiterer Abfall als signifikant zum 16wpi Wert gemessen $(\mathrm{p}<0,05)$. Nach diesem Abfall stiegen die LBP-Level zum Zeitpunkt AIDS jedoch wieder sprunghaft auf Werte über $100.000 \mathrm{ng} / \mathrm{ml}$ in beiden Gruppen an $(\mathrm{p}<0,02)$. 


\subsection{Endotoxin Core Antibodies (EndoCAb)}

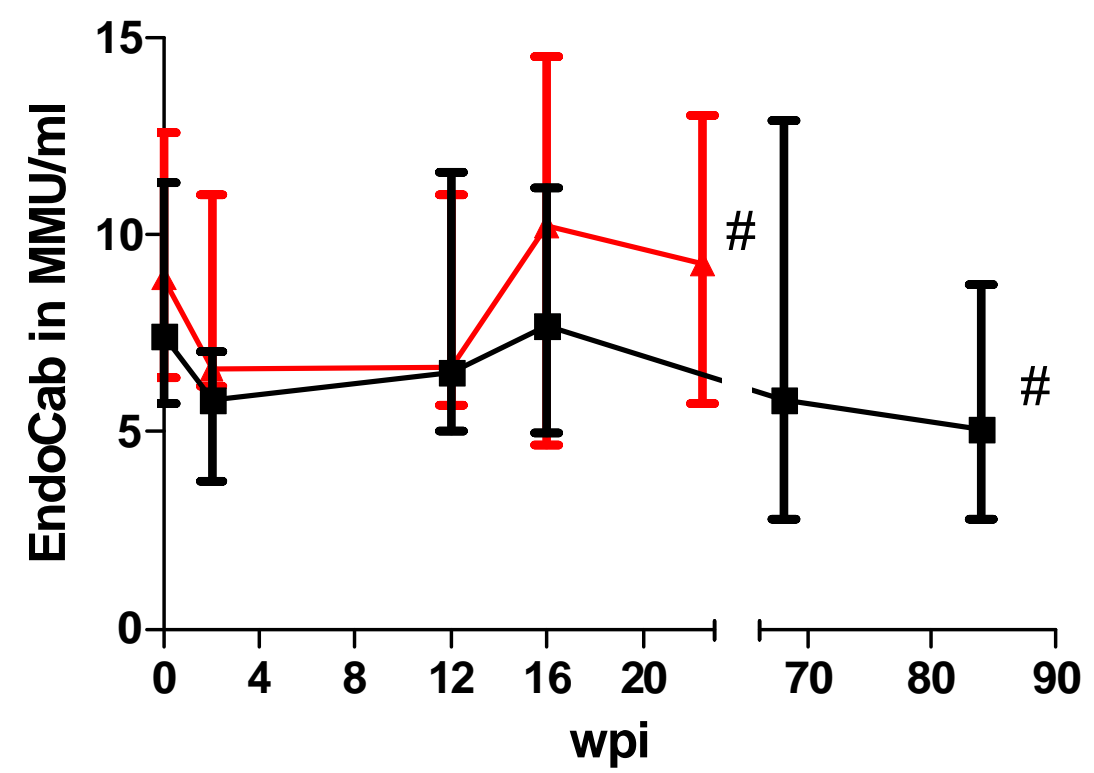

Abbildung 9: EndoCAb im Zeitverlauf. Auf der Y-Achse ist die EndoCAb-Konzentration im Plasma in MMU/ml aufgetragen, auf der X-Achse ist die Zeit in wpi dargestellt. Dargestellt sind Mediane inkl. der interquartilen Abstände. Die roten Dreiecke sind RP, die schwarzen Quadrate SP, \# markiert den Sektionszeitpunkt.

EndoCAb sind gegen einen Teil des Endotoxins gerichtete Antikörper, die zur Reduktion der zirkulierenden LPS-Titer beitragen. In der gesamten Kohorte fiel die Antikörpermenge in der akuten Infektion 2 wpi von ca. $8 \mathrm{MMU} / \mathrm{ml}$ vor der Infektion auf ca. $6 \mathrm{MMU} / \mathrm{ml}(\mathrm{p}<0,01 ; \mathrm{s}$. Abb. 9). Abgesehen davon konnten keine signifikanten Veränderungen im Infektionsverlauf oder abhängig von der Krankheitsprogression festgestellt werden. In den RP bestand ein Trend zu einem Anstieg zum Zeitpunkt der Sektion, der jedoch nicht signifikant ausfiel. 


\title{
3.6 Lösliches CD14 (sCD14)
}

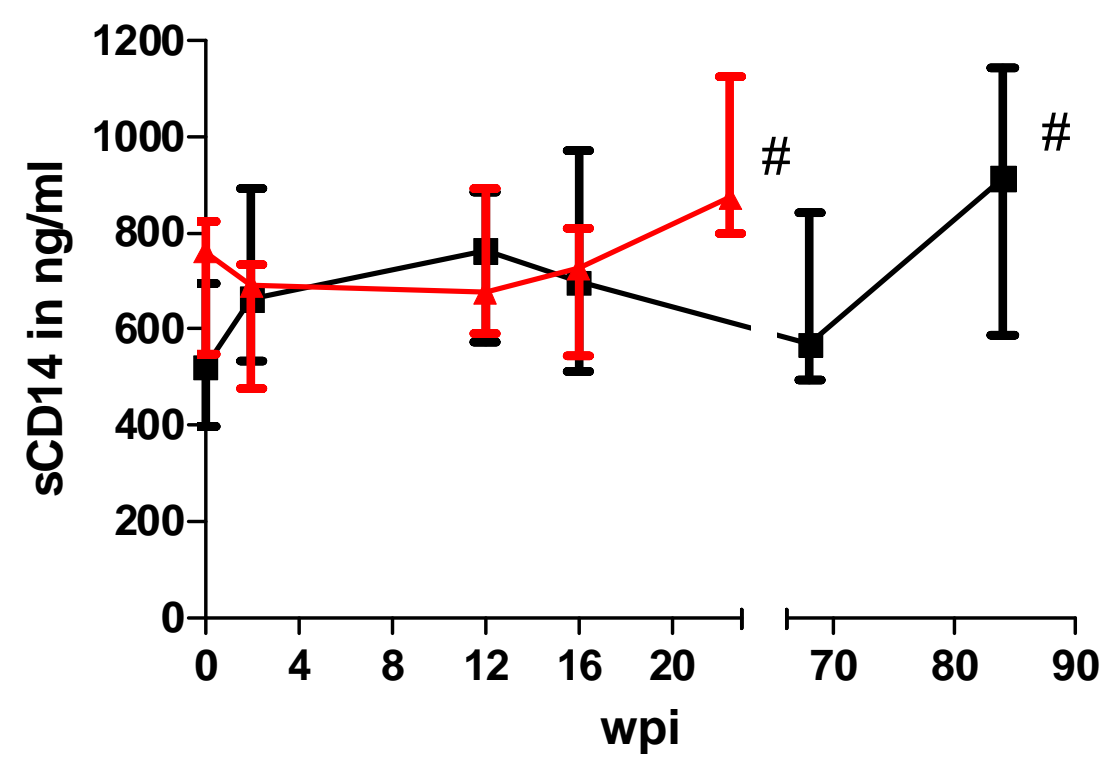

\begin{abstract}
Abbildung 10: sCD14 im Zeitverlauf. Auf der Y-Achse ist die sCD14-Konzentration im Plasma in $\mathrm{ng} / \mathrm{ml}$ aufgetragen, auf der X-Achse ist die Zeit in wpi dargestellt. Dargestellt sind Mediane inkl. der interquartilen Abstände. Die roten Dreiecke sind RP, die schwarzen Quadrate SP, \# markiert den Sektionszeitpunkt.
\end{abstract}

Lösliches CD14 ist ein von Makrophagen bei LPS-Kontakt abgegebenes Oberflächenantigen, das die LBP-Makrophagen-Interaktion erleichtert und so ebenfalls zur Reduktion der LPS im Plasma beiträgt. Nach der Infektion pendelte sich die Menge an sCD14 auf Werte um $700 \mathrm{ng} / \mathrm{ml}$ ein, was den Vorinfektionswerten entspricht (s. Abb. 10). Erst als die Tiere AIDSspezifische Symptome entwickelten und daraufhin seziert wurden, stiegen diese sCD14-Level in beiden Gruppen signifikant an $(\mathrm{p}<0,05)$. Signifikante Unterschiede zwischen den beiden Krankheitsverlaufsgruppen waren nicht vorhanden. Zu keinem Zeitpunkt der Infektion konnte eine signifikante Korrelation mit der Menge an LPS oder der Überlebenszeit der Tiere festgestellt werden. 


\title{
3.7 Neopterin
}

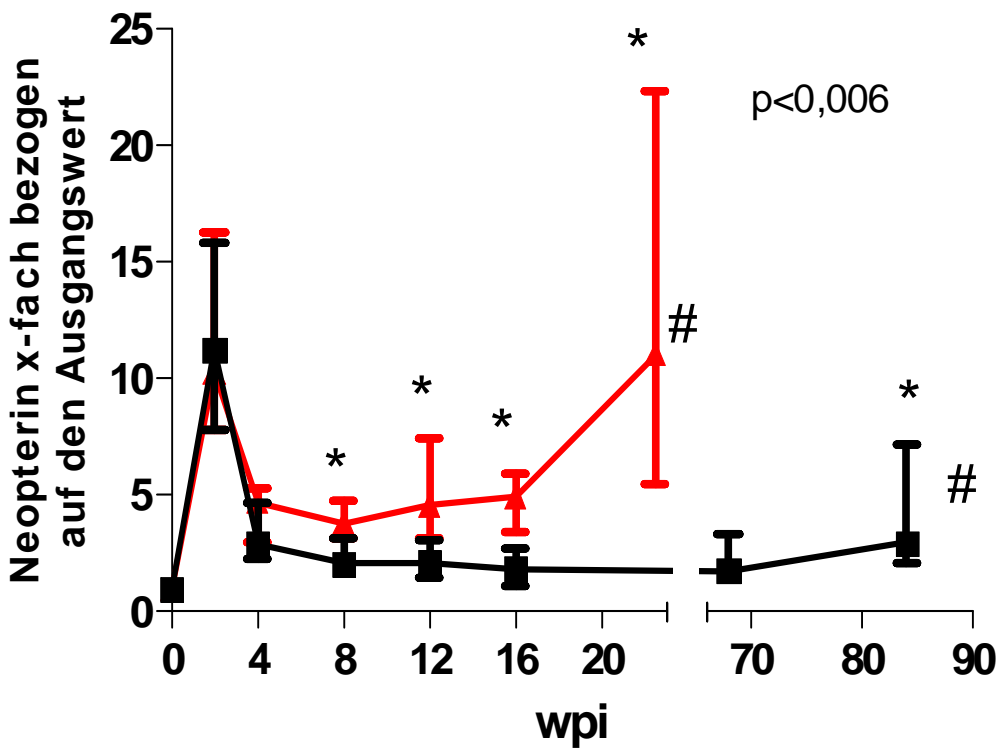

\begin{abstract}
Abbildung 11: Neopterin im Zeitverlauf. Auf der Y-Achse ist das Neopterin im Urin normiert auf den individuellen Ausgangswert aufgetragen, auf der X-Achse ist die Zeit in wpi dargestellt. Dargestellt sind Mediane inkl. der interquartilen Abstände. Die roten Dreiecke sind RP, die schwarzen Quadrate SP, \# markiert den Sektionszeitpunkt, * markiert signifikante Unterschiede zwischen RP und SP, der p-Wert stellt den am wenigsten signifikanten Unterschied dar und wurde mittels Mann-Whitney-Test ermittelt.
\end{abstract}

Neopterin stieg in der akut-virämischen Phase der Infektion 2wpi ähnlich der VL sprungartig an (s. Abb. 11). Im Durchschnitt wurden zehnfache Werterhöhungen gegenüber dem Ausgangsniveau verzeichnet. Ab 4wpi kam es zu einem Rückgang des Neopteringehalts und es etablierte sich, wiederum ähnlich der VL, eine Plateauphase der Neopterinwerte. Während dieser Plateauphase lagen die Neopterinwerte der RP durchgängig ca. doppelt so hoch wie die der SP $(p<0,006)$. Zum Zeitpunkt der AIDS-Entwicklung stieg der Neopteringehalt des Urins wieder sprunghaft an, wobei auch hier ein signifikanter Unterschied zwischen RP und SP bestand $(\mathrm{p}<0,004)$. 


\subsection{Expression von HLA-DR auf $\mathrm{CD4}^{+}-$und $\mathrm{CD8}^{+}-\mathrm{T}-\mathrm{Lymphozyten}$}

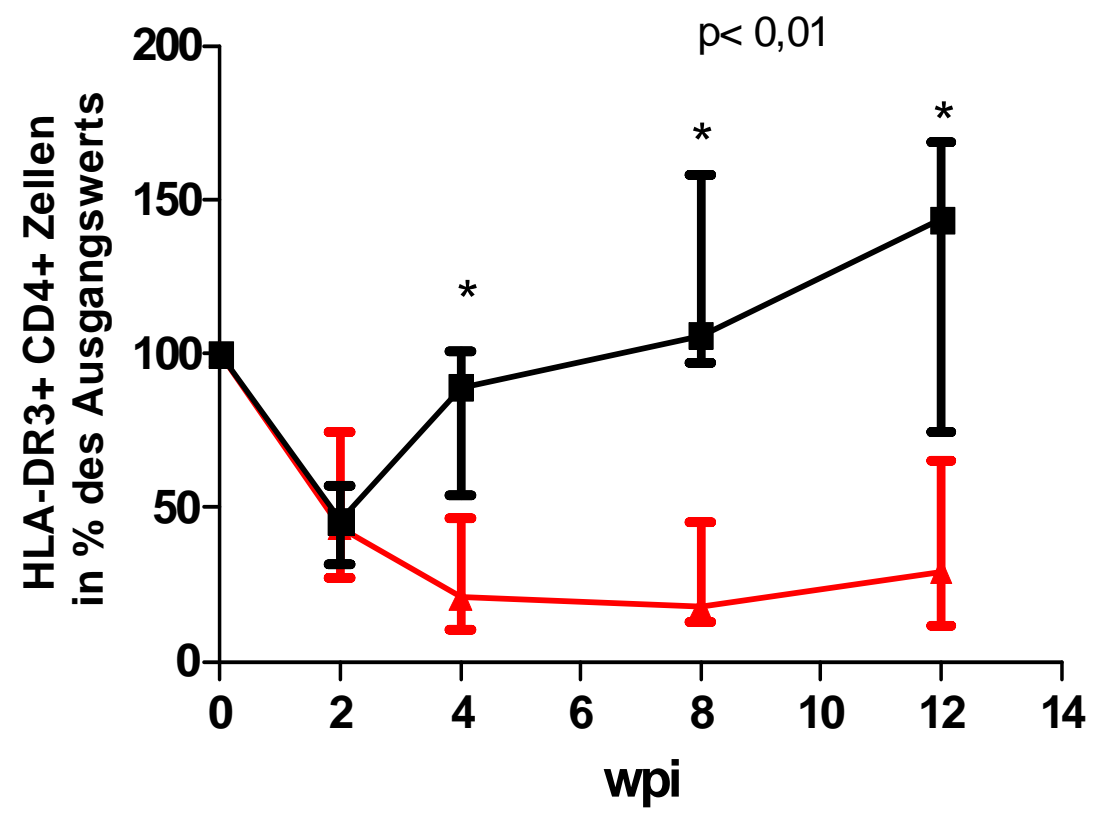

Abbildung 12: HLA-DR exprimierende CD4 ${ }^{+}$-T-Zellen im Zeitverlauf. Auf der Y-Achse ist die Veränderung der $\mathrm{HLA}_{-} \mathrm{DR}^{+} \mathrm{CD}^{+}$Zellen als Prozentsatz des individuellen Basiswertes angegeben, auf der X-Achse ist die Zeit in wpi dargestellt. Dargestellt sind Mediane inkl. der interquartilen Abstände. Die roten Dreiecke sind RP, die schwarzen Quadrate SP, * markiert signifikante Unterschiede zwischen RP und SP, der p-Wert stellt den am wenigsten signifikanten Unterschiede dar und wurde mittels Mann-Whitney-Test ermittelt.

Bei einem Teil der Tiere wurde in unserer Kohorte die HLA-Expression auf den CD4 ${ }^{+}$- bzw. CD8 ${ }^{+}-\mathrm{T}-Z$ ellen als IA-Parameter der unspezifischen IA gemessen. Bei den anderen Tieren der Kohorte war dieser Parameter nicht im Verlauf des Versuches erhoben worden und konnte, weil keine Zellen zur Verfügung standen, auch nicht nachgemessen werden.

Die HLA-DR-Expression der CD4 ${ }^{+}$-T-Zellen sank in der akuten Phase der Infektion in beiden Progressionsgruppen um ca. die Hälfte ab (s. Abb. 12). Anschließend kam es zu einem weiteren und anhaltenden Abfall in der RP Gruppe, wohingegen ein signifikanter Anstieg der HLA-DR-positiven T-Helferzellen bei den SP zwischen 2 und 4wpi messbar wurde $(\mathrm{p}<0,02)$. Die Expression bei den SP überstieg 8wpi sogar den Ursprungswert und 12wpi war ein signifikanter Anstieg gegenüber der Akutphase der Infektion messbar $(p<0,002)$. Die Werte der SP lagen ab 4wpi bis 12wpi zu jedem Zeitpunkt signifikant höher als die der $\operatorname{RP}(\mathrm{p}<0,01)$. 


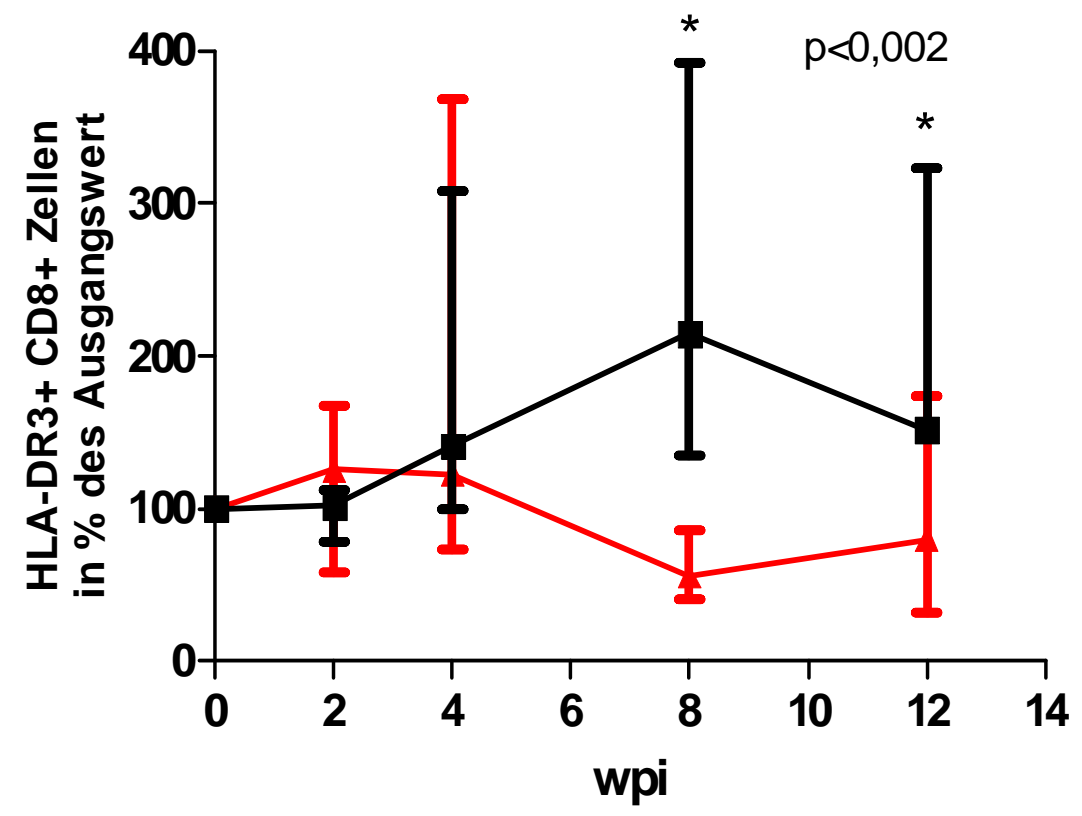

\begin{abstract}
Abbildung 13: HLA-DR exprimierende $C D 8^{+}$-T-Zellen im Zeitverlauf. Auf der Y-Achse ist die Veränderung der HLA-DR ${ }^{+}-\mathrm{CD} 8^{+}$-Zellen als Prozentsatz des individuellen Basiswertes angegeben, auf der X-Achse ist die Zeit in wpi dargestellt. Dargestellt sind Mediane inkl. der interquartilen Abstände. Die roten Dreiecke sind RP, die schwarzen Quadrate SP, * markiert signifikante Unterschiede zwischen RP und SP, der p-Wert stellt den am wenigsten signifikanten Unterschiede dar und wurde mittels Mann-Whitney-Test ermittelt.
\end{abstract}

In der akuten Phase der Infektion blieb die HLA-DR-Expression der CD8 ${ }^{+}$-T-Zellen konstant (s. Abb. 13). Darauffolgend kam es 8 und 12wpi zu einem signifikanten Absinken des Prozentsatzes der Expression auf den RP $(p<0,04)$ und zu einem Ansteigen auf den SP $(\mathrm{p}<0,004)$, jeweils im Vergleich mit Werten aus der Akutphase 2wpi. Zu den gleichen Zeitpunkten bestand ein signifikanter Unterschied zwischen den RP und den SP $(p<0,02)$. 


\subsection{Zusammenhänge zwischen den Versuchsparametern}

Durch die Darstellung der Korrelationen der Versuchsparameter untereinander sollen mögliche Zusammenhänge aufgezeigt werden. Hierbei werden die LPS-Konzentrationen bzw. die Parameter der IA ins Zentrum der Betrachtung gestellt, da ihnen eine besondere Bedeutung für die Pathogenese der HIV-Infektion beigemessen wird. Den aufgeführten Korrelationen liegen, wenn nicht anders angegeben, die Daten der Tiere beider Gruppen zu Grunde.

\subsubsection{Korrelationen der Lipopolysaccharide (LPS)}

Insgesamt korrelierten LPS-Titer nur $\mathrm{zu}$ wenigen Zeitpunkten mit anderen Parametern. Lediglich 16wpi war eine Korrelation mit LBP, als einem der drei endotoxin-assoziierten Moleküle, nachweisbar ( $\mathrm{p}=0,0139$, s. Abb. 14a). Eine Korrelation zwischen LPS und EndoCAb sowie LPS und sCD14 war zu keinem Zeitpunkt zu finden.

12wpi korrelierten LPS mit Neopterin als Ausdruck der unspezifischen IA ( $p=0,0191$, s. Abb. 14b). Eine Korrelation mit der IA war aber zu keinem weiteren Zeitpunkt zu finden, weder mit Neopterin noch mit der HLA-DR-Expression, die die spezifische IA repräsentiert.

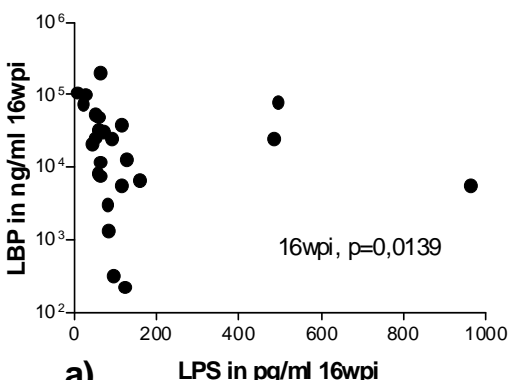

a)

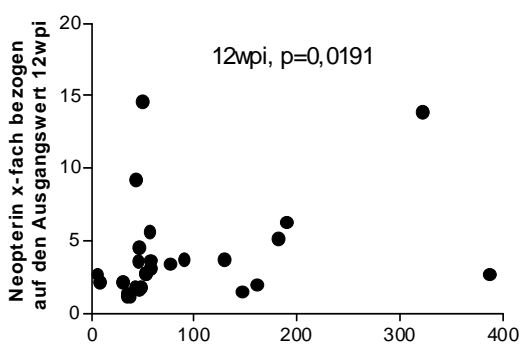

b)

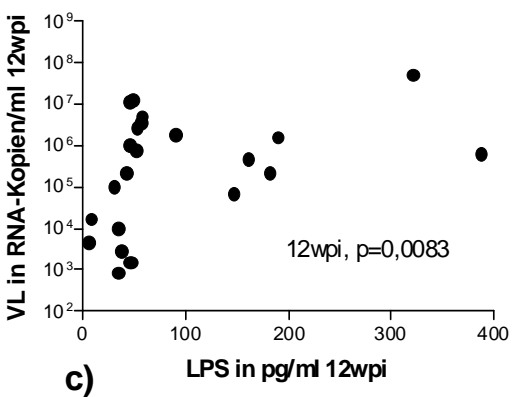

c)

Abbildung 14: Korrelationen zwischen LPS zu verschiedenen Zeitpunkten und VL, Neopterin bzw. LBP. Auf den Y-Achsen sind die VL im Plasma in RNA-Kopien/ml, die Neopterinkonzentration im Urin normiert auf den individuellen Ausgangswert bzw. LBP im Plasma in $\mathrm{ng} / \mathrm{ml}$ aufgetragen, auf den X-Achsen sind die LPS-Konzentrationen im Plasma in $\mathrm{pg} / \mathrm{ml}$ dargestellt. Die angegebenen $\mathrm{p}$-Werte wurden mittels Spearman-RankTest ermittelt. 
Zwar war eine Resorptionsstörung durch verminderte Aufnahme von $\beta$-Karotin nachweisbar, eine signifikante Korrelation zwischen $\beta$-Karotin und LPS konnte jedoch nicht festgestellt werden.

Die Viruslast und die Überlebenszeit zeigten untereinander eine anhaltend positive Korrelation zu den Zeitpunkten 4, 8, 12, 16wpi und AIDS in beiden Progressionsgruppen ( $\mathrm{p} \leq 0,002 ; \mathrm{s}$. Abb. 15). Auch mit diesen Markern des Krankheitsverlaufes korrelierten die LPS wiederum nur kaum. Lediglich zum Zeitpunkt 12wpi war eine Korrelation mit der VL zu finden ( $\mathrm{p}=0,0083$, s. Abb. 14c). Dagegen war nie ein Zusammenhang mit der Überlebenszeit nachweisbar.
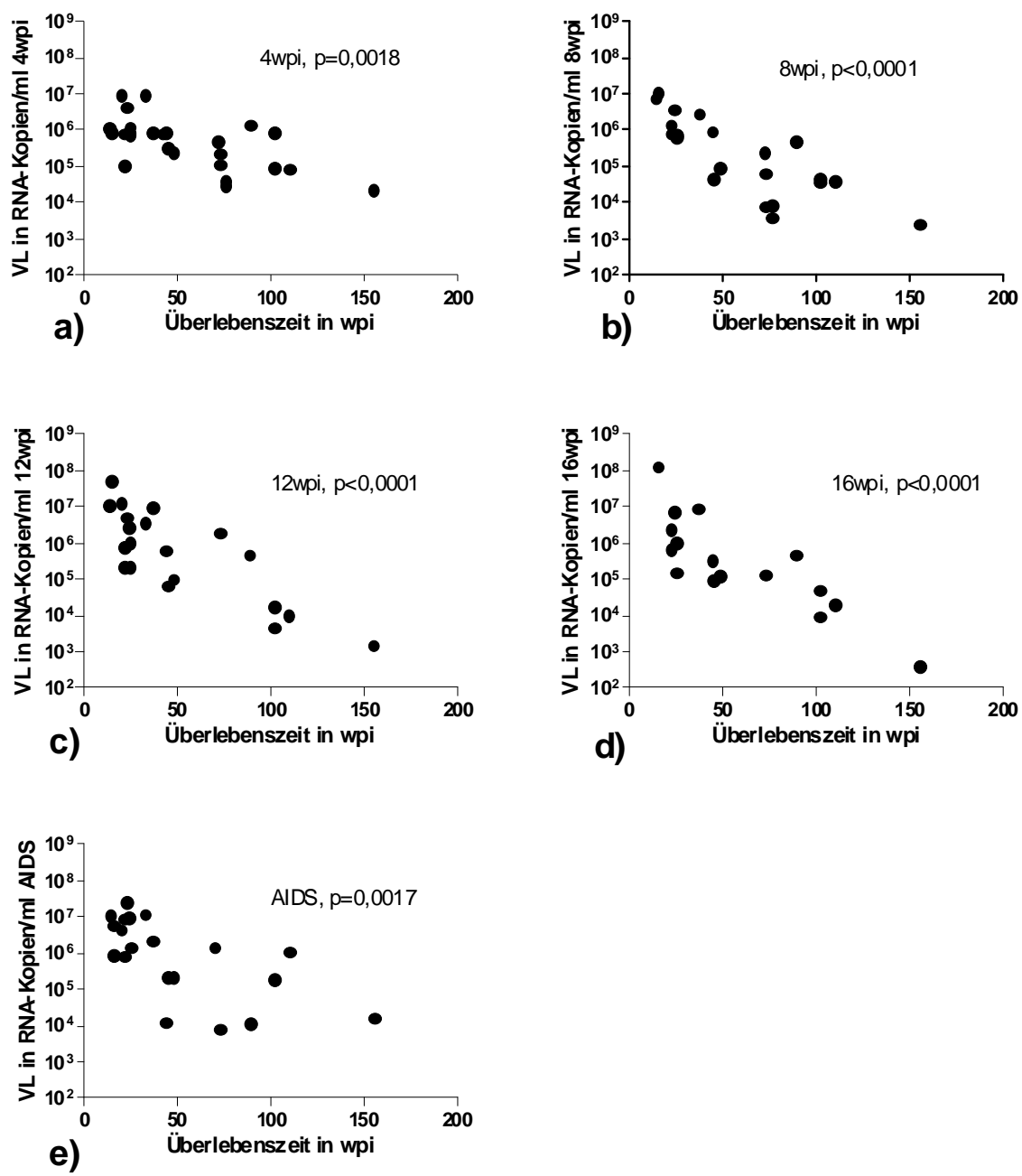

Abbildung 15: Korrelationen zwischen der Viruslast zu verschiedenen Zeitpunkten und der Überlebenszeit. Auf den Y-Achsen sind die VL in RNA-Kopien/ml aufgetragen, auf den X-Achsen sind die Überlebenszeiten in wpi dargestellt. Die angegebenen p-Werte wurden mittels Spearman-Rank-Test ermittelt. 


\subsubsection{Beziehung zwischen IA und Krankheitsverlauf}

Die Aktivierung des unspezifischen Immunsystems, gemessen als Neopterinauscheidung im Urin, korrelierte zu den Zeitpunkten 4, 8, 12 und 16wpi sowie zu AIDS signifikant mit der Viruslast ( $<<0,05$; s. Abb. 16).

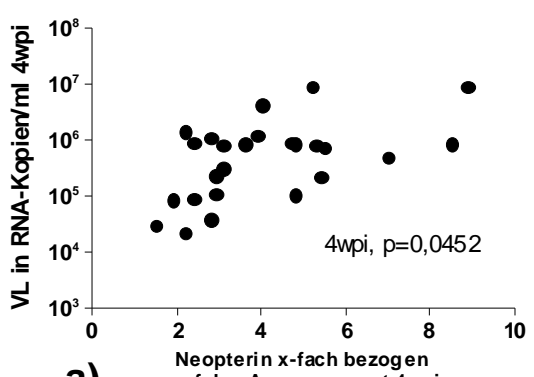

a) auf den Ausgangswert $4 w p i$

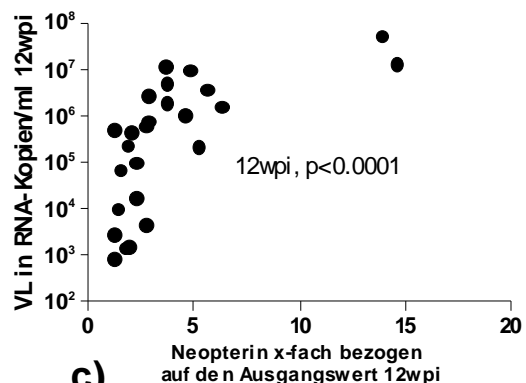

C) auf den Ausgangswert 12wp

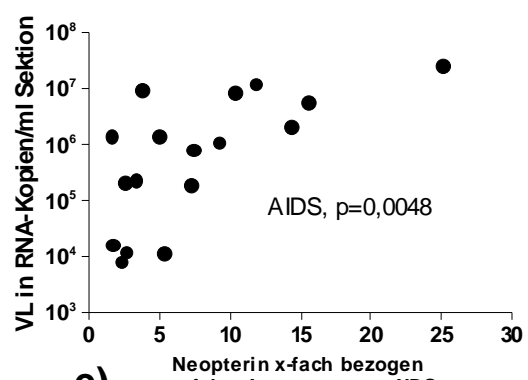

Neopterin $x$-fach bezogen
e)

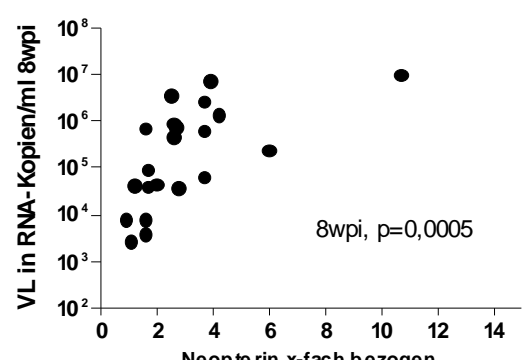

b) Neopte rin $x$-fach bezogen

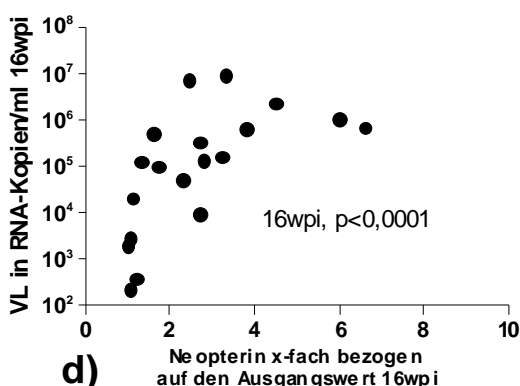

d) auf den Ausgangswe rt 16wpi

Abbildung 16: Korrelationen zwischen Neopterin zu verschiedenen Zeitpunkten und der Viruslast. Auf den Y-Achsen sind die VL im Plasma in RNA-Kopien/ml aufgetragen, auf den X-Achsen sind die Neopterinkonzentrationen im Urin normiert auf den individuellen Ausgangswert dargestellt. Die angegebenen p-Werte wurden mittels Spearman-Rank-Test ermittelt. 
Neopterin zeigte außerdem auch zu den Zeitpunkten 4, 8, 12, 16wpi und AIDS einen signifikanten Zusammenhang mit der Überlebenszeit der Tiere $(p<0,02 ; s$.

Abb. 17).

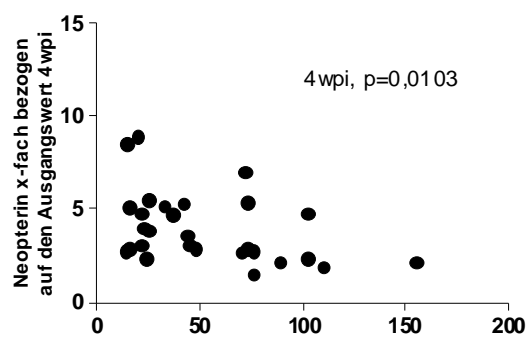

a)

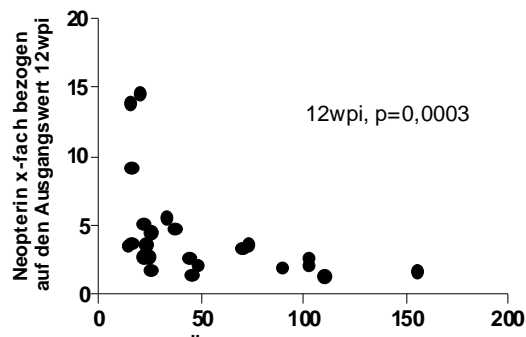

c)

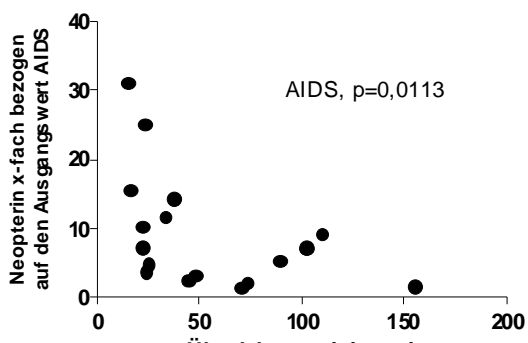

e)

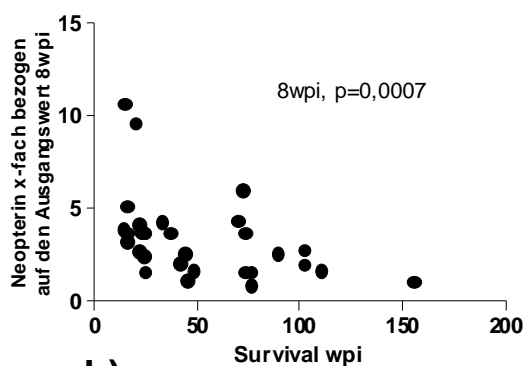

b)

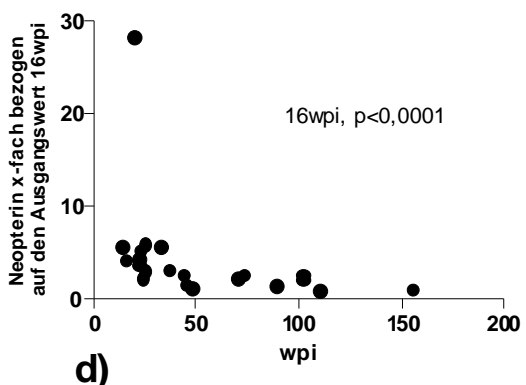

d)

Abbildung 17: Korrelationen zwischen Neopterin zu verschiedenen Zeitpunkten und der Überlebenszeit. Auf den Y-Achsen sind die Neopterinkonzentrationen im Urin normiert auf den individuellen Ausgangswert aufgetragen, auf den X-Achsen sind die Überlebenszeiten der Tiere dargestellt.. Die angegebenen $p$-Werte wurden mittels Spearman-Rank-Test ermittelt. 
In der Gruppe der SP konnte zudem eine signifikante Korrelation mit dem ebenfalls von Makrophagen abgegebenen sCD14 12 und 16wpi, sowie zum chronischen Zeitpunkt nachgewiesen werden $(\mathrm{p}<0,04$, s. Abb. 18).
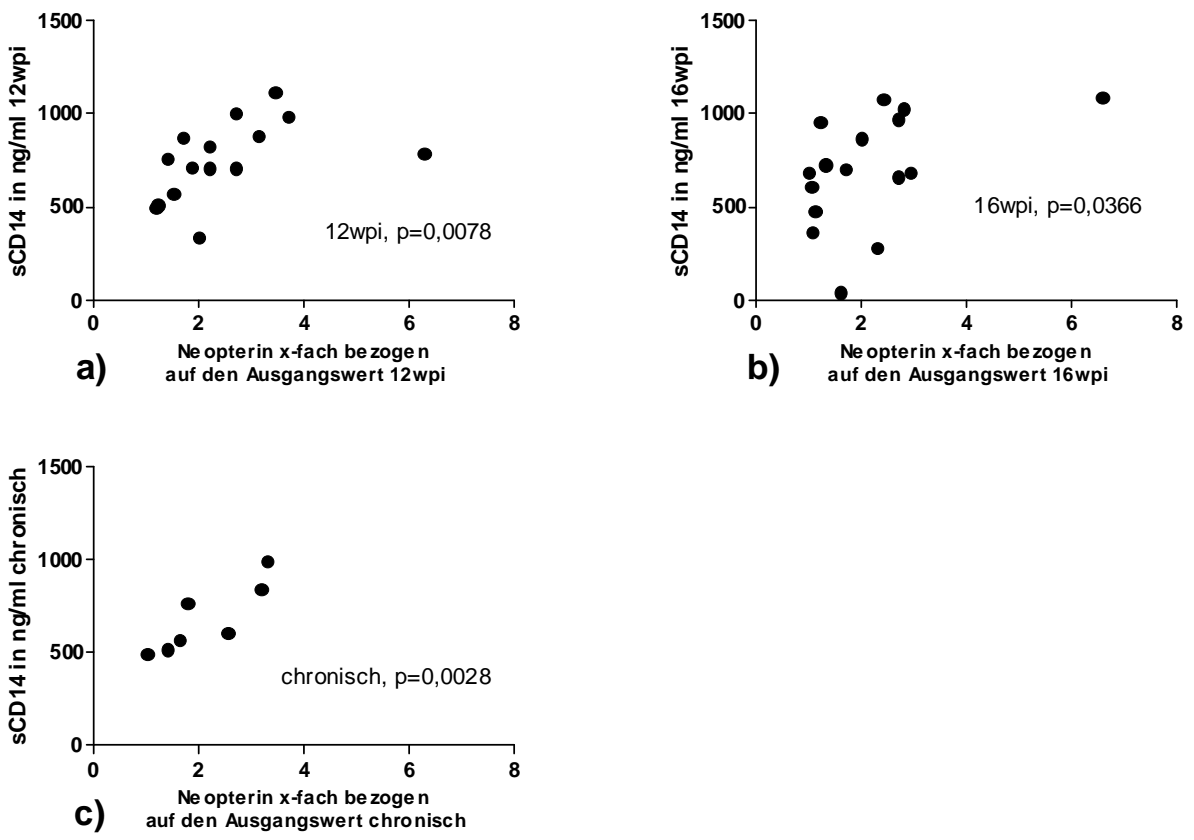

\begin{abstract}
Abbildung 18: Korrelationen zwischen sCD14 zu verschiedenen Zeitpunkten und der Neopterinausscheidung bei den SP. Auf den Y-Achsen sind sCD14 Spiegel im Plasma in $\mathrm{ng} / \mathrm{ml}$ aufgetragen, auf den X-Achsen sind die Neopterinkonzentrationen im Urin normiert auf den individuellen Ausgangswert dargestellt. Die angegebenen p-Werte wurden mittels Spearman-Rank-Test ermittelt.
\end{abstract}

Eine inverse Korrelation war zwischen Neopterin und der HLA-DR-Expression auf CD8 ${ }^{+}$-, wie auch $\mathrm{CD}^{+}$-T-Zellen zu den Zeitpunkten 8 und 12 wpi nachweisbar $(\mathrm{p}<0,005, \mathrm{~s}$. Abb. 19 und 20). Zusätzlich korrelierte Neopterin auch 2wpi invers mit der HLA-DR-Expression auf den $\mathrm{CD}^{+}(p=0,0083$, s. Abb. 19a). 


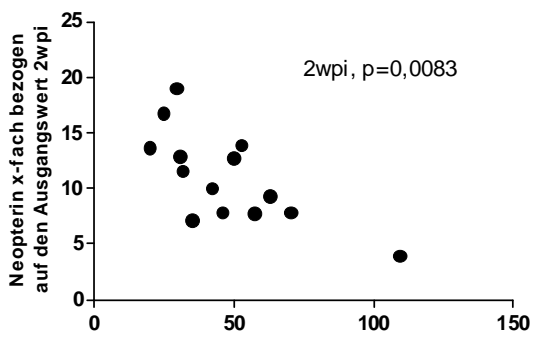

HLA-DR+ CD4+ Zellen
a) in \%des Ausgangswerts 2wpi

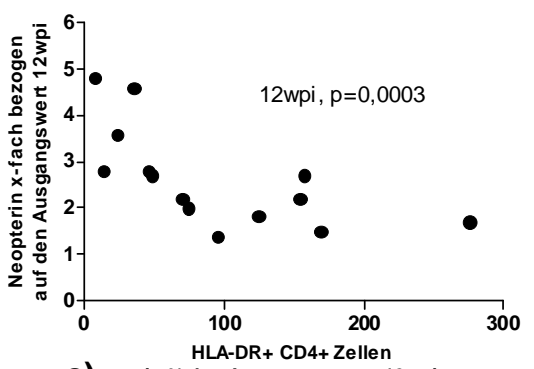

C) in \% des Ausgangswerts 12wpi

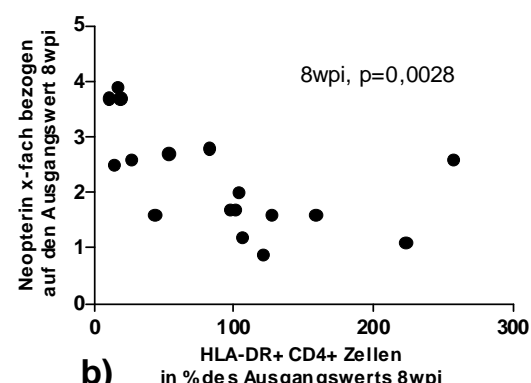

HLA-DR+ CD4+ Zellen
b) in \%des Ausgangswerts 8 wpi

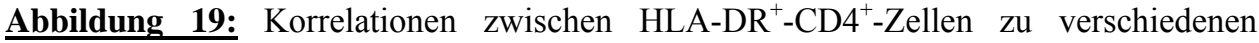
Zeitpunkten und der Neopterinausscheidung. Auf den Y-Achsen sind die Neopterinkonzentrationen im Urin normiert auf den individuellen Ausgangswert aufgetragen, auf den X-Achsen sind die Veränderungen der HLA-DR ${ }^{+}-\mathrm{CD}^{+}$-Zellen als Prozentsatz des individuellen Basiswertes dargestellt. Die angegebenen p-Werte wurden mittels Spearman-Rank-Test ermittelt.

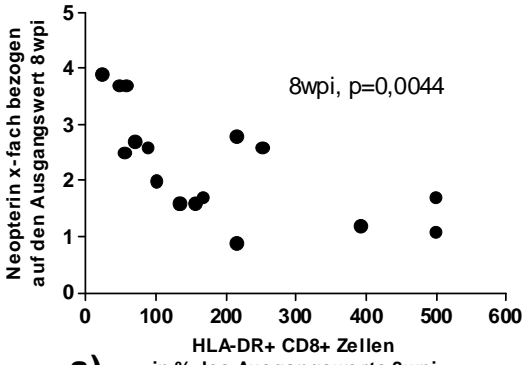

a)

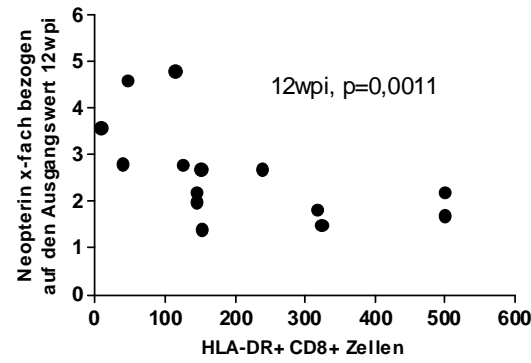

b)

Abbildung 20: Korrelationen zwischen HLA-DR ${ }^{+}-\mathrm{CD} 8^{+}-Z$ ellen $\mathrm{zu}$ verschiedenen Zeitpunkten und der Neopterinausscheidung. Auf den Y-Achsen sind die Neopterinkonzentrationen im Urin normiert auf den individuellen Ausgangswert aufgetragen, auf den X-Achsen sind die Veränderungen der HLA-DR ${ }^{+}$-CD8 ${ }^{+}$-Zellen als Prozentsatz des individuellen Basiswertes dargestellt. Die angegebenen p-Werte wurden mittels Spearman-Rank-Test ermittelt.

Im Gegensatz zu Neopterin korrelierte die HLA-DR-Expression beider T-Zellpopulationen invers mit der Viruslast zu den Zeitpunkten 8 und 12wpi (p<0,002, Abb. 21 und 22). Bei den $\mathrm{CD}^{+}$war zusätzlich auch schon 4 wpi, bei den $\mathrm{CD}^{+}$auch 2 wpi ein negativer signifikanter Zusammenhang messbar ( $<<0,03$, Abb. 21a und 22a). 


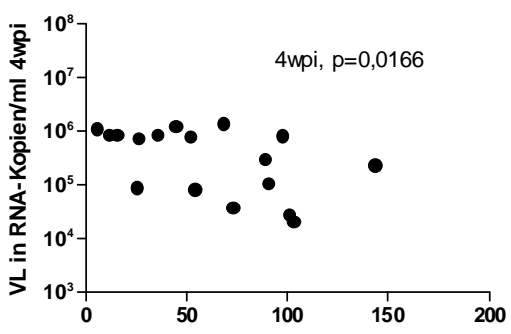

HLA-DR+ CD4+ Zellen
a) in \%des Ausgangswerts 4wp

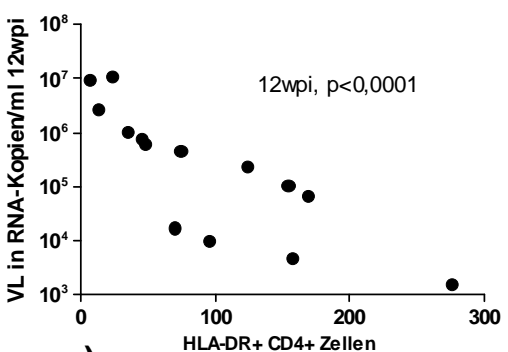

HLA-DR+ CD4+ Zellen
C) in \%des Ausgangswerts $12 w p$

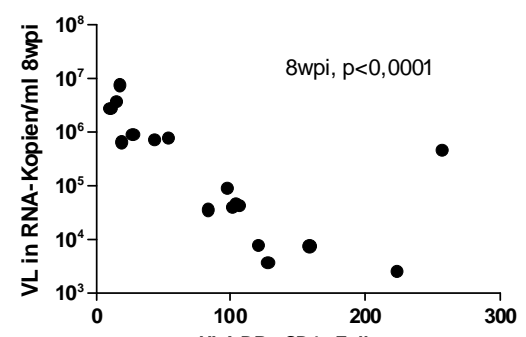

HLA-DR+ CD4+ Zellen
b) in \%des Ausgangswerts 8wpi

Abbildung 21: Korrelationen zwischen HLA-DR ${ }^{+}-\mathrm{CD} 4^{+}-$Zellen $\mathrm{zu}$ verschiedenen Zeitpunkten und der Viruslast. Auf den Y-Achsen sind die VL im Plasma in RNAKopien/ml aufgetragen, auf den X-Achsen sind die Veränderungen der HLA-DR ${ }^{+}-\mathrm{CD}^{+}$Zellen als Prozentsatz des individuellen Basiswertes dargestellt. Die angegebenen pWerte wurden mittels Spearman-Rank-Test ermittelt.

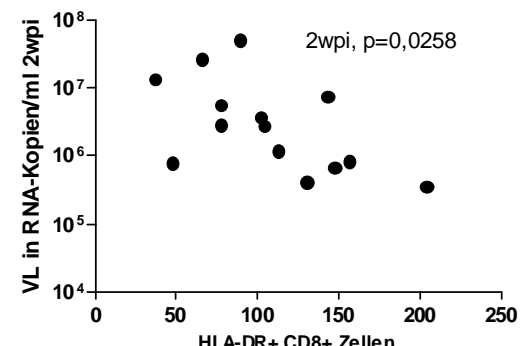

HLA-DR+ CD8+ Zellen
a) in \%des Ausgangswerts 2wpi

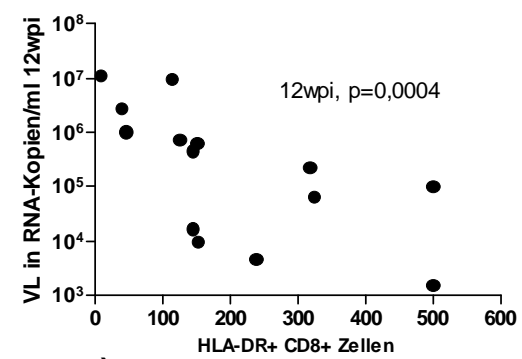

HLA-DR+ CD8+ Zellen
C) in \%des Ausgangswerts $12 \mathrm{wpi}$

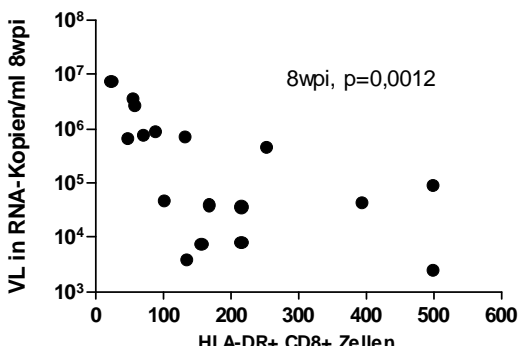

HLA-DR+ CD8+ Zellen
b) in \%des Ausgangswerts 8wpi

Abbildung 22: Korrelationen zwischen HLA-DR ${ }^{+}-\mathrm{CD}^{+}-$Zellen $\mathrm{zu}$ verschiedenen Zeitpunkten und der Viruslast. Auf den Y-Achsen sind die VL im Plasma in RNAKopien/ml aufgetragen, auf den X-Achsen sind die Veränderungen der HLA-DR ${ }^{+}-\mathrm{CD}^{+}$Zellen als Prozentsatz des individuellen Basiswertes dargestellt. Die angegebenen pWerte wurden mittels Spearman-Rank-Test ermittelt. 
Eine positive Korrelation mit der Überlebenszeit war bei den $\mathrm{CD}^{+} 4,8$ und 12 wpi und bei den $\mathrm{CD}^{+} 8$ und 12wpi nachweisbar (p<0,02, s. Abb. 23 und 24).

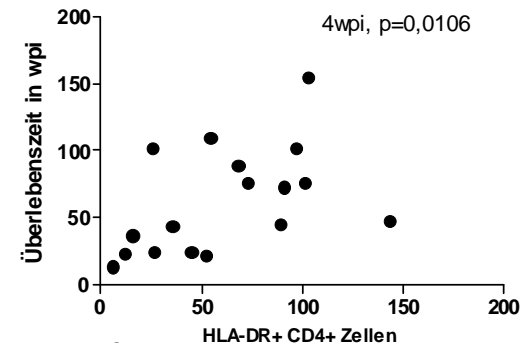

a) in \%des Ausgangswerts 4wpi

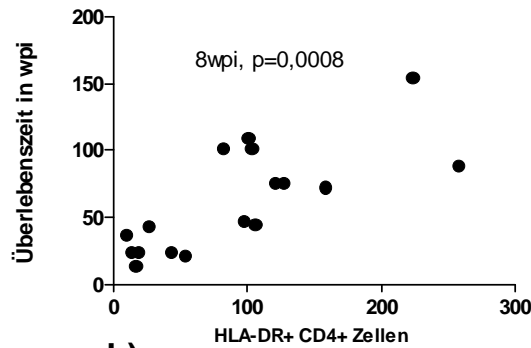

b) in \%des Ausgangswerts 8wpi

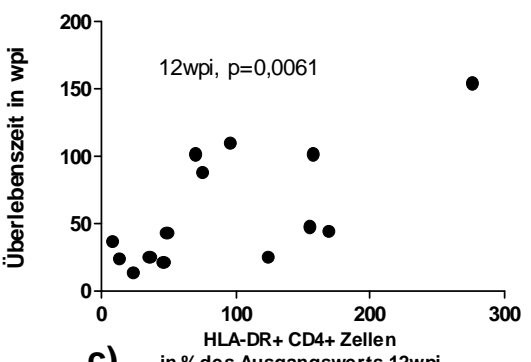

C) in \%des Ausgangswerts 12wpi

Abbildung 23: Korrelationen zwischen HLA-DR ${ }^{+}-\mathrm{CD}^{+}-\mathrm{Zellen} \mathrm{zu}$ verschiedenen Zeitpunkten und der Überlebenszeit. Auf den Y-Achsen sind die Überlebenszeiten in wpi aufgetragen, auf den X-Achsen sind die Veränderungen der HLA-DR ${ }^{+}$-CD8 ${ }^{+}$-Zellen als Prozentsatz des individuellen Basiswertes dargestellt. Die angegebenen p-Werte wurden mittels Spearman-Rank-Test ermittelt.

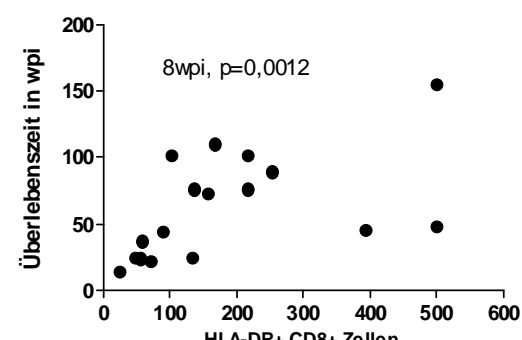

HLA-DR+ CD8+ Zellen
a) in \%des Ausgangswerts 8wpi

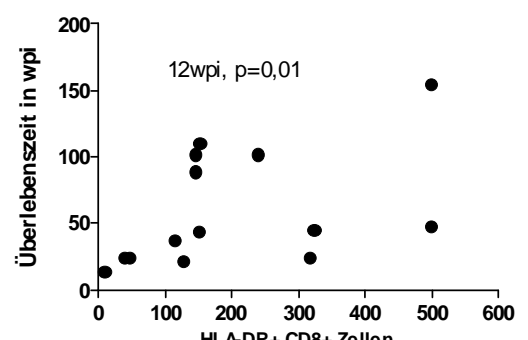

HLADR+ CD8+ Zellen
b) in \%des Ausgangswerts 12wpi

Abbildung 24: Korrelationen zwischen HLA-DR ${ }^{+}-\mathrm{CD} 8^{+}-\mathrm{Zellen}$ zu verschiedenen Zeitpunkten und der Überlebenszeit. Auf den Y-Achsen sind die Überlebenszeiten in wpi aufgetragen, auf den X-Achsen sind die Veränderungen der HLA-DR ${ }^{+}-\mathrm{CD}^{+}$-Zellen als Prozentsatz des individuellen Basiswertes dargestellt. Die angegebenen p-Werte wurden mittels Spearman-Rank-Test ermittelt. 


\section{Diskussion}

Die chronische Immunaktivierung spielt eine entscheidende Rolle in der Pathogenese der HIVirusinfektion (Hazenberg et al. 2003). Die genaue Ursache dieser IA ist jedoch nach wie vor unklar. Zuletzt wurde eine Schädigung des MDT als Ursache diskutiert (Brenchley et al. 2006a; Brenchley et al. 2006b; Lackner et al. 2009). Hierbei wurde die Hypothese aufgestellt, dass eine Translokation von Bakterien und Bakterienbestandteilen über eine geschädigte Darmmukosabarriere die chronische IA auslösen.

Das Ziel dieser Arbeit war es, die mögliche Bedeutung mikrobieller Translokation, gemessen in der Menge von LPS im Plasma, für die HIV-Pathogenese im SIV-Rhesusaffenmodell zu bestimmen. Hierzu wurden neben LPS auch verschiedene andere LPS-assoziierte Moleküle im Plasma der Tiere bestimmt und mit Parametern der spezifischen und unspezifischen Immunaktivierung sowie der Viruslast verglichen. Eine besondere Stärke des Rhesusaffenmodells war hierbei die Möglichkeit der engmaschigen Erhebung von Messwerten, sowohl vor als auch kurzfristig nach der Infektion in einem kontrollierten, longitudinalen Versuchsaufbau. Dies ermöglichte zusätzlich die Erhebung der individuellen Krankheitsverläufe und Überlebenszeiten der Tiere, die ebenfalls als Parameter herangezogen wurden.

Aus diesem Versuchsaufbau ergaben sich verschiedene Erwartungen an die Ergebnisse der Studie: Falls die bakterielle Translokation einen Einfluss auf die Immunaktivierung und damit auf den Krankheitsverlauf der einzelnen Tiere habe, müsste sich dies in signifikanten Korrelationen mit den bestimmten IA-Parametern ausdrücken. Tiere mit einem schnelleren Krankheitsverlauf müssten signifikant höhere LPS-Spiegel aufweisen als Tiere mit einer längeren Überlebensdauer. Im folgenden sollen die Ergebnisse dieser Studie nun insbesondere vor diesem Hintergrund erläutert und diskutiert werden.

\subsection{SIV-Enteropathie und LPS-Translokation}

Um das Maß einer SIV-Enteropathie, die als Ursache der bakteriellen Translokation angenommen wird, in unserer Kohorte festzustellen, wurde zunächst die mukosale Resorptionsfähigkeit anhand von $\beta$-Karotin bestimmt. Diese zeigte in einem repräsentativen Teil unserer Versuchstiere einen signifikanten Abfall zum Zeitpunkt 12wpi im Vergleich zum Zeitpunkt vor der Infektion $(\mathrm{p}<0,02)$. In einer Messung der LPS zu einem vergleichbaren Zeitpunkt konnte ebenfalls eine signifikante Veränderung, nämlich ein Anstieg des Endotoxins im Plasma, gemessen werden. Allerdings gab es keine Korrelation zwischen 
dieser Resorptionsstörung und den erhöhten Endotoxinspiegeln, die möglicherweise durch eine erhöhte Durchlässigkeit der Darmbarriere bedingt sein könnten. Daher bleibt ein Zusammenhang zwischen Enteropathie, die mit Malabsorption einhergeht, und dem Ursprung der LPS im Plasma unsicher. Hierzu muss angemerkt werden, dass die Malabsorption von $\beta$ Karotin ein pathologisches Korrelat in Form von Atrophien im oberen Dünndarm besitzt, der genaue Ort einer mikrobiellen Translokation aber ungewiss ist (Kewenig et al. 1999). Eine mikrobielle Translokation erscheint in weiter aboral gelegenen Darmabschnitten wie Ileum und Colon jedoch wahrscheinlicher, da hier eine höhere Besiedlung mit Darmbakterien vorhanden ist (Macpherson und Harris 2004). Des weiteren bedeutet eine eingeschränkte Resorptionsfähigkeit nicht zwangsläufig auch eine gestörte Barrierefunktion mit erhöhter Duchlässigkeit der Darmmukosa. Falls der Anstieg der LPS-Titer auf einer mukosalen Schädigung beruht, so kann davon ausgegangen werden, dass die Schädigung des Darmes in allen Abschnitten stattfindet, es scheinbar aber lokale Unterschiede gibt, die eine Korrelation der Ereignisse untereinander verhindern.

LPS wurde mittlerweile in mehreren Studien als Maßeinheit der mikrobiellen Translokation verwendet (Ancuta et al. 2008; Brenchley et al. 2006b; Gregson et al. 2009; Pandrea et al. 2008; Papasavvas et al. 2009). Es gibt jedoch auch einige wenige Studien, die alternativ andere Marker verwendet haben, um diesen Prozess zu beschreiben. Schon früher wurde von Stein et al. Buttersäure, als ein Stoffwechselendprodukt mikrobieller Organismen, im Urin von HIV-Patienten bestimmt und mit der IL-6 Ausscheidung im Urin als Marker der IA korreliert (Stein et al. 1997). Weiterhin wurde erst kürzlich 16S rDNA, die spezifisch nur in mikrobiellen Organismen vorkommt, als Marker herangezogen und mit der IA korreliert (Jiang et al. 2009). Hierbei konnte durch eine positive Korrelation zwischen 16S rDNA und LPS ein weiterer Hinweis gewonnen werden, dass die LPS die Anwesenheit mikrobieller Organismen in der Körperzirkulation zuverlässig widerspiegeln. Es gibt verschiedene zusätzliche Argumente, die LPS als besonders geeigneten Marker der bakteriellen Translokation ausweisen. LPS ist ein in allen gramnegativen Bakterien, zu denen die überwiegende Mehrheit der kommensalen Darmkeime zählen, enthaltener Virulenzfaktor (Macpherson und Harris 2004). Sie sind leicht zu bestimmen und stellen als Endotoxin zugleich einen direkten Aktivator des Immunsystems dar. In verschiedenen Studien zu anderen Krankheitsbildern, wie z.B. CED, Septischer Schock oder Abstoßungsreaktionen nach Organtransplantationen, wird ebenfalls seit längerem der Einfluss einer erhöhten Durchlässigkeit der Darmmukosa auf die Pathogenese diskutiert (Cooke et al. 2002; Danner 
et al. 1991; Gardiner et al. 1995). Hierbei sind LPS und zusätzlich auch die Moleküle der Körperantwort auf eine LPS-Exposition gut untersuchte und etablierte Marker.

\subsection{LPS-Titer im Infektionsverlauf}

Die Betrachtung der LPS-Spiegel im Affenplasma erfolgte in engmaschigen Kontrollen im Infektionsverlauf. In der akuten Phase konnte kein signifikanter Anstieg gegenüber den Vorinfektionswerten gezeigt werden. Dies wird auch von vorangegangenen Studien belegt (Brenchley et al. 2006b). In der postakuten Phase, insbesondere 4 und 8wpi, kam es zu einer signifikanten Erhöhung der LPS-Titer. Im weiteren Verlauf war jedoch selbst bei Tieren mit AIDS, abgesehen von einzelnen erhöhten Werten, kein Anstieg von LPS zu verzeichnen. In der chronischen Phase der Infektion, in der die mikrobielle Translokation als treibende Kraft für die Immunaktivierung angenommen wird (Brenchley et al. 2006b), fanden wir kaum erhöhte LPS-Spiegel, die wiederum keine Korrelationen mit den gemessenen Parametern der IA, der VL oder der Überlebenszeit aufwiesen. Diese Ergebnisse weichen also deutlich von den Erwartungen ab, die sich aus der beschriebenen Hypothese herleiten würden. Eine andere longitudinale Studie an afrikanischen HIV-Infizierten in Uganda, die ebenfalls keinen Zusammenhang zwischen LPS-Translokation und Krankheitsverlauf oder IA finden konnte, bestätigt hier unsere Ergebnisse (Redd et al. 2009).

Eine naheliegende Überlegung, um diese Inkongruenz zwischen der untersuchten Hypothese und den Ergebnissen der LPS-Messungen zu erklären, ist, dass der Körper durch verschiedene Mechanismen die im Plasma messbare LPS-Konzentration erniedrigen und damit verfälschen könnte. Deshalb haben wir zusätzlich verschiedene Moleküle im Plasma bestimmt, die in der systemischen Antwort auf den LPS-Kontakt involviert sind.

Wir maßen EndoCAb, sCD14 und LBP als drei von anderen Autoren im Zusammenhang mit LPS in der HIV-Infektion beschriebene Moleküle im Zeitverlauf der Infektion.

Die EndoCAb-Titer zeigten einen signifikanten Abfall in der akuten Infektion, danach kam es in den RP bis zum Stadium AIDS zu einem kontinuierlichen, aber nicht signifikanten Anstieg der EndoCAb Level, in den SP veränderte sich kaum etwas. Eine signifikante Korrelation mit den LPS-Werten war nicht nachweisbar. Zudem waren auch hier nie signifikante Unterschiede zwischen RP und SP messbar. Zuvor war ein kontinuierlicher Abfall der Antikörper beschrieben worden und sogar als mögliche Ursache für eine Insuffizienz der Anti-LPS-Antwort in der HIV-Infektion diskutiert worden (Ancuta et al. 2008; Brenchley et al. 2006b; Papasavvas et al. 2009). Diese insuffiziente Antwort führe erst dazu, dass es durch bakterielle Translokation zur chronischen IA käme. Eine Arbeitsgruppe, die EndoCAb-Titer 
in einer Population von afrikanischen HIV-Infizierten untersuchte, konnte jedoch ebenfalls keinen Abfall der Antikörper feststellen (Redd et al. 2009). In dieser Studie wurde weiterhin über den gesamten Infektionsverlauf eine unveränderte Höhe der Spiegel an EndoCAb gemessen. Ebenso konnte diese Studie weder eine Korrelation mit LPS, noch einen Unterschied zwischen unterschiedlichen Progressionstypen nachweisen, die auch im Rahmen dieser Studie betrachtet wurden.

Lösliches CD14 stieg im Infektionsverlauf an, zum Zeitpunkt AIDS war dieser Anstieg auch signifikant im Vergleich zu den Vorinfektionswerten. Ein Unterschied zwischen RP und SP konnte jedoch nicht festgestellt werden. Betrachtet man lediglich die SP, fällt eine gute Korrelation mit Neopterin zu mehreren Zeitpunkten auf, was sCD14 als Aktivierungsmarker für Makrophagen bestätigt. Dieser Zusammenhang ist bei Betrachtung der RP, die im Vergleich zu den SP die stärkere makrophagenspezifische IA aufweisen, nicht nachweisbar. Dies spricht dafür, dass bei den RP die Aktivierung der Makrophagen im wesentlichen nicht durch LPS ausgelöst wird und somit eine andere Ursache, wie z.B. die kontinuierliche virale Replikation, haben muss. Eine Korrelation von sCD14 mit LPS konnte zu keinem Punkt der Infektion nachgewiesen werden. Bestätigt wurde ein Anstieg von sCD14 im Rahmen der Infektion von der Arbeitsgruppe um Papasavvas et al., diese konnten jedoch zusätzlich auch eine Korrelation zwischen sCD14 und LPS nachweisen (Papasavvas et al. 2009). Gar keine sCD14 Erhöhung wurde in einer Population von afrikanischen HIV-Infizierten gemessen, in der jedoch eine Korrelation mit LBP, als anderem in die Aktivierungskaskade involvierten Molekül, nachgewiesen werden konnte (Redd et al. 2009). Wiederum andere Autoren konnten einen Zusammenhang zwischen LPS und sCD14 jedoch belegen (Ancuta et al. 2008; Brenchley et al. 2006b). Ancuta et al. maßen neben sCD14 auch CCL-2 und IL-6, die ebenfalls als lösliche Aktivierungsmarker von Makrophagen gelten. Sie konnten jedoch nur für sCD14 eine Korrelation mit LPS nachweisen (Ancuta et al. 2008).

LBP zeigte in der akuten Phase der Infektion und zum Zeitpunkt der Entstehung von AIDSSymptomen einen deutlichen Anstieg im Plasma. Diese Anstiege korrelierten aber weder mit der VL noch der Neopterinausscheidung, die beide ebenfalls Anstiege zu diesen Zeitpunkten zeigten. Als Ursache des zweiten LBP Anstieges in der AIDS Phase der Infektion nehmen wir die zu diesem Zeitpunkt charakteristischen opportunistischen Infektionen bzw. die Stoffwechselentgleisung beim Zusammenbruch des Immunsystems an, die über eine allgemeine Akut-Phase-Reaktion zum LBP-Anstieg führen. Eine Korrelation mit LPS konnten wir nur zum Zeitpunkt 16wpi feststellen, ansonsten zeigte LPS, insbesondere zu den sprunghaften Anstiegen der LBP Konzentration, kaum Veränderungen und auch zu keinem 
weiteren Zeitpunkt eine Korrelation mit LBP. Diese Diskrepanz zwischen LBP und LPS zu Beginn und gegen Ende der Infektion könnte damit zusammenhängen, dass die Produktion des Klasse-1-Akut-Phase-Proteins LBP in der Leber hauptsächlich durch proinflammatorische Zytokine und nur zu einem Teil durch LPS selbst stimuliert wird (Fang et al. 2004; Li et al. 2003; Schumann et al. 1996). Diese proinflammatorischen Zytokine sind am stärksten in der Akutphase und erreichen ihr Maximum sogar noch vor dem der VL und könnten den LBP Anstieg in der Akutphase somit gut erklären (Abel et al. 2005; Stacey et al. 2009).

In anderen Studien zur mikrobiellen Translokation bei HIV wird die Bedeutung von LBP, ähnlich wie schon bei EndoCAb und $\mathrm{sCD} 14$, unterschiedlich stark eingeschätzt. Einige Arbeiten berichten über eine signifikante Erhöhung im Infektionsverlauf und eine Korrelation mit LPS sowie sCD14 (Ancuta et al. 2008; Brenchley et al. 2006b). Andere Autoren berichten jedoch auch von gar keinen Plasmaspiegelveränderungen der LBP-Titer oder vom Abfall des Moleküls (Papasavvas et al. 2009; Redd et al. 2009). Der direkte Zusammenhang zwischen LBP-Produktion und LPS-Plasmaspiegeln wird auch von vielen Autoren aus dem Bereich der Sepsisstudien kontrovers diskutiert. Hier wird zum einen ein Zusammenhang zwischen einer gramnegativen Sepsis und LBP beschrieben, zum anderen aber LBP auch die Fähigkeit abgesprochen, zwischen Sepsis und dem Systemic Inflammatory Response Syndrome (engl., SIRS), das sich dadurch auszeichnet, dass kein Erreger nachweisbar ist, zu differenzieren (Prucha et al. 2003; Sablotzki et al. 2001). Von anderen Autoren wird beschrieben, dass LBP nicht nur spezifisch LPS binden könnte sondern auch Lipoteichonsäuren (LTA), die von grampositiven Bakterien abgegeben werden, und somit nicht in der Lage ist, zwischen grampositiven und gramnegativen Septitiden zu unterscheiden (Sakr et al. 2008; Schroder und Schumann 2005). Die Ergebnisse dieser Studien können keinen nachhaltigen Zusammenhang zwischen LPS- und LBP-Spiegeln belegen. Somit ist die Bedeutung von LBP wohl hauptsächlich als Akut-Phase-Protein zu sehen, das durch die IA stimuliert wird. Als spezifische Ursache dieser IA muss jedoch nicht LPS angenommen werden.

Zusammenfassend erbrachten unsere Untersuchungen zur Körperantwort auf LPS somit keinen Anhalt dafür, dass die Plasmaspiegel an LPS von der Körperantwort reduziert wurden und nur deshalb keine nachhaltige Erhöhung der LPS-Spiegel im Plasma nachzuweisen war. Ingesamt erbrachte die Untersuchung der verwendeten Marker in den unterschiedlichen Studien sogar widersprüchliche Ergebnisse, so dass insgesamt fraglich ist, ob diese Marker die LPS-Antwort des Organismus zuverlässig wiederzugeben vermögen.

Wenn man also davon ausgehen kann, dass die LPS-Spiegel nicht wesentlich durch die körpereigene LPS-Antwort erniedrigt werden, stellt sich die Frage, warum sich gerade in der 
frühen postakuten Phase besonders hohe LPS-Titer messen ließen. In der vorangegangenen akuten Phase der Infektion waren neben der stark erhöhten VL auch besonders hohe Konzentrationen an Neopterin erfassbar, einem seit langem verwendeten Marker für die unspezifische IA (Fuchs et al. 1988; Fuchs et al. 1990). Dieser Marker der angeborenen IA wurde in der vorliegenden Arbeit im Urin gemessen und korreliert ab 8wpi zu jedem gemessenen Zeitpunkt im Infektionsverlauf signifikant sowohl mit der VL als auch mit der Überlebenszeit der Tiere. Dagegen fanden wir weder 4 noch 8wpi eine Korrelation der erhöhten LPS-Spiegel mit der VL, der IA oder der Überlebenszeit der Tiere. Auch im weiteren Infektionsverlauf fanden sich nur zu einem postakuten Zeitpunkt (12wpi) eine signifikante Korrelation zwischen LPS und VL. Dies lässt einen Zusammenhang der IA in der Akutphase mit den anschließenden LPS-Spiegelerhöhungen im Sinne einer IA-assoziierten Darmpermeabilitätssteigerung mit einer anschließenden mikrobiellen Translokation vermuten. Dass es einen Zusammenhang zwischen LPS und der Darmpermeabilität gibt, belegen auch andere Studien. Es konnte gezeigt werden, dass es nach i.v. LPS-Injektion zu einer Erhöhung der Darmpermeabilität kommt (Hietbrink et al. 2009; O'Dwyer et al. 1988). Hietbrink et al. maßen in diesem Zusammenhang neben der erhöhten Permeabilität von Polyethylenglykol auch erhöhte Zytokinspiegel. Diese korrelierten teilweise miteinander, was die inflammatorische Antwort des Körpers auf die LPS-Injektion als Ursache der erhöhten Darmpermeabilität wahrscheinlich macht. Da LPS als Mittel zur Stimulation des Immunsystems verwandt wurde, bleibt jedoch offen, ob die erhöhte Darmpermeabilität auch zu einer Translokation von LPS geführt hat (Hietbrink et al. 2009).

Zusammengenommen lässt sich aus unseren Ergebnissen und denen Hietbrinks et al. ableiten, dass die Ursache der erhöhten LPS-Spiegel tatsächlich eine Translokation über einen in der Akutphase der Infektion geschädigten Darm ist. Diese ist jedoch insbesondere in der postakuten Phase der Infektion präsent und nicht, wie vorbeschrieben, in der chronischen Phase der Infektion. Eine Reduktion der LPS-Spiegel in dieser Phase durch eine vermehrte Antwort des Körpers auf den LPS-Reiz konnte ebenfalls ausgeschlossen werden. Als Ursache der Mukosaschädigung ist die IA in der Frühphase der Infektion als wahrscheinlich zu betrachten. Eine gegensinnige Kausalkette, in der die bakterielle Translokation zu einer erhöhten IA führt, ist dagegen unwahrscheinlich. 


\subsection{Einfluss von LPS auf die Viruspathogenese}

Im Vergleich der LPS-Spiegel der beiden Progressionsgruppen im Zeitverlauf konnte zu keinem Zeitpunkt ein signifikanter Unterschied zwischen RP und SP gemessen werden. Ein Einfluss der zwei unterschiedlichen Virusstämme, die zur Infektion der Rhesusaffen verwandt worden waren, auf den weiteren Infektionsverlauf konnte ausgeschlossen werden (Demuth et al. 2000). Es war zu erwarten gewesen, dass die rapid-progressive Verlaufsgruppe höhere LPS-Titer aufweisen würde, da diese zu einer vermehrten unspezifischen IA neigen (Sopper et al. 1998; Sopper et al. 2000). LPS hätte für diese Form der IA eine plausible Erklärung dargestellt, da LPS einen potenten Stimulus der angeborenen Immunität darstellen. Diese Erwartung wurde zusätzlich von einer Hypothese von Brown et al. bestärkt, die eine Neigung der RP zu einer monozytotropen SIV-Infektion und der Entwicklung einer Enteropathie beschreibt, die nach der Hypothese von Brenchley et al. die Ursache der mikrobiellen Translokation ist (Brown et al. 2007). Somit lässt sich die Betrachtung der beiden Progressionsgruppen als weiteres Argument gegen LPS als eine Hauptursache der IA anführen. Dagegen zeigten die Parameter der IA, die VL und ebenso die Überlebenszeit wiederum deutliche Unterschiede zwischen den beiden Progressionsgruppen. Ebenso konnten wir zu mehreren Zeitpunkten eine sehr viel höhere unspezifische Aktivierung der Makrophagen bei den Tieren der RP nachweisen, wogegen die IA der T-Zellen in der RPGruppe signifikant niedriger war.

Die Viruslast stellt einen wichtigen klinischen Marker der HIV-Infektion dar (Mellors et al. 1997; Mellors et al. 1996). Trotz einiger veröffentlichter Studien zum Thema der vorliegenden Arbeit konnte bisher von noch keiner Arbeitsgruppe eine positive Korrelation zwischen LPS-Titern und VL nachgewiesen werden (Ancuta et al. 2008; Brenchley et al. 2006b; Gregson et al. 2009; Jiang et al. 2009) Auch eine umfangreichere longitudinale Studie an afrikanischen HIV-Patienten konnte diesen Zusammenhang nicht nachweisen (Redd et al. 2009). Einer Gruppe war es jedoch gelungen, einen signifikant negativen Zusammenhang zwischen LPS Menge im Plasma und der VL nachzuweisen (Papasavvas et al. 2009). Bei unseren Messungen konnten wir lediglich zum Zeitpunkt 12wpi eine signifikante positive Korrelation zwischen VL und LPS-Spiegeln nachweisen $(p=0,0083)$. Diese Fragestellung wurde auch im apathogenen SIV-Tiermodell der AGM betrachtet. Die apathogene Infektion der AGM mit SIV zeichnet sich dadurch aus, dass trotz hoher VL und Depletion der mukosalen $\mathrm{CD}^{+}$Zellen weder eine chronischen IA noch eine LPS-Erhöhung im Plasma der Tiere nachweisbar ist (Brenchley und Douek 2008; Silvestri 2009). Einigen Tieren wurde daraufhin zur Simulation einer bakteriellen Translokation niedrige Dosen an LPS i.v. injiziert 
(Pandrea et al. 2008). Hierbei kam es zu einer transienten, aber nicht signifikanten Erhöhung der VL-Titer bei diesen Tieren. Im Gegensatz dazu berichtet dieselbe Studie über einen hochsignifikanten VL-Anstieg ( $\mathrm{p}=0,0001)$ unter den gleichen Bedingungen, wenn statt LPS ein Diphterietoxin-Fusionsprotein (Ontak) injiziert wurde. Unter Ontak-Injektion konnte zudem eine starke Erhöhung von IA-Parametern nachgewiesen werden, die unter niedrig dosiertem LPS ebenfalls ausblieb.

Die Ergebnisse dieser Studie zeigen eine deutliche Diskrepanz zwischen den Reaktionen des Organismus auf die beiden Bakterientoxine und lassen, zusammengenommen mit unseren Ergebnissen, an der hervorgehobenen Bedeutung von LPS für die Pathogenese der HIVInfektion zweifeln.

\subsection{Immunaktivierung im Infektionsverlauf}

Neben der VL wurde zuletzt die IA als exzellenter Prognosemarker der HIV Infektion etabliert (Giorgi et al. 1999). Von einigen Experten wird diese sogar als höherwertiger Prognoseparameter als die VL eingeschätzt (Giorgi et al. 1999). Das Verhältnis zwischen IA und LPS wurde zuletzt vielfach diskutiert, jedoch ohne eindeutige Ergebnisse zu erbringen. So konnte der von Brenchley et al. beschriebene Zusammenhang zwischen IA und LPSPlasmatitern von einigen Arbeitsgruppen bestätigt werden (Ancuta et al. 2008; Brenchley et al. 2006b; Jiang et al. 2009). Zuletzt wurde dieser Zusammenhang jedoch auch von mehreren Autoren nicht gefunden oder relativiert (Gregson et al. 2009; Pandrea et al. 2008; Papasavvas et al. 2009; Redd et al. 2009).

In der hier vorliegenden Arbeit wurde als IA-Marker der spezifischen T-Zell-Immunität der Expressionsmarker HLA-DR auf $\mathrm{CD}^{+}-$bzw. CD8 $8^{+}$-T-Lymphozyten gemessen. Zur Darstellung der angeborenen Immunität wurde im Urin der Versuchstiere Neopterin, das von aktivierten Makrophagen abgegeben wird, bestimmt.

Die Expression von HLA-DR wurde in den SP sowohl bei den $\mathrm{CD}^{+}-$als auch bei den CD8 ${ }^{+}-$ T-Zellen als erhöht gemessen. Dagegen war die Expression auf den RP signifikant erniedrigt. Dadurch ergab sich ein signifikanter Unterschied zwischen den beiden Progressionsgruppen im Zeitverlauf $(p<0,02)$. Eine Korrelation mit LPS war zu keinem der betrachteten Zeitpunkte messbar. In früheren Studien von Brenchley et al. konnte eine signifikant positive Korrelation zwischen der HLA-DR ${ }^{+}-\mathrm{CD}_{3} 8^{+}$-Expression auf $\mathrm{CD} 8^{+}$-Lymphozyten mit LPS dargestellt werden (Brenchley et al. 2006b). Auch eine schwache Korrelation zwischen 16s rDNA, als

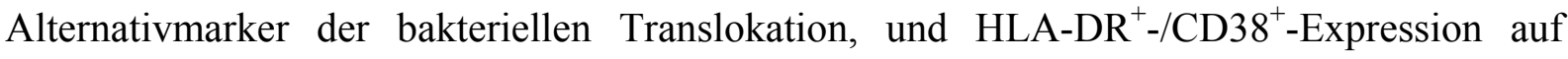
CD8 ${ }^{+}$-Zellen wurde bereits beschrieben (Jiang et al. 2009). Es gibt aber auch schon vor der 
vorliegenden Arbeit Studien, die keinen Zusammenhang finden konnten (Gregson et al. 2009; Papasavvas et al. 2009). Papasavvas et al. vermaßen ebenfalls HLA-DR ${ }^{+}-\mathrm{CD} 8^{+}-\mathrm{T}-Z \mathrm{Z}$ llen und konnten keine Korrelation mit LPS feststellen. Gregson et al. konnten zeigen, dass diese Art der spezifischen IA in Patienten mit chronisch-entzündlichen Darmerkrankungen, die ebenfalls erhöhte LPS-Plasmatiter aufweisen, so gut wie überhaupt nicht messbar ist (Gregson et al. 2009). Damit ist eine andere Ursache als LPS für die erhöhte HLA-DR-Expression wahrscheinlich. Die in unserer Studie erhobenen Daten weisen eine starke inverse Korrelation zwischen der VL und der HLA-DR-Expression nach $(\mathrm{p}<0,002)$. Somit stellt die Aktivierung von T-Zellen, die durch die HLA-DR-Expression angezeigt wird, einen wirksamen Mechanismus der spezifischen Körperabwehr dar, um die VL einzudämmen. Eine solche Bedeutung der zellulären Immunantwort für die Pathogenese konnte auch durch Depletionsexperimente von $\mathrm{CD}^{+}$-T-Zellen bei SIV-infizierten Rhesusaffen nachgewiesen werden (Schmitz et al. 2005).

Im Gegensatz zu der HLA-DR-Expression konnten signifikant erhöhte Neopterinwerte in RP im Vergleich zu SP gefunden werden. Betrachtet man Neopterin im Zeitverlauf der Infektion, fällt ein ähnlicher Kurvenverlauf wie bei der VL auf. Dies äußert sich auch in einer anhaltend signifikanten Positiv-Korrelation dieser beiden Parameter $(p<0,005)$, die auch schon in früheren Studien gefunden wurde (Murr et al. 2002; Wirleitner et al. 2005). Eine Korrelation mit LPS konnte, wie auch schon bei der VL, nur zum Zeitpunkt 12wpi nachgewiesen werden $(\mathrm{p}=0,0191)$. Interessanterweise wurden auch die von Brenchley et al. publizierten Korrelationen von LPS mit verschiedenen Parametern im Rhesusaffenmodell alle etwa zu diesem Zeitpunkt gemessen (Brenchley et al. 2006b). Der genaue Stellenwert der LPSTranslokation zu diesem Zeitpunkt bleibt ungewiss, eine nachhaltige Korrelation zu mehreren Zeitpunkten im Infektionsverlauf ist jedoch nicht nachweisbar.

In einer von Redd et al. veröffentlichten Studie wurden 9 verschiedene Zytokine mit den LPSTitern HIV positiver Afrikaner im Zeitverlauf verglichen (Redd et al. 2009). Bei keinem dieser Zytokine konnte eine Korrelation mit LPS zu irgendeinem Zeitpunkt nachgewiesen werden.

Vor dem Hintergrund unserer Ergebnisse und denen anderer publizierter Daten ist ein Zusammenhang zwischen LPS bzw. der dadurch erfassten mikrobiellen Translokation und der systemischen IA insgesamt anzuzweifeln.

Vergleicht man die angeborene und die adaptive Immunantwort in unserer Kohorte, fällt auf, dass die SP im Modell der SIV-Infektion zu einer signifikant stärkeren T-Zell-Antwort tendieren (Brown et al. 2007; Sopper et al. 1998; Sopper et al. 2000). Die Tiere mit einem 
schnell-progressiven Krankheitsverlauf weisen dagegen eine signifikant niedrigere spezifische T-Zell-Aktivierung auf. Dafür ist bei den RP eine deutlich stärkere IA des angeborenen Immunsystems im Sinne einer Makrophagenaktivierung nachweisbar. Zusätzlich ist eine starke positive Korrelation des Neopterins mit der Viruslast messbar. Dagegen ist die Korrelation der HLA-DR-Expression mit der VL invers. Die genau umgekehrten Verhältnisse ergeben sich, wenn man die Korrelation der IA mit der Überlebenszeit betrachtet: Die HLADR-Expression korreliert positiv mit der Überlebenszeit, die Neopterinausscheidung, genauso wie die VL, korreliert negativ mit ihr.

Aus diesen Ergebnissen lässt sich folgern, dass eine Aktivierung der spezifischen Immunität die Ausbreitung des Virus bekämpft, die Aktivierung des angeborenen Immunsystems die VL jedoch steigert und die Ausbreitung des Virus unterstützt und sogar die Überlebenszeit der Tiere signifikant beeinträchtigt. Somit wäre es angebracht, im Rahmen der Immunaktivierung zwischen einer „guten“, der spezifischen IA, und einer „bösen“, der angeborenen IA, zu differenzieren. 


\section{Zusammenfassung und Ausblick}

Die Hypothese, die die bakterielle Translokation als einen Hauptpathogenesefaktor der HIVInfektion beschreibt, konnte in der vorliegenden Arbeit nicht bestätigt werden. Zwar wurde das Vorhandensein einer mikrobiellen Translokation über eine geschädigte Darmmukosa bei SIV-infizierten Tieren in dieser Arbeit belegt, einen Zusammenhang zwischen den translozierten LPS und einer Aktivierung des Immunsystems konnte jedoch nicht gezeigt werden. Erhöhte Spiegel von LPS waren zwar zu manchen Zeitpunkten messbar, allerdings korrelierten diese nur teilweise mit der IA und der VL und zeigten nie einen Unterschied zwischen den Tieren mit schnellem bzw. einem langsamen Krankheitsverlauf. Somit ist LPS als Ursache für eine persistierende chronische IA anzuzweifeln. Die Sequenz der Ereignisse in unserer longitudinalen Studie sprechen eher für die IA als Ursache der erhöhten Darmpermeabilität, was bedeuten würde, dass die bakterielle Translokation für die eigentliche Pathogenese eine eher untergeordnete Rolle spielt.

Zusammenfassend belegt diese Studie jedoch die Relevanz der IA als einen Hauptfaktor für die Pathogenese der SIV/HIV Infektion. Die IA zeigte nachhaltige Korrelationen mit der VL, dem Krankheitsverlauf und auch der Überlebenszeit der Versuchskohorte. Weiterhin ließ sich in dieser Studie die IA der unspezifischen Abwehr von der IA der spezifischen Abwehr insofern unterscheiden, dass eine erhöhte spezifische IA positiv mit dem Infektionsverlauf und dem Überleben der Tiere korreliert, dagegen die unspezifische IA mit diesen Parametern einen negativen Zusammenhang aufweist. Somit trägt, nach unseren Daten, insbesondere die unspezifische Immunaktivierung von Makrophagen, am ehesten bedingt durch die virale Replikation, zur chronischen IA bei, die letztendlich zur Entstehung von AIDS führt. 


\section{Literaturverzeichnis}

Abel K, Rocke DM, Chohan B, Fritts L Miller CJ (2005): "Temporal and anatomic relationship between virus replication and cytokine gene expression after vaginal simian immunodeficiency virus infection." J Virol 79(19): 12164-12172.

Ancuta P, Kamat A, Kunstman KJ, Kim EY, Autissier P, Wurcel A, Zaman T, Stone D, Mefford M, Morgello S, et al. (2008): "Microbial translocation is associated with increased monocyte activation and dementia in AIDS patients." PLoS ONE $\underline{3}(6)$ : e2516.

Ascher MS Sheppard HW (1990): "AIDS as immune system activation. II. The panergic imnesia hypothesis." J Acquir Immune Defic Syndr 3⑵: 177-191.

Barclay GR (1995): "Endogenous endotoxin-core antibody (EndoCAb) as a marker of endotoxin exposure and a prognostic indicator: a review." Prog Clin Biol Res 392: 263-272.

Barre-Sinoussi F, Chermann JC, Rey F, Nugeyre MT, Chamaret S, Gruest J, Dauguet C, Axler-Blin C, Vezinet-Brun F, Rouzioux C, et al. (1983): "Isolation of a Tlymphotropic retrovirus from a patient at risk for acquired immune deficiency syndrome (AIDS)." Science 220(4599): 868-871.

Bazil V Strominger JL (1991): "Shedding as a mechanism of down-modulation of CD14 on stimulated human monocytes." J Immunol 147(5): 1567-1574.

Brenchley JM Douek DC (2008): "The mucosal barrier and immune activation in HIV pathogenesis." Curr Opin HIV AIDS $\underline{3}$ (3): 356-361.

Brenchley JM, Schacker TW, Ruff LE, Price DA, Taylor JH, Beilman GJ, Nguyen PL, Khoruts A, Larson M, Haase AT, et al. (2004): "CD4+ T cell depletion during all stages of HIV disease occurs predominantly in the gastrointestinal tract." J Exp Med 200(6): 749-759.

Brenchley JM, Price DA Douek DC (2006a): "HIV disease: fallout from a mucosal catastrophe?" Nat Immunol 7(3): 235-239.

Brenchley JM, Price DA, Schacker TW, Asher TE, Silvestri G, Rao S, Kazzaz Z, Bornstein E, Lambotte O, Altmann D, et al. (2006b): "Microbial translocation is a cause of systemic immune activation in chronic HIV infection." Nat Med 12(12): 1365-1371.

Brown CR, Czapiga M, Kabat J, Dang Q, Ourmanov I, Nishimura Y, Martin MA Hirsch VM (2007): "Unique pathology in simian immunodeficiency virus-infected rapid progressor macaques is consistent with a pathogenesis distinct from that of classical AIDS." J Virol 81(11): 5594-5606.

CDC, center for disease control USA (1992): "1993 revised classification system for HIV infection and expanded surveillance case definition for AIDS among adolescents and adults." MMWR Recomm Rep 41(RR-17): 1-19.

Clavel F, Guetard D, Brun-Vezinet F, Chamaret S, Rey MA, Santos-Ferreira MO, Laurent AG, Dauguet C, Katlama C, Rouzioux C, et al. (1986): "Isolation of a new human retrovirus from West African patients with AIDS." Science 233(4761): 343-346.

Clayton F, Kotler DP, Kuwada SK, Morgan T, Stepan C, Kuang J, Le J Fantini J (2001): "Gp120-induced Bob/GPR15 activation: a possible cause of human immunodeficiency virus enteropathy." Am J Pathol 159(5): 1933-1939.

Coffin J, Haase A, Levy JA, Montagnier L, Oroszlan S, Teich N, Temin H, Toyoshima K, Varmus H, Vogt P, et al. (1986): "What to call the AIDS virus?" Nature 321(6065): 10.

Cooke KR, Olkiewicz K, Erickson N Ferrara JL (2002): "The role of endotoxin and the innate immune response in the pathophysiology of acute graft versus host disease." J Endotoxin Res $\underline{8}(6)$ : 441-448. 
Dalgleish AG, Beverley PC, Clapham PR, Crawford DH, Greaves MF Weiss RA (1984): "The CD4 (T4) antigen is an essential component of the receptor for the AIDS retrovirus." Nature 312(5996): 763-767.

Daniel MD, Letvin NL, King NW, Kannagi M, Sehgal PK, Hunt RD, Kanki PJ, Essex M Desrosiers RC (1985): "Isolation of T-cell tropic HTLV-III-like retrovirus from macaques." Science 228(4704): 1201-1204.

Danner RL, Elin RJ, Hosseini JM, Wesley RA, Reilly JM Parillo JE (1991): "Endotoxemia in human septic shock." Chest 99(1): 169-175.

Demuth M, Czub S, Sauer U, Koutsilieri E, Haaft P, Heeney J, Stahl-Hennig C, ter Meulen V Sopper S (2000): "Relationship between viral load in blood, cerebrospinal fluid, brain tissue and isolated microglia with neurological disease in macaques infected with different strains of SIV." J Neurovirol $\underline{6}$ (3): 187-201.

Deng H, Liu R, Ellmeier W, Choe S, Unutmaz D, Burkhart M, Di Marzio P, Marmon S, Sutton RE, Hill CM, et al. (1996): "Identification of a major co-receptor for primary isolates of HIV-1." Nature 381(6584): 661-666.

Derdeyn CA Silvestri G (2005): "Viral and host factors in the pathogenesis of HIV infection." Curr Opin Immunol 17(4): 366-373.

Desrosiers RC (1990): "The simian immunodeficiency viruses." Annu Rev Immunol $\underline{8}$ : 557578.

Doranz BJ, Rucker J, Yi Y, Smyth RJ, Samson M, Peiper SC, Parmentier M, Collman RG Doms RW (1996): "A dual-tropic primary HIV-1 isolate that uses fusin and the betachemokine receptors CKR-5, CKR-3, and CKR-2b as fusion cofactors." Cell $\underline{85}(7)$ : 1149-1158.

Dragic T, Litwin V, Allaway GP, Martin SR, Huang Y, Nagashima KA, Cayanan C, Maddon PJ, Koup RA, Moore JP, et al. (1996): "HIV-1 entry into CD4+ cells is mediated by the chemokine receptor CC-CKR-5." Nature 381(6584): 667-673.

Fahey JL, Taylor JM, Manna B, Nishanian P, Aziz N, Giorgi JV Detels R (1998): "Prognostic significance of plasma markers of immune activation, HIV viral load and CD4 T-cell measurements." AIDS 12(13): 1581-1590.

Fang CW, Yao YM, Zhai HX, Yu Y, Wu Y, Lu LR, Sheng ZY Sheng CY (2004): "Tissue lipopolysaccharide-binding protein expression in rats after thermal injury: potential role of TNF-alpha." Burns 30(3): 225-231.

Fendrich C, Luke W, Stahl-Hennig C, Herchenroder O, Fuchs D, Wachter H Hunsmann G (1989): "Urinary neopterin concentrations in rhesus monkeys after infection with simian immunodeficiency virus (SIVmac 251)." AIDS $\underline{3}$ (5): 305-307.

Feng Y, Broder CC, Kennedy PE Berger EA (1996): "HIV-1 entry cofactor: functional cDNA cloning of a seven-transmembrane, G protein-coupled receptor." Science 272(5263): 872-877.

Fenton MJ Golenbock DT (1998): "LPS-binding proteins and receptors." J Leukoc Biol 64(1): 25-32.

Finkel TH, Tudor-Williams G, Banda NK, Cotton MF, Curiel T, Monks C, Baba TW, Ruprecht RM Kupfer A (1995): "Apoptosis occurs predominantly in bystander cells and not in productively infected cells of HIV- and SIV-infected lymph nodes." Nat Med 1(2): 129-134.

Frey EA, Miller DS, Jahr TG, Sundan A, Bazil V, Espevik T, Finlay BB Wright SD (1992): "Soluble CD14 participates in the response of cells to lipopolysaccharide." J Exp Med 176(6): 1665-1671.

Fuchs D, Hausen A, Reibnegger G, Werner ER, Dierich MP Wachter H (1988): "Neopterin as a marker for activated cell-mediated immunity: application in HIV infection." Immunol Today $\underline{9}(5):$ 150-155. 
Fuchs D, Jager H, Popescu M, Reibnegger G, Werner ER, Dierich MP, Kaboth W, Tilz GP Wachter H (1990): "Immune activation markers to predict AIDS and survival in HIV1 seropositives." Immunol Lett 26(1): 75-79.

Fukui H, Brauner B, Bode JC Bode C (1989): "Chromogenic endotoxin assay in plasma. Selection of plasma pretreatment and production of standard curves." J Clin Chem Clin Biochem 27(12): 941-946.

Gallo RC, Sarin PS, Gelmann EP, Robert-Guroff M, Richardson E, Kalyanaraman VS, Mann D, Sidhu GD, Stahl RE, Zolla-Pazner S, et al. (1983): "Isolation of human T-cell leukemia virus in acquired immune deficiency syndrome (AIDS)." Science 220(4599): 865-867.

Gardiner KR, Halliday MI, Barclay GR, Milne L, Brown D, Stephens S, Maxwell RJ Rowlands BJ (1995): "Significance of systemic endotoxaemia in inflammatory bowel disease." Gut 36(6): 897-901.

Giorgi JV, Hultin LE, McKeating JA, Johnson TD, Owens B, Jacobson LP, Shih R, Lewis J, Wiley DJ, Phair JP, et al. (1999): "Shorter survival in advanced human immunodeficiency virus type 1 infection is more closely associated with $\mathrm{T}$ lymphocyte activation than with plasma virus burden or virus chemokine coreceptor usage." J Infect Dis 179(4): 859-870.

Gottlieb MS, Schroff R, Schanker HM, Weisman JD, Fan PT, Wolf RA Saxon A (1981): "Pneumocystis carinii pneumonia and mucosal candidiasis in previously healthy homosexual men: evidence of a new acquired cellular immunodeficiency." N Engl J Med 305(24): 1425-1431.

Gregson JN, Steel A, Bower M, Gazzard BG, Gotch FM Goodier MR (2009): "Elevated plasma lipopolysaccharide is not sufficient to drive natural killer cell activation in HIV-1-infected individuals." AIDS 23(1): 29-34.

Grossman Z, Meier-Schellersheim M, Paul WE Picker LJ (2006): "Pathogenesis of HIV infection: what the virus spares is as important as what it destroys." Nat Med 12(3): 289-295.

Hahn BH, Shaw GM, De Cock KM Sharp PM (2000): "AIDS as a zoonosis: scientific and public health implications." Science 287(5453): 607-614.

Hazenberg MD, Otto SA, van Benthem BH, Roos MT, Coutinho RA, Lange JM, Hamann D, Prins M Miedema F (2003): "Persistent immune activation in HIV-1 infection is associated with progression to AIDS." AIDS 17(13): 1881-1888.

Heumann D Roger T (2002): "Initial responses to endotoxins and Gram-negative bacteria." Clin Chim Acta 323 (1-2): 59-72.

Hietbrink F, Besselink MG, Renooij W, de Smet MB, Draisma A, van der Hoeven H Pickkers P (2009): "Systemic inflammation increases intestinal permeability during experimental human endotoxemia." Shock 32(4): 374-378.

Hoffmann G, Wirleitner B Fuchs D (2003): "Potential role of immune system activationassociated production of neopterin derivatives in humans." Inflamm Res 52(8): 313321.

Jiang W, Lederman MM, Hunt P, Sieg SF, Haley K, Rodriguez B, Landay A, Martin J, Sinclair E, Asher AI, et al. (2009): "Plasma Levels of Bacterial DNA Correlate with Immune Activation and the Magnitude of Immune Restoration in Persons with Antiretroviral-Treated HIV Infection." J Infect Dis 199(8): 1177-1185.

Johnson PR Hirsch VM (1992): "SIV infection of macaques as a model for AIDS pathogenesis." Int Rev Immunol $\underline{8}(1)$ : 55-63.

Kapembwa MS, Fleming SC, Sewankambo N, Serwadda D, Lucas S, Moody A Griffin GE (1991): "Altered small-intestinal permeability associated with diarrhoea in humanimmunodeficiency-virus-infected Caucasian and African subjects." Clin Sci (Lond) 81(3): 327-334. 
Kestler H, Kodama T, Ringler D, Marthas M, Pedersen N, Lackner A, Regier D, Sehgal P, Daniel M, King N, et al. (1990): "Induction of AIDS in rhesus monkeys by molecularly cloned simian immunodeficiency virus." Science 248(4959): 1109-1112.

Kewenig S, Schneider T, Hohloch K, Lampe-Dreyer K, Ullrich R, Stolte N, Stahl-Hennig C, Kaup FJ, Stallmach A Zeitz M (1999): "Rapid mucosal CD4(+) T-cell depletion and enteropathy in simian immunodeficiency virus-infected rhesus macaques." Gastroenterology 116(5): 1115-1123.

Klatzmann D, Champagne E, Chamaret S, Gruest J, Guetard D, Hercend T, Gluckman JC Montagnier L (1984): "T-lymphocyte T4 molecule behaves as the receptor for human retrovirus LAV." Nature 312(5996): 767-768.

Kotler DP, Gaetz HP, Lange M, Klein EB Holt PR (1984): "Enteropathy associated with the acquired immunodeficiency syndrome." Ann Intern Med 101(4): 421-428.

Kotler DP, Reka S Clayton F (1993): "Intestinal mucosal inflammation associated with human immunodeficiency virus infection." Dig Dis Sci 38(6): 1119-1127.

Lackner AA, Mohan M Veazey RS (2009): "The gastrointestinal tract and AIDS pathogenesis." Gastroenterology 136(6): 1965-1978.

Le Grand R, Vogt G, Vaslin B, Roques P, Theodoro F, Aubertin AM Dormont D (1992): "Specific and non-specific immunity and protection of macaques against SIV infection." Vaccine 10(12): 873-879.

Letvin NL King NW (1990): "Immunologic and pathologic manifestations of the infection of rhesus monkeys with simian immunodeficiency virus of macaques." J Acquir Immune Defic Syndr 3(11): 1023-1040.

Li Q, Duan L, Estes JD, Ma ZM, Rourke T, Wang Y, Reilly C, Carlis J, Miller CJ Haase AT (2005): "Peak SIV replication in resting memory CD4+ T cells depletes gut lamina propria CD4+ T cells." Nature 434(7037): 1148-1152.

Li Q, Estes JD, Duan L, Jessurun J, Pambuccian S, Forster C, Wietgrefe S, Zupancic M, Schacker T, Reilly C, et al. (2008): "Simian immunodeficiency virus-induced intestinal cell apoptosis is the underlying mechanism of the regenerative enteropathy of early infection." J Infect Dis 197(3): 420-429.

Li XH, Gong JP, Tu B, Shi YJ Liu CA (2003): "In vivo expression of lipopolysaccharide binding protein and its gene induced by endotoxin." Chin J Traumatol $\underline{6}(5): 280-283$.

Macpherson AJ Harris NL (2004): "Interactions between commensal intestinal bacteria and the immune system." Nat Rev Immunol 4(6): 478-485.

Masur H, Michelis MA, Greene JB, Onorato I, Stouwe RA, Holzman RS, Wormser G, Brettman L, Lange M, Murray HW, et al. (1981): "An outbreak of communityacquired Pneumocystis carinii pneumonia: initial manifestation of cellular immune dysfunction." N Engl J Med 305(24): 1431-1438.

Mattapallil JJ, Douek DC, Hill B, Nishimura Y, Martin M Roederer M (2005): "Massive infection and loss of memory CD4+ T cells in multiple tissues during acute SIV infection." Nature 434(7037): 1093-1097.

Mehandru S, Poles MA, Tenner-Racz K, Manuelli V, Jean-Pierre P, Lopez P, Shet A, Low A, Mohri H, Boden D, et al. (2007): "Mechanisms of gastrointestinal CD4+ T-cell depletion during acute and early human immunodeficiency virus type 1 infection." J Virol 81(2): 599-612.

Mellors JW, Rinaldo CR, Jr., Gupta P, White RM, Todd JA Kingsley LA (1996): "Prognosis in HIV-1 infection predicted by the quantity of virus in plasma." Science 272(5265): 1167-1170.

Mellors JW, Munoz A, Giorgi JV, Margolick JB, Tassoni CJ, Gupta P, Kingsley LA, Todd JA, Saah AJ, Detels R, et al. (1997): "Plasma viral load and CD4+ lymphocytes as prognostic markers of HIV-1 infection." Ann Intern Med 126(12): 946-954. 
Meyaard L, Otto SA, Jonker RR, Mijnster MJ, Keet RP Miedema F (1992): "Programmed death of T cells in HIV-1 infection." Science 257(5067): 217-219.

Meyaard L, Otto SA, Keet IP, Roos MT Miedema F (1994): "Programmed death of T cells in human immunodeficiency virus infection. No correlation with progression to disease." J Clin Invest 93(3): 982-988.

Mitaka C (2005): "Clinical laboratory differentiation of infectious versus non-infectious systemic inflammatory response syndrome." Clin Chim Acta 351(1-2): 17-29.

Modrow S, Falke D, Schaetzl H Truyen U: "Molekulare Virologie." Spektrum Akademischer Verlag, Heidelbert, 2009, 3. Auflage: 640.

Murr C, Widner B, Wirleitner B Fuchs D (2002): "Neopterin as a marker for immune system activation." Curr Drug Metab $\underline{3}(2): 175-187$.

O'Dwyer ST, Michie HR, Ziegler TR, Revhaug A, Smith RJ Wilmore DW (1988): "A single dose of endotoxin increases intestinal permeability in healthy humans." Arch Surg 123(12): 1459-1464.

Pandrea I, Gaufin T, Brenchley JM, Gautam R, Monjure C, Gautam A, Coleman C, Lackner AA, Ribeiro RM, Douek DC, et al. (2008): "Cutting edge: Experimentally induced immune activation in natural hosts of simian immunodeficiency virus induces significant increases in viral replication and CD4+ T cell depletion." J Immunol 181(10): 6687-6691.

Papasavvas E, Pistilli M, Reynolds G, Bucki R, Azzoni L, Chehimi J, Janmey PA, DiNubile MJ, Ondercin J, Kostman JR, et al. (2009): "Delayed loss of control of plasma lipopolysaccharide levels after therapy interruption in chronically HIV-1-infected patients." Aids 23(3): 369-375.

Picker LJ, Hagen SI, Lum R, Reed-Inderbitzin EF, Daly LM, Sylwester AW, Walker JM, Siess DC, Piatak M, Jr., Wang C, et al. (2004): "Insufficient production and tissue delivery of CD4+ memory $\mathrm{T}$ cells in rapidly progressive simian immunodeficiency virus infection." J Exp Med 200(10): 1299-1314.

Prucha M, Herold I, Zazula R, Dubska L, Dostal M, Hildebrand T Hyanek J (2003): "Significance of lipopolysaccharide-binding protein (an acute phase protein) in monitoring critically ill patients." Crit Care 7(6): R154-159.

Redd AD, Dabitao D, Bream JH, Charvat B, Laeyendecker O, Kiwanuka N, Lutalo T, Kigozi G, Tobian AA, Gamiel J, et al. (2009): "Microbial translocation, the innate cytokine response, and HIV-1 disease progression in Africa." Proc Natl Acad Sci U S A 106(16): 6718-6723.

Sablotzki A, Borgermann J, Baulig W, Friedrich I, Spillner J, Silber RE Czeslick E (2001): "Lipopolysaccharide-binding protein (LBP) and markers of acute-phase response in patients with multiple organ dysfunction syndrome (MODS) following open heart surgery." Thorac Cardiovasc Surg 49(5): 273-278.

Sakr Y, Burgett U, Nacul FE, Reinhart K Brunkhorst F (2008): "Lipopolysaccharide binding protein in a surgical intensive care unit: a marker of sepsis?" Crit Care Med 36(7): 2014-2022.

Santiago ML, Rodenburg CM, Kamenya S, Bibollet-Ruche F, Gao F, Bailes E, Meleth S, Soong SJ, Kilby JM, Moldoveanu Z, et al. (2002): "SIVcpz in wild chimpanzees." Science 295(5554): 465.

Schmitz JE, Johnson RP, McClure HM, Manson KH, Wyand MS, Kuroda MJ, Lifton MA, Khunkhun RS, McEvers KJ, Gillis J, et al. (2005): "Effect of CD8+ lymphocyte depletion on virus containment after simian immunodeficiency virus SIVmac251 challenge of live attenuated SIVmac239delta3-vaccinated rhesus macaques." J Virol 79(13): 8131-8141.

Schroder NW Schumann RR (2005): "Non-LPS targets and actions of LPS binding protein (LBP)." J Endotoxin Res 11(4): 237-242. 
Schulte R, Suh YS, Sauermann U, Ochieng W, Sopper S, Kim KS, Ahn SS, Park KS, StolteLeeb N, Hunsmann G, et al. (2009): "Mucosal prior to systemic application of recombinant adenovirus boosting is more immunogenic than systemic application twice but confers similar protection against SIV-challenge in DNA vaccine-primed macaques." Virology 383(2): 300-309.

Schumann RR, Kirschning CJ, Unbehaun A, Aberle HP, Knope HP, Lamping N, Ulevitch RJ Herrmann F (1996): "The lipopolysaccharide-binding protein is a secretory class 1 acute-phase protein whose gene is transcriptionally activated by APRF/STAT/3 and other cytokine-inducible nuclear proteins." Mol Cell Biol 16(7): 3490-3503.

Sharpstone D, Neild P, Crane R, Taylor C, Hodgson C, Sherwood R, Gazzard B Bjarnason I (1999): "Small intestinal transit, absorption, and permeability in patients with AIDS with and without diarrhoea." Gut 45(1): 70-76.

Siegal FP, Lopez C, Hammer GS, Brown AE, Kornfeld SJ, Gold J, Hassett J, Hirschman SZ, Cunningham-Rundles C, Adelsberg BR, et al. (1981): "Severe acquired immunodeficiency in male homosexuals, manifested by chronic perianal ulcerative herpes simplex lesions." N Engl J Med 305(24): 1439-1444.

Silvestri G (2009): "Immunity in natural SIV infections." J Intern Med 265(1): 97-109.

Sopper S, Sauer U, Muller JG, Stahl-Hennig C ter Meulen V (2000): "Early activation and proliferation of $\mathrm{T}$ cells in simian immunodeficiency virus-infected rhesus monkeys." AIDS Res Hum Retroviruses 16(7): 689-697.

Sopper S, Sauer U, Hemm S, Demuth M, Muller J, Stahl-Hennig C, Hunsmann G, ter Meulen V Dorries R (1998): "Protective role of the virus-specific immune response for development of severe neurologic signs in simian immunodeficiency virus-infected macaques." J Virol 72(12): 9940-9947.

Stacey AR, Norris PJ, Qin L, Haygreen EA, Taylor E, Heitman J, Lebedeva M, DeCamp A, Li D, Grove D, et al. (2009): "Induction of a striking systemic cytokine cascade prior to peak viremia in acute human immunodeficiency virus type 1 infection, in contrast to more modest and delayed responses in acute hepatitis $\mathrm{B}$ and $\mathrm{C}$ virus infections." $\mathrm{J}$ Virol 83(8): 3719-3733.

Stein TP, Koerner B, Schluter MD, Leskiw MJ, Gaprindachvilli T, Richards EW, Cope FO Condolucci D (1997): "Weight loss, the gut and the inflammatory response in aids patients." Cytokine 9(2): 143-147.

Tenner-Racz K, Stahl Hennig C, Uberla K, Stoiber H, Ignatius R, Heeney J, Steinman RM Racz P (2004): "Early protection against pathogenic virus infection at a mucosal challenge site after vaccination with attenuated simian immunodeficiency virus." Proc Natl Acad Sci U S A 101(9): 3017-3022.

Veazey RS, DeMaria M, Chalifoux LV, Shvetz DE, Pauley DR, Knight HL, Rosenzweig M, Johnson RP, Desrosiers RC Lackner AA (1998): "Gastrointestinal tract as a major site of CD4+ T cell depletion and viral replication in SIV infection." Science 280(5362): 427-431.

Wirleitner B, Schroecksnadel K, Winkler C Fuchs D (2005): "Neopterin in HIV-1 infection." Mol Immunol 42(2): 183-194. 


\section{Danksagungen}

Herrn Prof. Gerhard Hunsmann (emerit.) danke ich für die Möglichkeit der Anfertigung meiner medizinischen Dissertation in der Abteilung Virologie und Immunologie am Deutschen Primatenzentrum Göttingen.

Mein Dank gilt Herrn PD Dr. Sieghart Sopper für die Vergabe des Themas und die Aufnahme in seine Arbeitsgruppe. Insbesondere danke ich ihm für die exzellente Betreuung der Arbeit und die angenehme Zusammenarbeit.

Frau Wiebke Rettberg möchte ich für die hilfsbereite Unterstützung meiner Laborarbeit, Frau Nicola Schwedhelm für die freundliche Einführung in das Labor danken.

Allen Mitgliedern der AG Sopper möchte ich für die freundliche Zusammenarbeit und die schöne Zeit, die ich in- und außerhalb des Labors mit ihnen verbringen durfte, danken. Insbesondere möchte ich hier Frau Dr. Tanja Bischoff, Frau Dr. Bianka Mußil und abermals Frau Wiebke Rettberg erwähnen.

Außerdem danke ich Frau Dr. Monika Franz, Frau Dr. Ulrike Sauermann und Frau Dr. Christiane Stahl-Henning für die entgegengebrachte Unterstützung. 


\section{$\underline{\text { Lebenslauf }}$}

Ich, Christoph Alexander Leinert, wurde am 12. September 1984 in Hamburg geboren. Meine Eltern sind Jochen Leinert, Dipl. Kaufmann, und Christa Leinert, Dipl. Handelslehrerin.

Von 1991 bis 1995 besuchte ich die Grundschule Großflottbeker Weg in Hamburg, danach von 1995 bis 2004 das Ökumenische Gymnasium zu Bremen. Während meiner Schullaufbahn absolvierte ich u.a. Studienaufenthalte in Tacoma, USA, und Madrid. 2004 schloss ich meine Schullaufbahn mit der Allgemeinen Hochschulreife ab.

Im Herbst 2004 immatrikulierte ich mich an der Georg-August-Universität Göttingen für das Studienfach Humanmedizin. Ich bestand im Sommer 2006 meine 1. Ärztliche Prüfung.

Im Sommer 2007 begann ich unter der Betreuung von Herrn PD Dr. Sieghart Sopper die Anfertigung der vorliegenden experimentellen Dissertation unter dem Titel: Bedeutung der mikrobiellen Transmission im SIV-Rhesusaffen-Tiermodell für die HIV/AIDS-Pathogenese. Während der Anfertigung dieser Arbeit wurden Auszüge daraus unter anderem auf der Jahrestagung der Deutschen Gesellschaft für Virologie 2009 in einem Posterbeitrag, sowie auf dem Deutsch-Österreichisch-Schweizerischem AIDS-Kongress (SÖDAK) 2009 in St.-Gallen, Schweiz, der Jahrestagung für Nichthumane Primatenmodelle für AIDS 2009 in Boston, USA, und dem Japanisch-Deutschem AIDS Symposium 2010 in Tokyo, Japan, in einem Vortrag vorgestellt. Teile der hier vorgestellten Daten sind im Journal of Medical Primatology (August 2010) unter dem Titel: „Microbial translocation in simian immunodeficiency virusinfected rhesus monkeys“ veröffentlicht, eine Publikation der restlichen Ergebnisse meiner Arbeit ist in Vorbereitung.

Seit August 2009 befinde ich mich im Praktischen Jahr des Studiums der Humanmedizin, das ich in Bremen, Bremerhaven, Neu-Delhi und Leicester ableiste. Voraussichtlich werde ich mein Studium im Herbst 2010 mit der 2. Ärztlichen Prüfung abschließen. 